\title{
Sedimentology and climatic environment of alluvial fans in the martian Saheki crater and a comparison with terrestrial fans in the Atacama Desert
}

\author{
A.M. Morgan ${ }^{\text {a,* }}$, A.D. Howard ${ }^{\text {a }}$, D.E.J. Hobley ${ }^{\mathrm{a}, 1}$, J.M. Moore ${ }^{\mathrm{b}}$, W.E. Dietrich ${ }^{\mathrm{c}}$, R.M.E. Williams ${ }^{\mathrm{d}}$, D.M. Burr ${ }^{\mathrm{e}}$, \\ J.A. Grant ${ }^{\mathrm{f}}$, S.A. Wilson ${ }^{\mathrm{f}}$, Y. Matsubara ${ }^{\mathrm{a}}$ \\ ${ }^{a}$ Department of Environmental Sciences, University of Virginia, P.O. Box 400123, VA 22904-4123, United States \\ ${ }^{\mathrm{b}}$ NASA Ames Research Center, MS 245-3, Moffett Field, CA 94035-1000, United States \\ c Department of Earth and Planetary Science, University of California, Berkeley, CA 94720-4767, United States \\ d Planetary Science Institute, 1700 E. Fort Lowell, Suite 106, Tucson, AZ 85719, United States \\ ${ }^{\mathrm{e}}$ Earth and Planetary Sciences Department, University of Tennessee-Knoxville, 1412 Circle Drive, Knoxville, TN 37996-1410, United States \\ ${ }^{\mathrm{f}}$ Center for Earth and Planetary Studies, National Air and Space Museum, Smithsonian Institution, MRC 315, 6th Street at Independence Avenue, SW, Washington, DC 20013, \\ United States
}

\section{A R T I C L E I N F O}

\section{Article history:}

Received 22 April 2013

Revised 10 October 2013

Accepted 5 November 2013

Available online 12 November 2013

\section{Keywords:}

Geological processes

Mars

Mars, surface

\begin{abstract}
A B S T R A C T
The deflated surfaces of the alluvial fans in Saheki crater reveal the most detailed record of fan stratigraphy and evolution found, to date, on Mars. During deposition of at least the uppermost $100 \mathrm{~m}$ of fan deposits, discharges from the source basin consisted of channelized flows transporting sediment (which we infer to be primarily sand- and gravel-sized) as bedload coupled with extensive overbank mud-rich flows depositing planar beds of sand-sized or finer sediment. Flow events are inferred to have been of modest magnitude (probably less than $\sim 60 \mathrm{~m}^{3} / \mathrm{s}$ ), of short duration, and probably occupied only a few distributaries during any individual flow event. Occasional channel avulsions resulted in the distribution of sediment across the entire fan. A comparison with fine-grained alluvial fans in Chile's Atacama Desert provides insights into the processes responsible for constructing the Saheki crater fans: sediment is deposited by channelized flows (transporting sand through boulder-sized material) and overbank mudflows (sand size and finer) and wind erosion leaves channels expressed in inverted topographic relief. The most likely source of water was snowmelt released after annual or epochal accumulation of snow in the headwater source basin on the interior crater rim during the Hesperian to Amazonian periods. We infer the Saheki fans to have been constructed by many hundreds of separate flow events, and accumulation of the necessary snow and release of meltwater may have required favorable orbital configurations or transient global warming.
\end{abstract}

(c) 2013 Elsevier Inc. All rights reserved.

\section{Introduction}

An alluvial fan is a semi-conical landform that develops where a channel exits a confined valley, and through avulsions and channel branching spreads sediment across the unconfined terrain (Blair and McPherson, 2009). The combination of slope reduction and lateral spreading reduces the carrying capacity and forces progressive sediment deposition. Martian alluvial fans have been identified ranging in scale from sub-kilometer (Williams and Malin, 2008) to a few kilometers (Burr et al., 2009) to tens of kilometers (Moore and Howard, 2005; Kraal et al., 2008; Anderson and Bell, 2010;

\footnotetext{
* Corresponding author.

E-mail address: amm5sy@virginia.edu (A.M. Morgan).

Present address: Department of Geological Sciences, University of Colorado Boulder, UCB 399, 2200 Colorado Avenue, Boulder, CO 80309-0399, United States.
}

Grant and Wilson, 2011, 2012). The well-preserved, mid-latitude fans of the Hesperian (and perhaps even younger) (Grant and Wilson, 2011; Kraal et al., 2008; Moore and Howard, 2005; Morgan et al., 2012a,b) are of particular interest because they, along with deltas (e.g., Malin and Edgett, 2003; Moore et al., 2003; Lewis and Aharonson, 2006; Pondrelli et al., 2008,2011; Mangold et al., 2012b; Wilson et al., 2013) and small valleys in the mid-latitude regions (e.g., Hynek et al., 2010; Fassett et al., 2010; Howard and Moore, 2011; Mangold, 2012), may represent a widespread episode of large-scale fluvial landform construction and modification on Mars occurring well after the Late Noachian to Early Hesperian epoch of valley network incision (Grant and Wilson, 2011; Howard and Moore, 2011). This later period of fluvial activity occurred in an environment thought to be characterized by a relatively thin atmosphere and global cryosphere (Carr and Head, 2010; Fassett and Head, 2011; Lasue et al., 2013). Although difficult to decipher, 
the effects of water (both fluid and ice) on a paleo-landscape are the most unambiguous markers of past climatic environment and have significant potential to further our understanding of the climate evolution and potential late-stage habitability of Mars.

Almost all mapped martian alluvial fan systems have been found to be enclosed within basins (craters) and source from deeply incised crater rim alcove basins (Moore and Howard, 2005; Kraal et al., 2008; Wilson et al., 2013)., which strongly constrains both the hydrological and sedimentary environments. The association between the sediment and water source areas in the dissected crater wall and the fan system is short and direct. The presence of a large alluvial fan in an enclosed basin limits the possible range of the hydrologic regime; on the low end it is constrained by the necessity to erode and transport sediment from the headwater source and on the high end by the apparent absence of coincident deep lakes within the crater. Previous work on the larger equatorial fans has concluded that they formed during periods of enhanced precipitation (probably as snowfall) primarily through hundreds of flow events over tens of thousands (to perhaps millions) of years (Armitage et al., 2011; Grant and Wilson, 2011, 2012; Moore and Howard, 2005).

This study focuses on Saheki crater $\left(85 \mathrm{~km}\right.$-diameter, $21.7^{\circ} \mathrm{S}$, $73.2^{\circ} \mathrm{E}$ ), one of several fan-bearing craters along the northern rim of the Hellas basin (Figs. 1 and 2). Fans in this crater are among the largest catalogued by Kraal et al. (2008) and Moore and Howard (2005) and contain the clearest exposed stratigraphy yet identified on Mars (Table 1). The studies of alluvial fans in southern Margaritifer Terra (Grant and Wilson, 2011, 2012) revealed that the fans and fan-deltas of this region date to the Late Hesperian to Early Amazonian rather than being coeval with the extensive valley networks of Late Noachian to Early Hesperian, which had been suggested by Howard et al. (2005). The exquisite alluvial fan stratigraphy exposed in craters of the Hellas north rim (Fig. 1), and Saheki crater in particular (Fig. 2), permits a comprehensive assessment of several unresolved issues concerning martian alluvial fans, including the mode of sedimentation (e.g. fluvial versus debris flows), the magnitude, frequency and duration of formative flows, the age of the alluvial fans and the associated climatic environment. We address these issues through a detailed stratigraphic analysis, crater count-derived ages, quantitative interpretation of the flows (velocity and discharge) forming the fans, and a comparison with a terrestrial analog fan system in the Chilean Atacama Desert. This is followed by our synthesis of the fan sedimentology, geologic history of fan deposition, and the associated hydrologic and climatologic environment. We conclude that the Saheki crater fans were deposited by a combination of channelized fluvial and muddy overbank flows by many separate flow events numbering in the hundreds to thousands over an extended time period around the Hesperian-Amazonian boundary. Snowmelt sourced from upper crater walls is found to be the most tenable water source.

\section{Observations and interpretations}

\subsection{Geologic setting and data used}

Six fan-bearing craters, labeled " $G$ ", "K" (since named Saheki by the IAU), "L", "M" (since named Harris by the IAU), "P", and "X" (Fig. 1) have been identified in the far western Terra

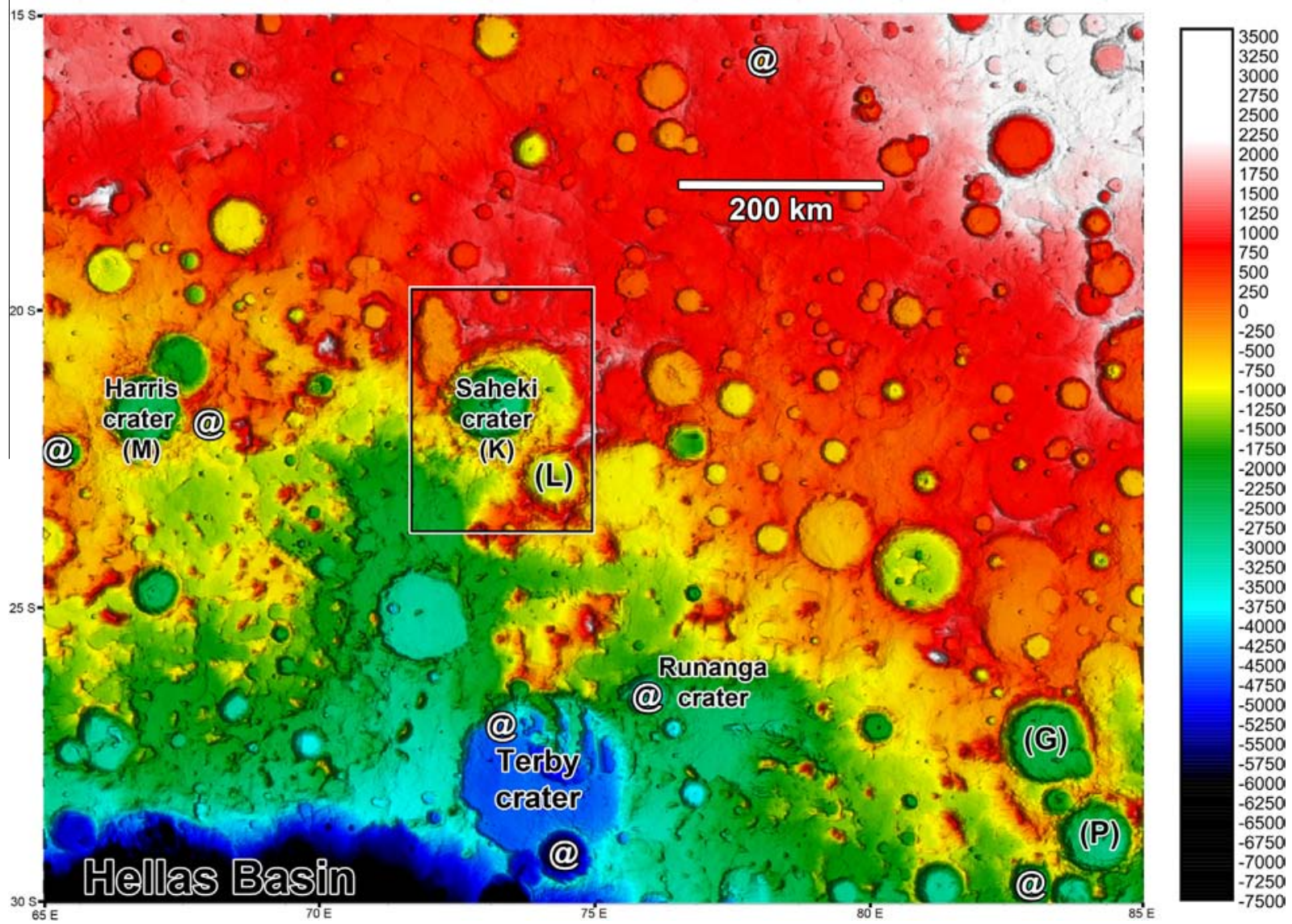

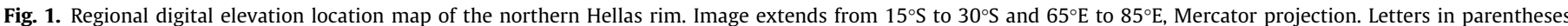

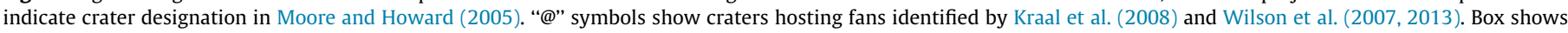
location of Fig. 2. Topographic scale is in meters to Mars datum. North is up in this and all following figures (excluding photographs) 


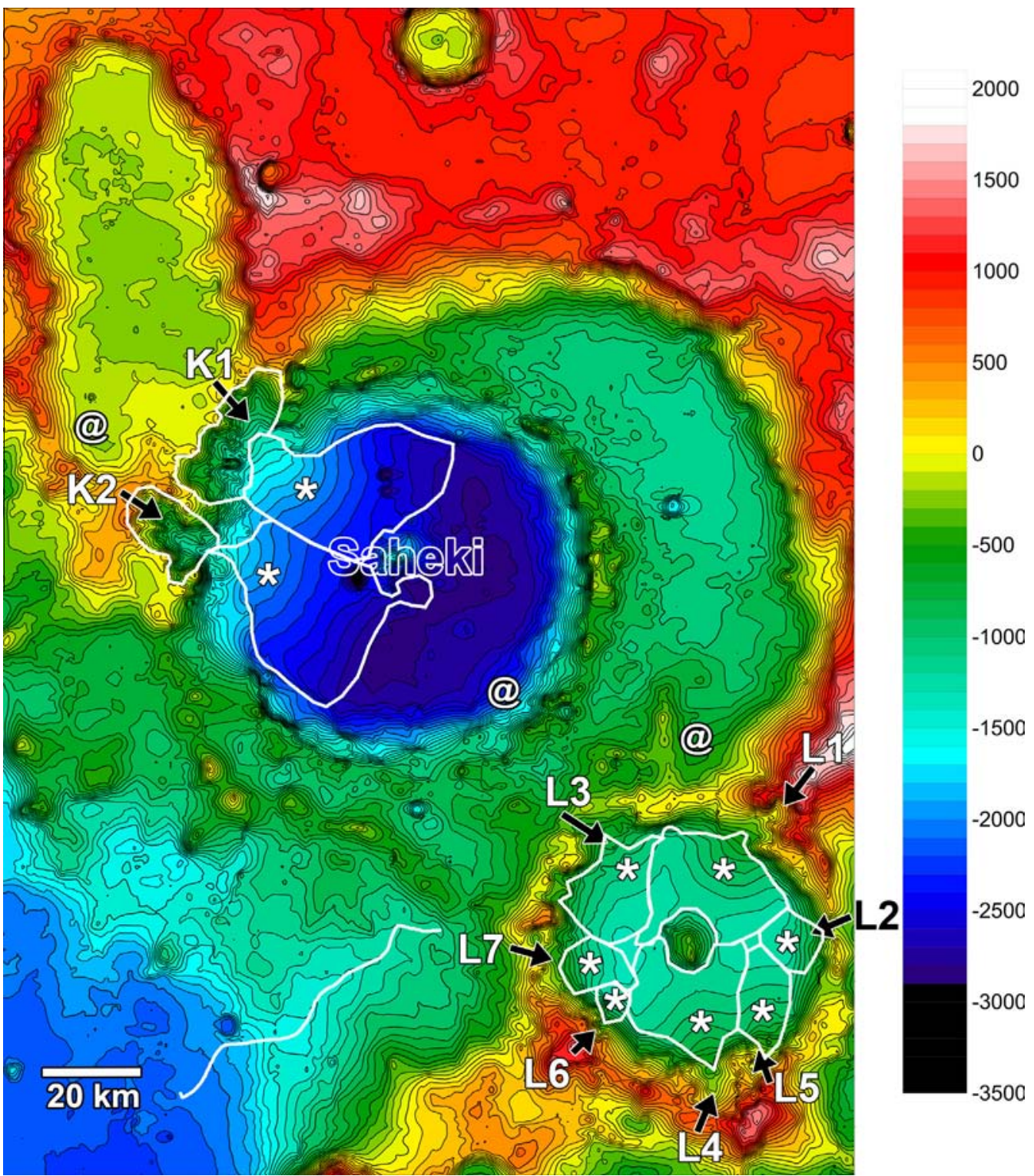

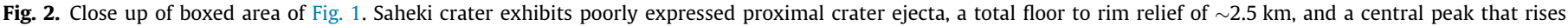

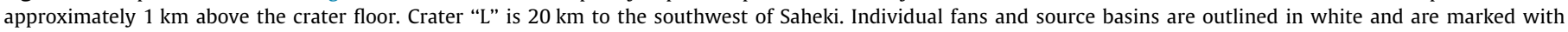
asterisks and arrows, respectively. Small fans denoted by “@”. Fan notation follows Moore and Howard (2005). Scale is in meters to Mars datum.

Table 1

Properties of Saheki crater fans and terrestrial Atacama Desert fans.

\begin{tabular}{|c|c|c|c|c|c|}
\hline Property & $\mathrm{K} 1 \mathrm{fan}$ & K2 fan & Average Mars fan ${ }^{a}$ & Atacama fan 1 & Atacama fan 2 \\
\hline Catchment size, $\mathrm{km}^{2}$ & 501 & 319 & 149 & 910 & 328 \\
\hline Catchment relief, km & 1.5 & 2.3 & 1.6 & 3.7 & 3.0 \\
\hline Catchment gradient & 0.096 & 0.089 & 0.118 & 0.050 & 0.084 \\
\hline Fan size, $\mathrm{km}^{2}$ & 813 & 750 & 251 & 199 & 215 \\
\hline Fan relief, km & 1.33 & 1.22 & 0.72 & 0.3 & 0.38 \\
\hline Overall fan gradient & 0.030 & 0.031 & 0.041 & 0.0094 & 0.018 \\
\hline Mid-fan gradient & 0.038 & 0.030 & - & $0.02^{\mathrm{b}}$ & $0.028^{\mathrm{b}}$ \\
\hline Fan length, km & 44.8 & 40.1 & 18.74 & 30.0 & 20.5 \\
\hline Fan concavity ${ }^{c}$ & 0.0193 & 0.0045 & 0.0700 & 0.048 & 0.072 \\
\hline
\end{tabular}

a Average of 31 large fans reported in Moore and Howard (2005).

b Fan gradient near apex.

c Fan concavity is measured by $-\left(d^{2} z / d x^{2}\right) /(d z / d x)$, where $z$ is surface elevation ( $\left.\mathrm{m}\right)$ and $x$ is distance from the fan apex (km), estimated from measurements at the fan apex, midpoint, and termination (Moore and Howard, 2005).

Tyrhenna (Moore and Howard, 2005; Kraal et al., 2008; Williams et al., 2011). As part of a new global inventory of alluvial fans (Wilson et al., 2013), several additional fan-hosting craters have been identified in the north Hellas rim region (“@” symbols in Fig. 1). Our morphologic and stratigraphic study primarily focuses on the fans within Saheki. 
Saheki crater is superimposed onto a larger $\sim 100 \mathrm{~km}$ crater to the east and an elongated elliptical basin measuring $90 \mathrm{~km}$ by $45 \mathrm{~km}$ to the northwest. It contains two prominent fans (K1 and $\mathrm{K} 2$ in Fig. 2) sourcing from its western rim and one much smaller fan sourcing from the southeastern rim. The Saheki fans are of shallow gradient $(\sim 0.03)$ and large size (greater than $750 \mathrm{~km}^{2}$ ) (Table 1), comparable to dimensions of other alluvial fans in the region. Localized fluvial dissection occurs on the craters' ejecta as well as within the main cavity and is of an uncertain age relationship to the fans. The southern rim of Saheki features large slumps presumably formed by failure of the steep transient crater wall shortly after the crater itself was formed. These slumps have been modified by mass wasting and fluvial erosion and based on their superposition must pre-date the fan deposits discussed (Fig. 3). All of the large fans in this region are sourced from steep-walled, sharply defined alcoves carved into the crater rim that act as the sole sediment source region and drainage basin supplying the fan.

The Saheki fans have been completely imaged by the Mars Reconnaissance Orbiter's (MRO) CTX camera (Context Camera, resolution $\sim 6 \mathrm{~m} /$ pixel (Malin et al., 2007)) and have varying degrees of HiRISE coverage (High Resolution Imaging Science Experiment, resolution $\sim 30 \mathrm{~cm} /$ pixel (McEwen et al., 2007)). We have produced digital elevation models (DEMs) from select HiRISE and CTX stereo pairs with the Ames Stereo Pipeline software package (Morato et al., 2010). MOLA topographic data (Zuber et al., 1992) was used for areas not covered by our DEMs. Spectral data from the Thermal Emission Imaging System (THEMIS) and the Compact Reconnaissance Imaging Spectrometer for Mars (CRISM) datasets (Murchie et al., 2007) were not useful in this investigation; two CRISM images covering the fans indicated the presence of hydrated

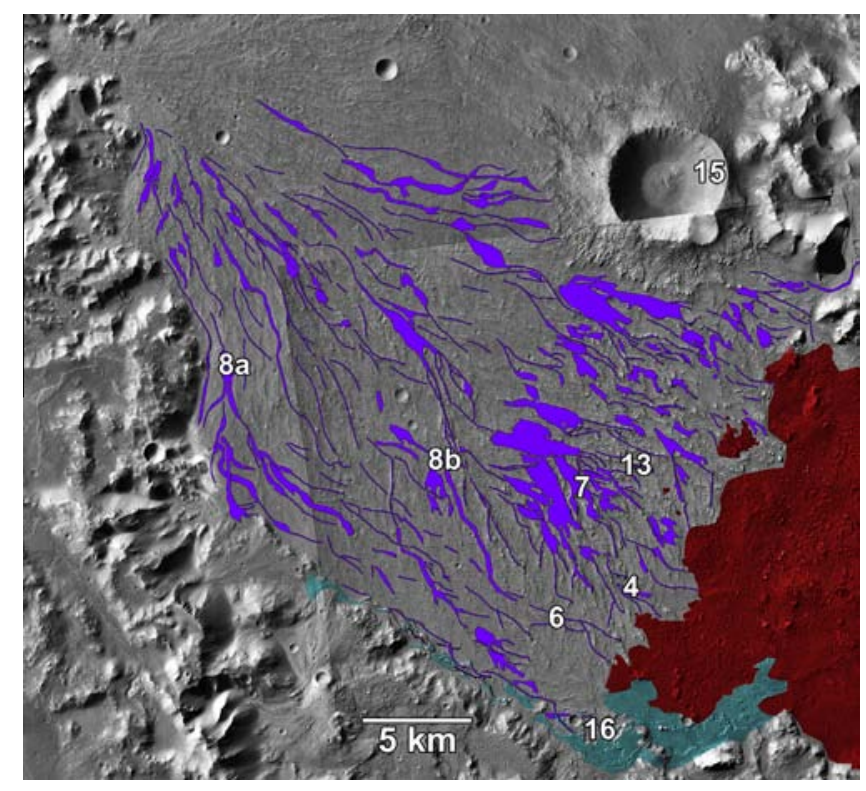

Fig. 3. Interpretive map of southern portion of the Saheki crater K 2 fan and related features. The central peak and degraded interior rim are in the upper right and lower left, respectively. Also along the southern edge of the fan are slumps sourced from the crater walls which pre-date the fan material. Numbers indicate locations of additional figures. Purple lines and areas are raised ridges and platforms interpreted to be fluvial distributaries radiating from the fan apex at the upper left. Where the linear ridges or paired ridges are less than about $100 \mathrm{~m}$ in width they are shown as purple lines, but broader ridges and level platforms are portrayed as purple areas. Aeolian erosion has raised these into varying degrees of inverted relief. Red areas are crater floor materials interpreted to be megabreccia. Cyan features along southern margin of fan are flat-topped benches interpreted to be lacustrine or playa deposits contemporaneous with the fan. Uncolored areas on the fan are discontinuous distributaries and low areas partially mantled by transverse aeolian ridges (TARs). Mosaic of $\sim 6 \mathrm{~m} /$ pixel CTX images P17_007543_1586, P19_008545_1576, and B09_007543_1586 centered at $21.96^{\circ} \mathrm{S}, 72.81^{\circ} \mathrm{E}$. minerals but did not resolve any spatial pattern that could be correlated with visible features.

\subsection{Fan morphology and stratigraphy}

The fans in Saheki, particularly the more southern of the two principal fans (K2, Fig. 3) exhibit surface texture and erosionaccentuated bedding at hectometer scale (Moore and Howard, 2005 ) that is far more pronounced than observed on other martian fans. Both the K1 and K2 fans (Fig. 2) form typical conical morphology and are sourced from deeply dissected source basins on the northwestern and western crater rim. The K1 and K2 fans merge concordantly at their lateral boundaries, but no clear superposition relationship was identified and they likely formed simultaneously, resulting in interfingered deposits. The two fans are of similar size, surface gradient and source basin characteristics (Table 1). The surface of the upper parts of the $\mathrm{K} 1$ fan is relatively featureless at the decameter scale except for superimposed impact craters and a $650 \mathrm{~m}$ wide valley extending about $10 \mathrm{~km}$ into the fan from the apex. Several indistinct shallow valleys radiate from this incised valley. The eastern, distal $10 \mathrm{~km}$ of the $\mathrm{K} 1$ fan has been winddissected into linear ridges similar to those on the $\mathrm{K} 2$ fan (discussed below). In contrast, the upper portion of the K1 fan appears to be relatively unaffected by wind erosion, but meter to decameter features of the original fan surface have been obscured by post-fan impact gardening and modest aeolian deposition, largely occurring as scattered transverse aeolian ripples (TARs) (Wilson and Zimbelman, 2004; Balme et al., 2008; Berman et al., 2011). As a result, fluvial morphology and stratigraphy is poorly exposed, so this study emphasizes the better exposures on the K2 fan.

The K2 fan surface features prominent ridges radiating from the fan apex (Fig. 3). These ridges have the greatest relief and continuity on the southern and eastern distal portions of the fan. Clear exposures of layered deposits on the sides of the inverted ridges indicate that winds keep exposures free of dust and that wind is the likely erosional agent inverting the ridges (Fig. 4). TARs with a dominant E-W orientation mantle much of the depressed inter-ridge surfaces, although whether winds were northerly or southerly is uncertain. Layer exposures on the south side of the dominantly E-W trending ridges are generally clearer than on the north side, suggesting that the strongest winds are southerly. Consistent with this interpretation, composite IRB HiRISE images (composites with the near-IR, red, and blue-green images displayed in red, green, and blue channels, respectively) indicate a distinct bluish cast on the north side of some ridges indicative of a different composition, which, when coupled with obscuration of layers, suggests aeolian accumulation on the sheltered side (Fig. 4). The TARs suggest a high availability of sand-to-granule size sediment (our terminology for grain size is summarized in Table 2) to aid aeolian scour, and because the TARs are concentrated on the fan surfaces rather than on the exposed crater floor, the fan deposits are a likely sediment source.

Thicknesses of the Saheki fans were estimated by comparing topographic profiles of the nearly flat eastern half of the crater floor to profiles through the fans (Fig. 5), so that the fans are likely 800$850 \mathrm{~m}$ thick near the apices and approximately $300 \mathrm{~m}$ thick where they impinge upon the central peak. The volume of the fan deposits was estimated in two ways. The first method gives an order of magnitude estimate by multiplying an assumed average fan thickness $(400 \mathrm{~m})$ by the combined surface area of $\mathrm{K} 1$ and $\mathrm{K} 2$ fans $\left(1563 \mathrm{~km}^{2}\right)$ giving $525 \mathrm{~km}^{3}$. Another estimate is based on circular projection of the profiles A through $\mathrm{E}$ in Fig. 5 to produce the estimated basal fan topography and calculating the volumetric difference with the modern DEM, giving $586 \mathrm{~km}^{3}$. This second value is likely a slight underestimate because valley fill deposits above 


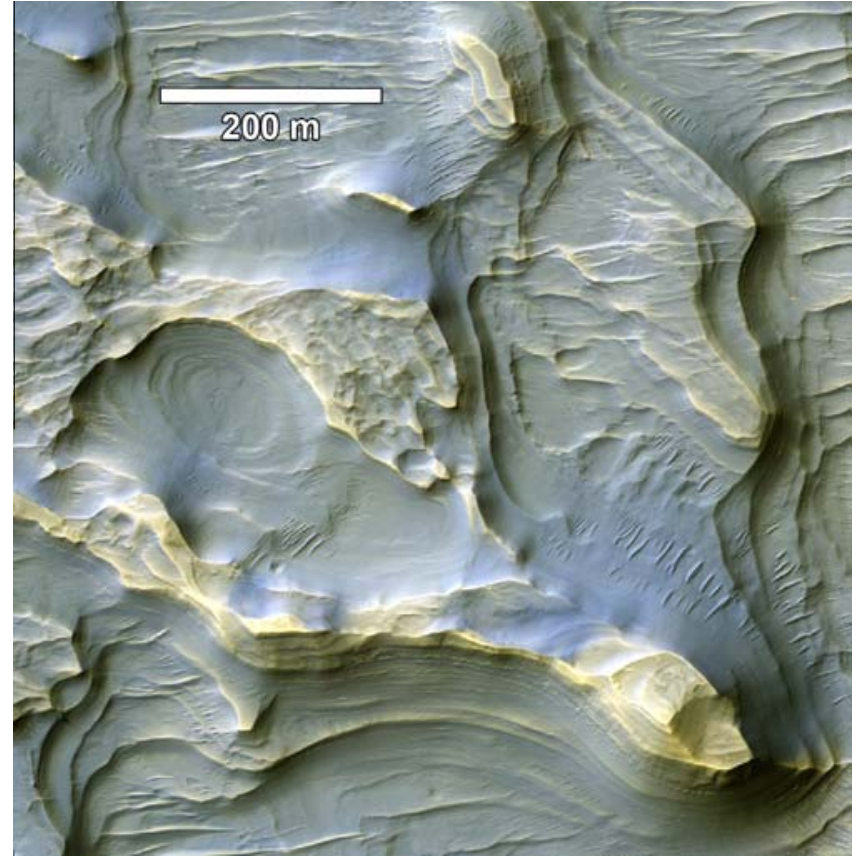

Fig. 4. Detail of inverted ridges and interbedded fine sediment exposed on subjacent slopes sediment capping ridge crests have yellowish cast relative to fine sediment. Fine aeolian sediment concentrated on north side of ridges has distinct bluish tone. Note scalloped indentations on ridge crests, presumably due to wind scour. Part of IRB color $\sim .3 \mathrm{~m} /$ pixel HiRISE image PSP_007688_1575 centered on $22.092^{\circ} \mathrm{S}, 72.966^{\circ} \mathrm{E}$, with colors stretched for clarity. Portions of low areas are occupied by TAR ridges. (For interpretation of the references to color in this figure legend, the reader is referred to the web version of this article.)

the fan apex were not accounted for. Unfortunately, the MOLA DEM has insufficient resolution to estimate the eroded volume of the source basin, and higher resolution stereo imaging was not available there.

Three distinct geomorphic and associated sedimentary features are associated with the Saheki fans, each of which is described below: (1) linear ridge and broad platform features and associated deposits that locally broaden into nearly flat benches with roughtextured surfaces; (2) fine-textured layered deposits largely exposed on side-slopes beneath ridges and platforms; and (3) level benches at distinct elevations bordering the fan deposits at their southern and eastern margin.

\subsubsection{Linear and platform features}

We broadly define this class of features as downslope-oriented ridges or depressions radiating from the fan apex and traceable over kilometer or longer distances (Figs. 6-8). These features occur as four subtypes. The dominant morphology occurs as linear to modestly sinuous $(<1.2)$, narrow (10s of meters in width) ridges that stand up to $70 \mathrm{~m}$ above the surrounding terrain. With distance downslope, ridges often become narrower, discontinuous, and higher relative to their surroundings, although the ridge tops define an accordant, sloping surface. A second, less common morphology consists of two parallel ridges that are separated by a few 10 s of meters. A third morphology comprises linear depressions generally $100 \mathrm{~m}$ or more across. In a few cases, a systematic down-fan transition from a depression through parallel ridges to a single ridge is observed, although unequivocal examples are rare (Fig. 6). Individual linear features can locally be traced $15 \mathrm{~km}$ or more down-fan, but none of the features extends from the fan apex to the distal fan margin (Fig. 3). A fourth morphology occurs as broad, nearly level platforms that display a ridge and swale topography, generally with the long axis oriented downstream although sometimes displaying a curved pattern (Fig. 7). Ridges are typically spaced a few 10s of meters apart and platforms commonly connect to linear ridges upslope or downslope (Fig. 3). In the mid-section of the fan, these platforms mostly occur as isolated features, often widening downstream in small flared forms (Fig. 8) that are usually dissected at their downstream ends (black arrows in Fig. 8). About $10 \mathrm{~km}$ from the distal end of the fan, the platforms become broader, more numerous, and interfinger at different stratigraphic levels (e.g., Figs. 7 and 9). Comparing the actual elevations of the lower fan surface to a virtual conic surface projected from the upper fan suggests that as much as $120 \mathrm{~m}$ of sediment may have been wind-eroded from low regions between ridges (Fig. 9).

Onlap and superposition relations are visible locally all over the fan surface (Figs. 3, 7 and 9). In almost every case, each linear ridge projects downstream to a higher elevation than ridges originating farther downstream. Although superposition relationships are evident locally, correlations across the entire fan surface are not possible. Essentially all of the linear ridges and depressions are oriented downslope, but ridges at different levels occasionally cross at acute angles. Definitive examples of ridge intersections at an accordant level are sparse. Where they occur, they generally exhibit downslope branching, although rare braiding patterns occur.

The top surface of the linear ridges typically has a scalloped appearance at decameter scales (Figs. 3 and 10). Blocks up to several meters in diameter are visible locally on the ridge surfaces, and in numerous locations the surface shows occasional $\sim 1 \mathrm{~m}$ blocks interspersed with a characteristic mottling or speckling (Fig. 10 inset) that appears to be limited in occurrence to the ridge surfaces. Elsewhere, the ridge crests are relatively smooth at meter to submeter scales. To establish the distribution and setting of the blocks, we mapped occurrences by careful examination of three HiRISE images covering the K2 fan surface (Fig. 11). Concentrations of blocks occur almost exclusively on the tops of linear ridges or as exposures on the top few meters of side-slopes at the edge of the ridges. Block exposures are generally elongated along the direction of the ridge crests and often occur in close association with mottled/speckled surfaces. Both blocks and mottling become less frequent towards the distal end of the $\mathrm{K} 2 \mathrm{fan}$, so that ridge crests are smooth at meter scale (although frequently scalloped at decameter scale).

\subsubsection{Interpretation of linear and platform features}

The linear and platform features radiate from the apex, trend downslope, and generally exhibit nearly uniform widths downstream. Consistent with channelized flow, we interpret these features as fluvial distributaries constituting the sediment dispersal backbone of the alluvial fans (Grant and Wilson, 2012; Moore and Howard, 2005; Williams et al., 2009b, 2011) and the fact that most of these linear features are exposed as ridges to indicate they have been inverted by differential aeolian erosion. The channelized distributaries must have been embedded within finer and/or more poorly cemented deposits that were preferentially stripped. The characteristics of these easily-eroded deposits are discussed in Section 2.2.4.

Boulders on the Saheki fan surface might have originated through a variety of processes, such as fluvial deposition, through cementation of a deposit and its subsequent weathering into blocks, or as impact ejecta. We, however, interpret the visible blocks exposed on the ridges (Fig. 10) to be fluvially transported and deposited boulders ranging from 0.25 to $4 \mathrm{~m}$ in diameter. Blocks are largely absent in the depressions between ridges, although the frequent mantling by TARs could obscure some deposits. Exposures of coarse-grained material occur primarily from the $\mathrm{K} 2$ fan apex to about $10 \mathrm{~km}$ from the distal margin of the fan (Fig. 11), and are positively correlated with an apparent increase in total incision into the fan surface (Fig. 9). This observation 
Table 2

Terminology for grain sizes used in this paper based on the Wentworth (1922) classification.

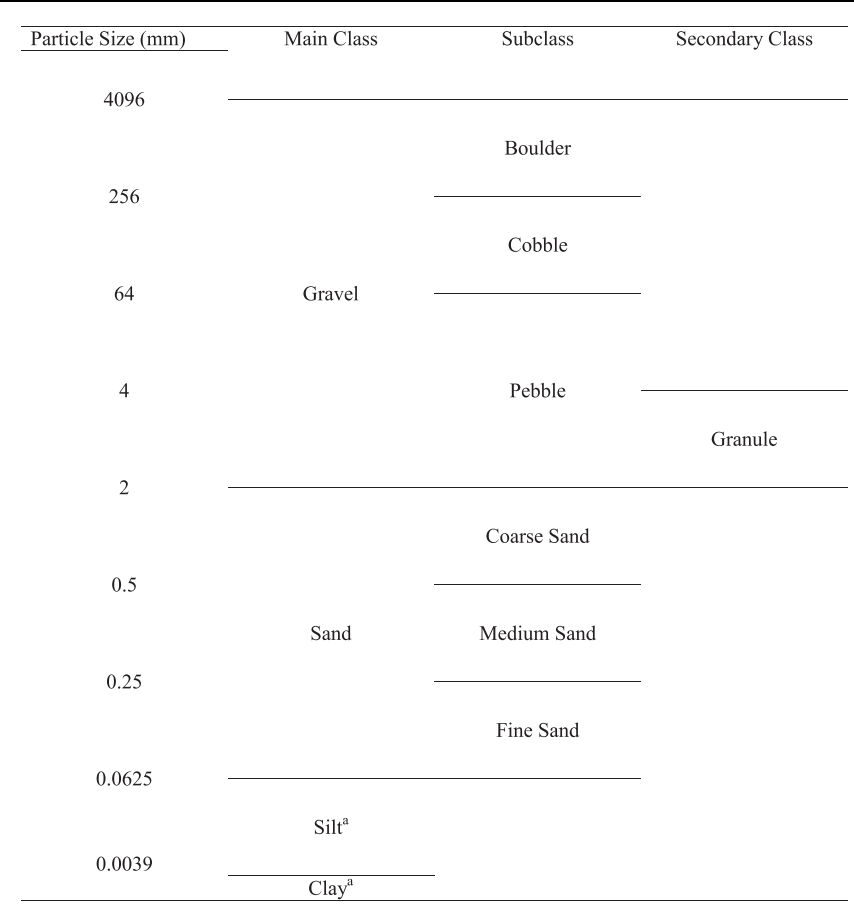

a Silt and clay grouped together are termed "mud".

is consistent with a downstream fining of channel bed sediment, with boulders giving way to finer gravel and sand as the distance from the fan apex increases, as sometimes observed in terrestrial fluvial fans (Stock et al., 2008; Stock, 2013). On terrestrial fans dominated by debris flows, systematic downstream changes in grain size would not be expected, reinforcing our interpretation that these Saheki fans are not debris flow fans (Blair and McPherson, 2009). The observation that fluvial conglomerates are present on an alluvial fan in Gale crater (Williams et al., 2013) supports the interpretation that runoff on martian alluvial fans was capable of transport of gravel.

On portions of the distributary deposits near the downstream end of areas with visible boulders, the ridge tops are commonly mottled or speckled at $30 \mathrm{~cm} /$ pixel HiRISE resolution (Fig. 10). Mottling in images could result from a variety of surface morphologies, including wind ripples and patterned ground, but the association of these mottled surfaces with visible coarser-grained material in nearby exposures suggests that they are gravels below the limit of HiRISE resolution. Distributary ridges that do not display either visible boulders or a mottled surface are presumably deposits finer than a few tens of $\mathrm{cm}$ in diameter.

Distributary ridges are often discontinuous (Fig. 7), implying that ridges can be eroded, either by direct removal by wind erosion and/or by lateral backwasting of hillslope scarps. The resistance of the fluvial distributaries to wind erosion that results in their topographic inversion could be due either to diagenetic cementation or to a component of the fluvial sediment being coarser than a few $\mathrm{mm}$ in diameter (the effective limit to wind transport (Greeley et al., 1976; Zimbelman et al., 2009; Gillies et al., 2012). Sand and gravel in fluvial deposits, being permeable, often become cemented from percolating groundwater, whereas interbedded and largely impermeable fine deposits are not (Spötl and Wright, 1992). The decameter-scale fluting on the surface of many of the inverted channels suggests a loose component of the sediment that can be deflated; in such locations cementation is probably less important than the presence of a component of coarse sediment that can form a wind-resistant pavement. Similar wind fluting occurs on fine, apparently modestly cemented deposits in Terby crater (Ansan et al., 2011; Wilson et al., 2007) and on fine-grained deposits on Atacama Desert fans (discussed in Section 3.1.1). The local presence of fluvially-deposited boulders (Fig. 10) suggests that mass wasting must dominate ridge backwasting at least locally because wind cannot strip such coarse debris.

The pattern shown in Figs. 3 and 6 in which distributaries emerge from beneath stratigraphically higher deposits, increase in relative height and height of inversion downslope, and terminate before reaching the distal fan edge indicate that the degree of aeolian stripping increases systematically towards the distal end of the K2 fan. Near the apex of the K2 fan, distributaries are in low relative relief and difficult to differentiate. This muted topography would be expected near a fan apex, where distributaries shift frequently (thereby covering a greater area with coarser material) and where deposition would likely be dominated by coarse-grained channel deposits.

Occasionally the K2 fan surface has eroded into two parallel ridges which typically transition down-fan into raised ridges of similar width (black arrows in Fig. 6 and red arrows in Fig. 7) but which often become indistinct hollows when traced upstream (Fig. 6). We interpret these parallel ridges to be narrow natural levees that would be the first coarse-grained component of an overbank channel deposit to emerge during wind scour, with the finer distal overbank deposits being preferentially removed. Likewise, the interiors of such channels were presumably filled with finer, more readily-eroded sediment after abandonment.

The wider platform features mapped in Fig. 3 are interpreted as fluvial deposits created either by multiple, braided channels (Fig. 8) or by a single, slightly sinuous channel that migrates laterally, leaving scroll-bar ridges (Fig. 7), as suggested by Moore and Howard (2005). Similar inverted features interpreted as scroll bars occur on the Eberswalde crater delta (Malin and Edgett, 2003; Moore et al., 2003) and sinuous channels in the Aeolis-Zephyria region (Burr et al., 2009, 2010). It is likely that flow did not occupy the entire width of these broad expanses at any given time.

The isolated platform deposits in the mid-section of the $\mathrm{K} 2 \mathrm{fan}$ (Figs. 3 and 8) might form by two processes, one related to avulsion and the other to autogenic processes. The avulsion scenario would accompany distributary shifts into a new course. As fans aggrade, the inactive portions of the fan become relative depressions. When an avulsion penetrates into a depression, splay-like bedload deposition may occur until the depression becomes filled and material can be transported further down-fan. Subsequent fluvial erosion downstream from the relative depression can result in entrenchment of the splay deposits or abandonment due to an avulsion. The second scenario involves local flow expansion, transverse gravel bar deposition, infilling of the resultant upstream depression, and eventual breaching and trenching of the bar (Field, 2001; Stock, 2013).

The broad band of overlapping platform deposits about 5$10 \mathrm{~km}$ upstream from the distal end of the fan might have resulted from the effects of a rising temporary lake (playa) base level at the fan terminus which would encourage enhanced deposition and a spreading flow pattern. The high relief on the distal end of the fan suggests that wind erosion has stripped at least $70 \mathrm{~m}$ and perhaps up to $120 \mathrm{~m}$ of fan and basin-floor deposits, indicating a higher base level when the uppermost fan deposits were laid down (Fig. 9). As discussed in Section 2.2.7, benches along the southern margin of the fan also suggest a higher base level was present during deposition of the youngest fan deposits. It is also possible that decreasing grain size downstream simply led to reduced formation of levees around the channels, resulting in more sheet-like and laterally unconstrained flow and deposition. 

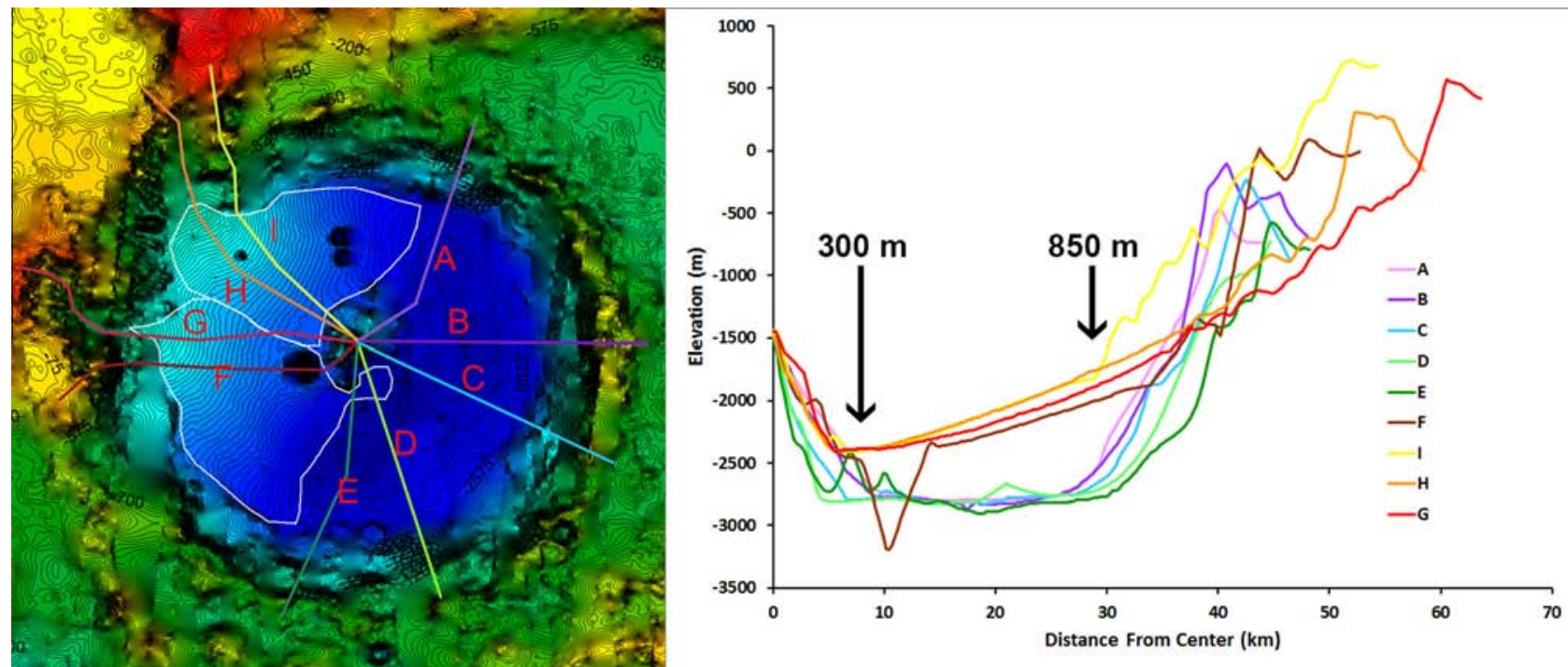

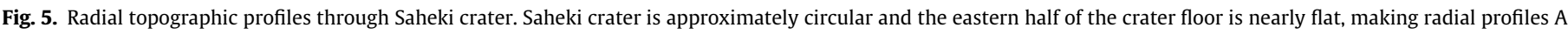

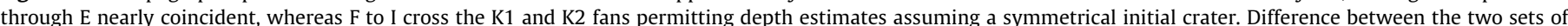

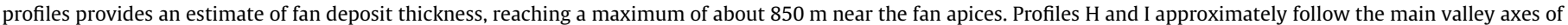
the source basins upstream from the K1 and K2 fans. Topography from interpolated MOLA PEDR data.

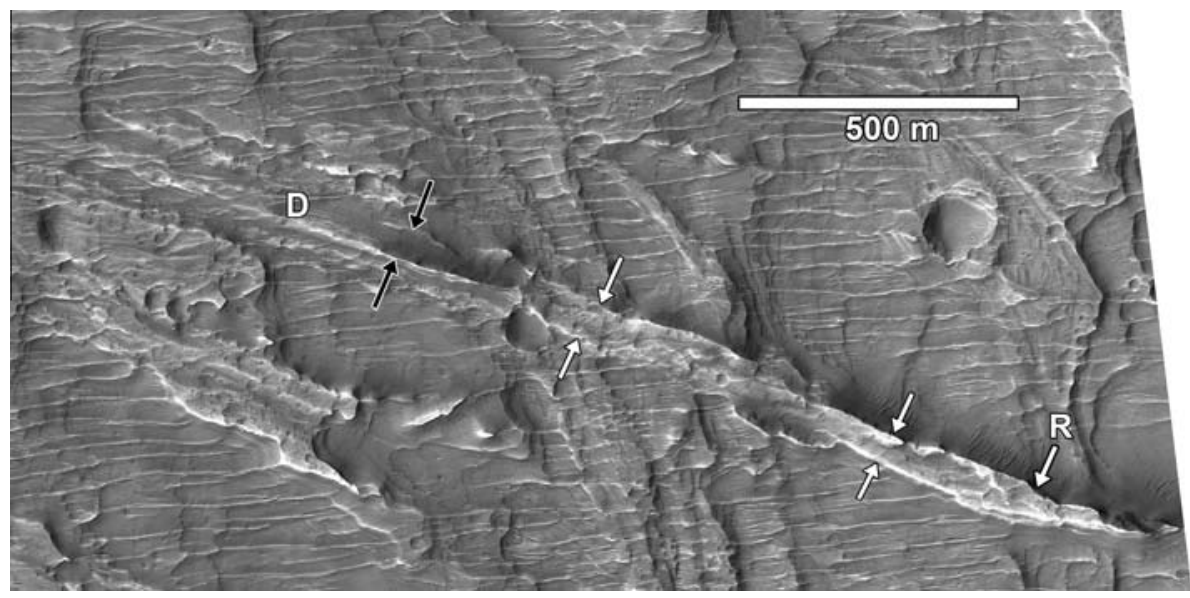

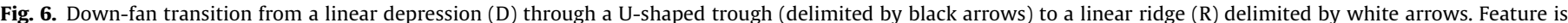

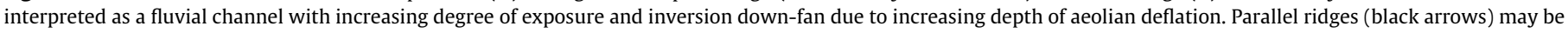
narrow natural levees. Part of .3 m/pixel HiRISE image ESP_029788_1575, centered at $22.123^{\circ} \mathrm{S}, 7_{2} .906^{\circ} \mathrm{E}$.

\subsubsection{Distributary widths}

Information on distributary widths is important for analysis of flow discharges. The aeolian erosion that inverts the distributaries serves to expose the channels, but may also narrow them as a result of lateral backwasting of the channel edges by mass wasting triggered by aeolian erosion of weaker surrounding layers. Burr et al. (2010) conclude that many inverted meandering channels in the Aeolis Dorsa/Zephyria Plana region have been significantly narrowed because of an observed meander wavelength to preserved ridge width that significantly exceeds the typical terrestrial value of about 10-14 (Knighton, 1998, p. 215). In some environments, however, wavelength/width ratios can reach $20-25$, as along the low gradient, mud-bank Quinn River in Nevada (Matsubara et al., 2012). If the interpretation of the meander pattern in Fig. 7 is correct, the wavelength of about $750 \mathrm{~m}$ divided by an average distributary width of $40 \mathrm{~m}$ gives a meander wavelength/width ratio of about 19 . Although we suspect large observational variance and perhaps some bias in resolving distributary width, a best estimate will serve to calculate approximate formative discharges. Width measurements of 68 inverted channel seg- ments on the $\mathrm{K} 2$ fan where ridge tops are flat with well-defined margins with consistent widths over reasonable $(>500 \mathrm{~m})$ distances (Fig. 7) yielded no systematic spatial trend with position on the fan. The distribution of these widths has a sharp, well-defined peak at $38 \mathrm{~m}$ (Fig. 12), though with a significant positive skew of apparently wider channels. This tail may be in part due to misidentification of wider platforms as single-thread instead of braided channels or to lateral migration of meandering channels. In the few cases where ridges measured for width can be traced upstream to parallel ridges (presumed to be levees), the ridge spacing is approximately equal (within several meters) to the ridge width. Limited HiRISE coverage over other fans in the vicinity of Saheki (Fig. 1) and the lack of additional well-preserved flat-topped ridges in other fan systems prevents a thorough assessment of channel widths elsewhere, though channel widths appear to be qualitatively similar (Burr et al., 2010; Grant and Wilson, 2012).

\subsubsection{Fine-textured, layered fan deposits}

The topographic inversion of the distributary fluvial deposits and the presence of broad depressions between individual 


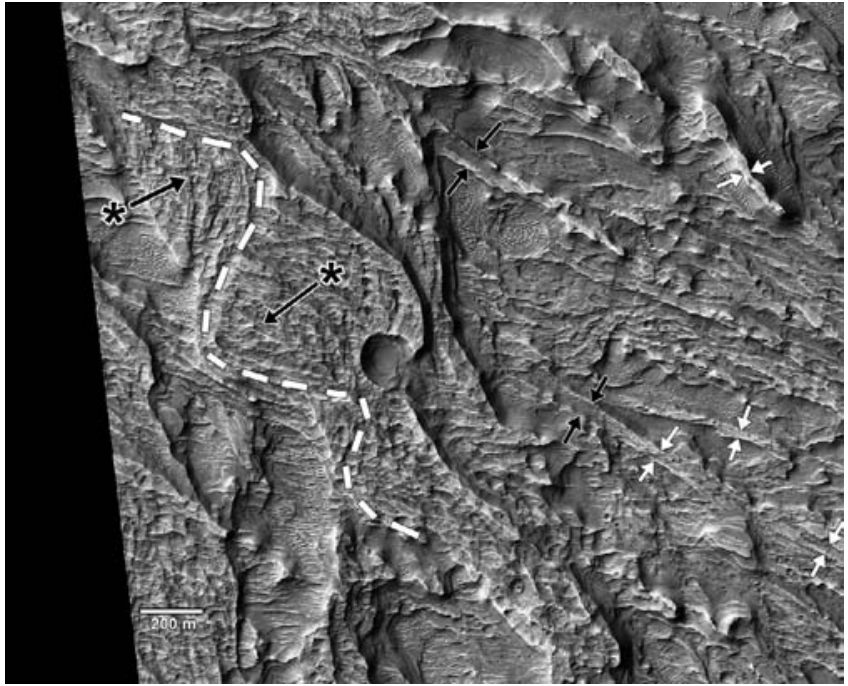

Fig. 7. Flat platforms on the $\mathrm{K} 2$ fan. We interpret the ridges to be mantled with gravelly sediment deposited by low-sinuosity meandering or braiding streams during deposition. An interpreted meander bend is shown by dashed white lines, and possible point-bar deposits interior to the bend occur near the asterisks, with black arrows pointing in the direction of inferred meandering. Paired white arrows on right hand of image shows ridges representative of those sampled to determine original widths. Paired black arrows show paired narrow ridges interpreted to be natural levees exposed through partial aeolian distributary exposure. Part of $\sim .3 \mathrm{~m} /$ pixel HiRISE image PSP_007588_1675, centered at $22.016^{\circ} \mathrm{S}$ and $72.936^{\circ} \mathrm{E}$.
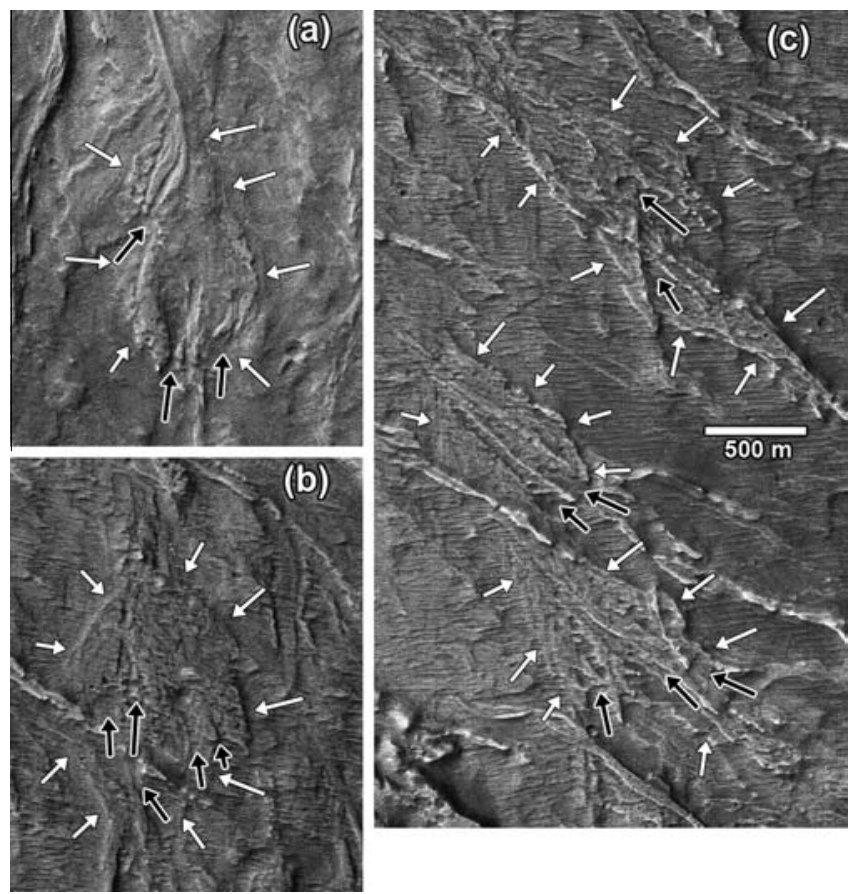

Fig. 8. Splay-like inverted platforms. White arrows show outer limits of splay. Ridges on surface of ridge suggest a spreading, possibly avulsive set of channels. Splays generally terminate down-fan in multiple finger-like ridges, separated by incised linear depressions (black arrows point upstream). All images at same scale. These structures are interpreted as fluvial deposits generally fed by a single channel upstream that spread into local depressions on the fan surface, or as autogenic transverse bars causing upstream deposition. Flows across the splay deposit eventually incise into the distal end of the deposit (black arrows). Images are part of $\sim 6 \mathrm{~m} /$ pixel CTX image P14_006686_1579. (a) Centered at $21.927^{\circ} \mathrm{S} 72.634^{\circ} \mathrm{E}$, (b) at $22.019^{\circ} \mathrm{S}, 72.811^{\circ} \mathrm{E}$, and (c) at $22.141^{\circ} \mathrm{S}, 72.863^{\circ} \mathrm{E}$.

distributaries imply that wind erosion has excavated extensive deposits of erodible sediment interbedded with the channel depos-

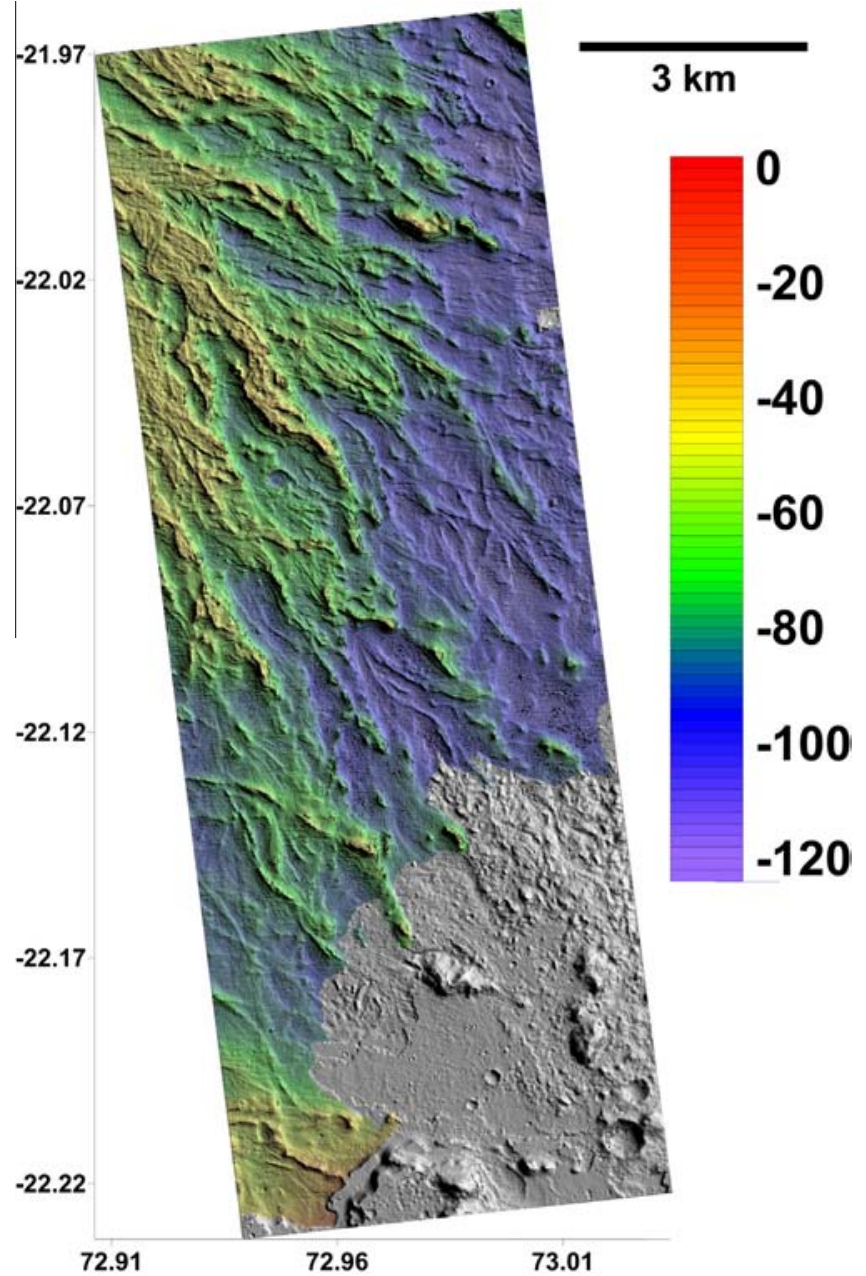

Fig. 9. Shaded relief image of the distal end of the Saheki K2 fan from $\sim 3 \mathrm{~m}$ DEM constructed from HiRISE stereo image pair PSP 7688_1575 and PSP 008545_1575, centered at $22.10^{\circ} \mathrm{S}, 72.97^{\circ} \mathrm{E}$. A plane fit to the overall dip (0.03 ESE) and strike (NNE) of the fan surface was subtracted from the DEM, and elevations (in meters) relative to that plane are indicated in color shading. Portions of the fan surface at approximately equal stratigraphic level have the same relative elevation. This indicates that the depth of aeolian erosion increases towards the distal end of the fan, which is accordant with higher ridge inversion near the distal end of the fan Axis labels in degrees North and East. Portions of image not mantled with fan deposits are uncolored.

its. In most locations, exposures of these deposits are largely obscured by the TAR bedforms mantling inter-ridge depressions. However, at the distal end of the $\mathrm{K} 2 \mathrm{fan}$, the extensive wind erosion has inverted the fluvial ridges into as much as $70 \mathrm{~m}$ of relative relief. Exposures of layered deposits are common on the sideslopes below the ridges (Figs. 4, 10 and 13). These sideslopes are generally smoother at multi-meter scales than the scalloped ridge crests and typically the slopes exposing the layers incline close to the angle of repose for loose sediment $\left(\sim 30^{\circ}\right)$. Resolvable layers are typically 2-3 m thick, although image resolution may limit detection of finer-scale bedding. The beds are commonly massive in appearance and contain no blocks visible at HiRISE resolution (Fig. 13). Beds are often separated by thin light layers that appear to be slightly more resistant to wind erosion and are less continuous, possibly nodular or upward-scalloped (Figs. 13 and 14). Wellexposed individual layers can be traced for several hundred meters but with subtle pinching out occurring locally (Fig. 13b). Thick layered sequences of very similar beds are exposed on the interior walls of several craters that are superimposed onto the $\mathrm{K} 1$ and $\mathrm{K} 2$ fans. A 300 $\mathrm{m}$ thick section of the distal fan exposed in a crater 


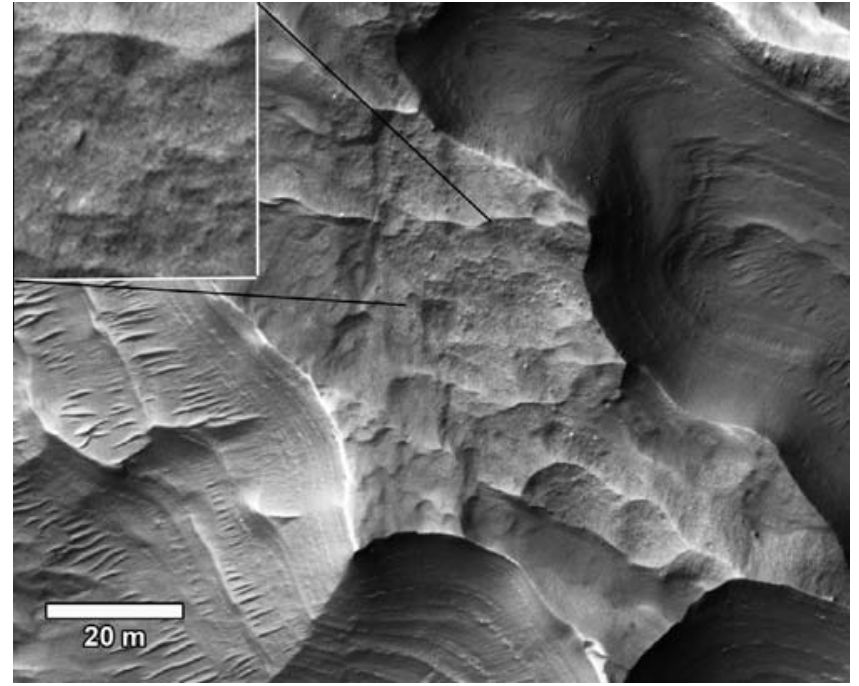

Fig. 10. Detail of inverted ridge showing gravelly sediment and wind scoured surface. Inset is magnified $3 \times$. Layered sediments exposed on slopes below ridge. Part of $\sim .3 \mathrm{~m} /$ pixel HiRISE image PSP_007688_1575 centered at 22.049 ${ }^{\circ} \mathrm{S}$ and $72.944^{\circ} \mathrm{E}$.

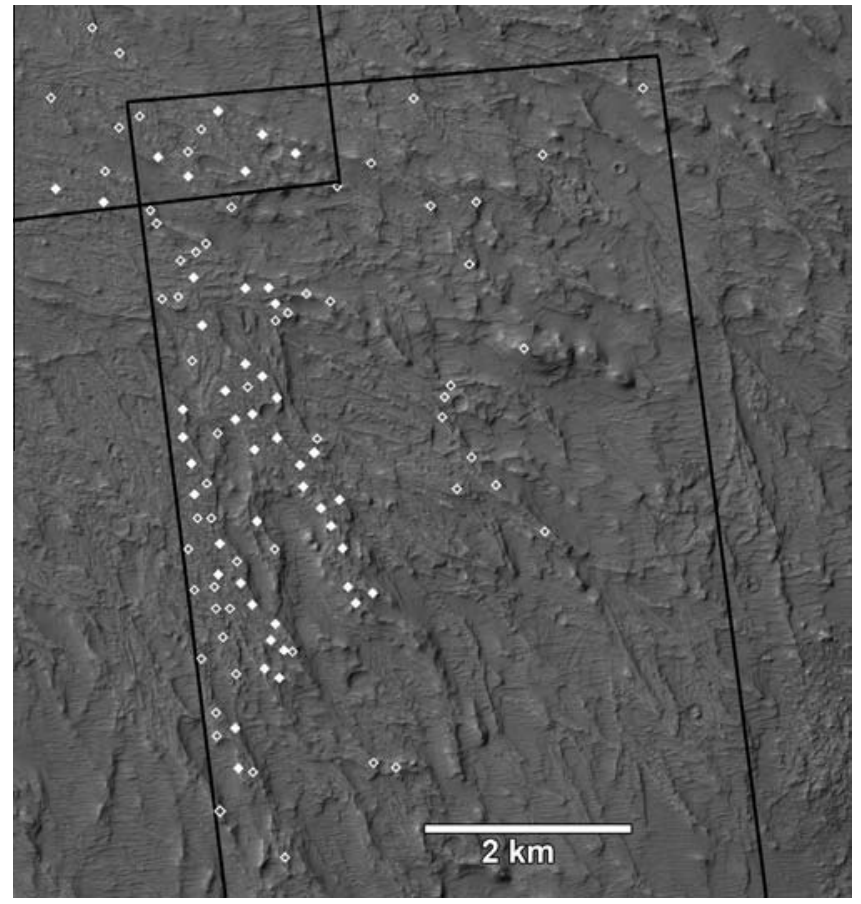

Fig. 11. Distribution of coarse-grained deposits on part of the Saheki K2 fan. These occurrences were mapped on 0.25 m/pixel HiRISE images PSP_007686_1575 (lower black outlined area) and PSP_006686_1580 (upper left black area). Mapping additionally included the remainder of these images and HiRISE image PSP_007899_1580 near the apex of the K2 fan (not shown). Visible coarse deposits and characteristic mottling or speckling in HiRISE images indicated by solid and hollow diamonds, respectively. These are interpreted as deposits of gravel just below the limit of resolution of individual boulders. Image base is CTX image P19_008545_1576 centered at $22.02^{\circ} \mathrm{S}, 92.96^{\circ} \mathrm{E}$. (For interpretation of the references to color in this figure legend, the reader is referred to the web version of this article.)

wall near Saheki's central peak indicates the finest resolvable layers are $\sim 2 \mathrm{~m}$ thick, and many individual layers can be traced several kilometers along the crater wall (Fig. 15). This exposure reveals no resolvable meter-scale blocks except at the base of the section where probable central peak materials appear to be exposed.
The beds exposed on the slopes below the inverted ridges are largely conformable in their dip to the gradient of the ridges (e.g., Fig. 13c). Individual beds cross-cut elevation contours along the trend of the ridge seen in Fig. 13c, with an interpreted gradient of about 0.021 to the southeast following the general dip of the fan using individual prominent beds crossing multiple mapped contours. Similar measurements of bed dips at eight locations elsewhere on the portion of the fan covered by the HiRISE DEM yielded dips ranging from 0.025 to 0.041 ; the mean for the nine total measurements is 0.032 , very close to the $\sim 0.03$ gradient of the entire $\mathrm{K} 2$ fan surface as measured from MOLA tracks.

\subsubsection{Interpretation of fine-textured deposits}

The ease by which wind can erode the layered deposits and the near absence of exposed blocks (save for the thin interbeds) suggests that these deposits are sand size or smaller in dominant grain size. If the deposits were loose sand, however, wind erosion would probably readily sculpt the deposits into dunes. Also if sand were the principal component of the layers, appreciable accumulation of sand dunes might be expected within the Saheki crater, but are not found. The observed TARs comprise a small volume of material compared to the total wind-eroded volume. This proportionality suggests an appreciable component of silt and possibly clay within the layered deposits that can be removed in suspension.

The observation that the fine-textured layers dip concordantly with the superjacent ridges eliminates the possibility that they are exposures of layering pre-dating the fluvial fan ridges, e.g., lacustrine deposits. Rather, the finer-textured deposits must be a distinct facies generally coeval to the channel deposits. We interpret the layered sediment to be deposited by overbank flows sourced from flows within distributary channels that are sufficiently deep to spread across the adjacent fan surface, analogous to overbank deposits on floodplains. Such deposits are likely to be continuous over long distances downstream and to border the source distributaries, but thin laterally. The subtle pinch-outs of layers shown in Fig. 13b may reflect the limited lateral extent of deposition from an individual distributary channel. The apparent thickness of 2-3 $\mathrm{m}$ for individual layers could indicate deep, long-duration flows through individual distributaries with large concentrations of suspended sediment. Because of limited image resolution, however, individual visible beds may be composed of many thin layers from multiple smaller flow events. Because exposed layers are stratigraphically lower than the superjacent channel deposit capping the ridges (e.g., Figs. 4, 10 and 13), we infer they are would have been sourced from a different channel at the same stratigraphic level as the exposed layer rather than being related to the superjacent ridge.

The thin, light-toned, and possibly nodular layers that separate the smoother, darker, and thicker $(\sim 2-3 \mathrm{~m})$ units in layered exposures (Figs. 13 and 14) may result from processes occurring on the fan surface in the time intervals between overbank flooding events, or possibly are some form of graded bedding. However, their thinness compared to the more massive units, the sharpness of their expression and lack of gradual transitions to the overlying or underlying massive beds argues against graded bedding. If, as we postulate, the character of the beds represents post-depositional modification, this alteration likely occurred during times when depositional activity has shifted to other parts of the fan, or during periods of fan inactivity associated with quasi-cyclical climatic variations orbital variations (Laskar et al., 2004; Ward, 1979). Such processes could include wind erosion and surface concentration of granule layers, surface cementation, wetting and drying events, or cold-climate processes. The concave scalloping of some of the light-toned layers has an apparent spatial scale of $2-5 \mathrm{~m}$ (Fig. 14), and might be the result of desiccation-crack development, which occurs at spatial scales ranging from centimeters to tens of 
meters (El Maarry et al., 2010, 2012; Harris, 2004; Neal et al., 1968; Weinberger, 1999), teepee structures from chemical precipitates (Dixon, 2009; Shaw and Thomas, 1989), or patterned ground from thermal cycling or ice-related processes (Chan et al., 2008; Korteniemi and Kreslavsky, 2012; Levy et al., 2009; Mangold et al., 2004; Mellon, 1997). There are no obvious vertical structures in the sediment beneath the scalloped layer edges, however, so that direct evidence for any of these mechanisms is lacking.

The clearest exposures of layered deposits occur on $25-35^{\circ}$ side slopes of flanking ridges capped by fluvial deposits. No interbedded boulders are visible at HiRISE scale. The exposure of layering indicates the slopes are not deeply mantled with debris. Gradients close to the angle of repose of loose sediment $\left(\sim 32-35^{\circ}\right)$ and the smoothness of the side slopes, however, suggest that the exposures may be shallowly, and possibly discontinuously, mantled by debris mass-wasted from the ridge-capping fluvial deposits plus sediment derived from the beds themselves. Such threshold slopes are common on terrestrial badlands (e.g., Howard, 2009). Despite the shallow mantling, indurated beds are often exposed in outcrop, helping to define the stratigraphic relationships. The thin, lighttoned layers visible in Figs. 10, 13 and 14 are probably such examples. In some situations the apparent mantling obscures expression of the layering (e.g., the northerly slope of the hill near (a) in Fig. 13), but it is likely that at least discontinuous mantling occurs on the southwest-facing slope in Figs. 10 and 13 to account for the uniformity of the slope. The sediment may be friable and thus easily eroded, although some weathering of the layered deposits, forming a thin regolith similar to that observed in terrestrial badlands, might be necessary prior to their erosion by wind.

\subsubsection{Benches}

A vertically-stacked series of nearly horizontal benches border the southern margin of the K2 fan against the Saheki crater interior wall (Figs. 3 and 16). HiRISE stereo imaging of part of this bench complex (Fig. 9) demonstrates that the individual bench surfaces are essentially flat-lying with a slope of less than $0.5 \%$. At meter to decameter scales, the surfaces of the benches are quite rough, with numerous quasi-circular depressions (Fig. 17). The surface is littered with numerous angular, meter-scale blocks and the outer edges of the benches form abrupt scarps with irregular outlines. Angular blocks that apparently mass-wasted from the bench surface often discontinuously mantle the steep sideslopes of the benches. Where not mantled by debris, the subjacent slopes are smooth and express subtle layering that appears to be conformable with the overlying terraces (Fig. 17). This layering is very similar to the fine-textured layers exposed on the sides of inverted fan distributary ridges upslope (Fig. 13). The highest bench within the HiRISE DEM is about $85 \mathrm{~m}$ above the similarly-textured basin floor surface, although a slightly higher bench lies just to the south of

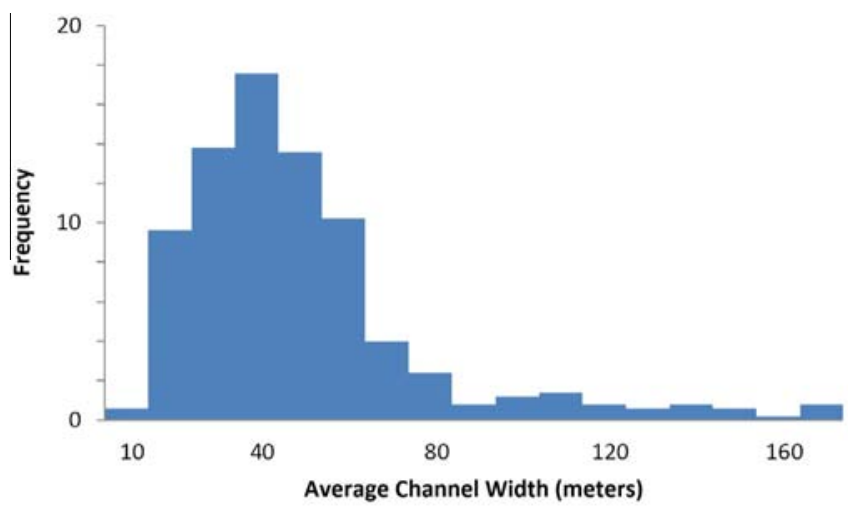

Fig. 12. Histogram of measured channel widths. Average width of segments is $38 \mathrm{~m}$.

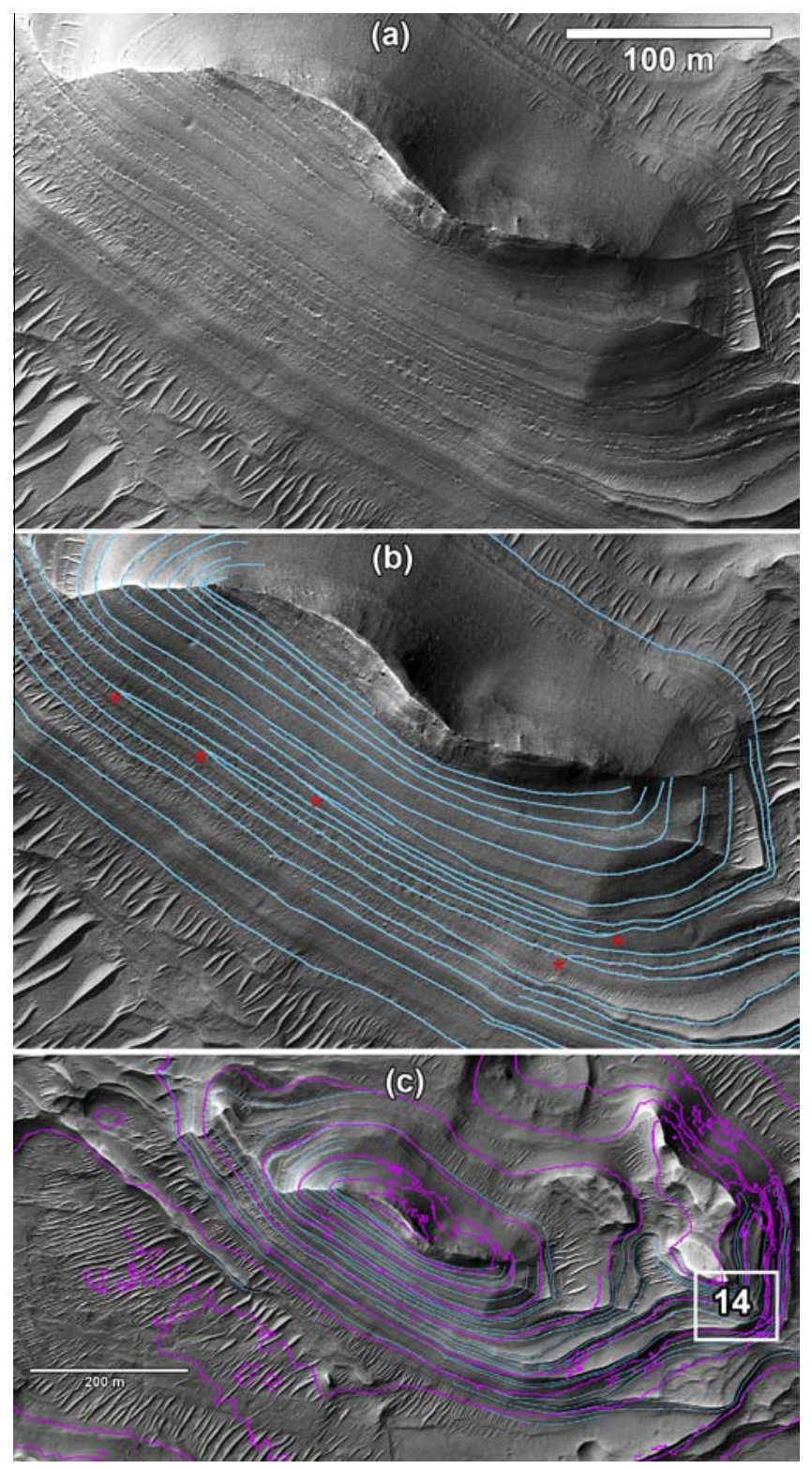

Fig. 13. Layered deposits exposed on slope below narrow ridge. (a) Exposed layers. Note thick, medium toned layers about $2-3 \mathrm{~m}$ thick separated by thin, light-toned layers with nodular or discontinuous presentation. (b) Interpretation of layering in (a), showing layer pinch-out locations indicated with an asterisk. (c) Contours from a $3 \mathrm{~m} /$ pixel DEM (pink) from HiRISE stereo pair PSP_7688_1575 and PSP_008545_1575 DEM superimposed on layer drawing. Ten meter contour interval. Note very shallow dip of layers broadly to the SE. Box at lower right indicates location of Fig. 14. Image scale is reduced in (c) relative to (a) and (b). Part of HiRISE image PSP_007688_1575, centered at $22.007^{\circ}$ S, $72.975^{\circ} \mathrm{E}$.

the DEM. Along the southern margin of the K2 fan some linear ridges interpreted as distributary channels appear to overlie or to merge accordantly with the rough-textured benches, and in such locations the ridges take on the rough texture of the benches. Fine-textured layered deposits also locally superpose the benches. Similar surfaces appear elsewhere, including the lowest point of the eastern half of the nearby "L" crater where a rough, flat-lying surface occurs at the terminus of four large fans (Fig. 18). Part of the Saheki crater floor immediately adjacent to the fan deposits also has a similar flat surface at $100+\mathrm{m}$ scale that is rough at decameter scale, although it has not been eroded laterally to form a bench (Fig. 3). Similarly rough-textured surfaces also occur in small depressions along channels dissecting the southwestward flank of Saheki crater. 


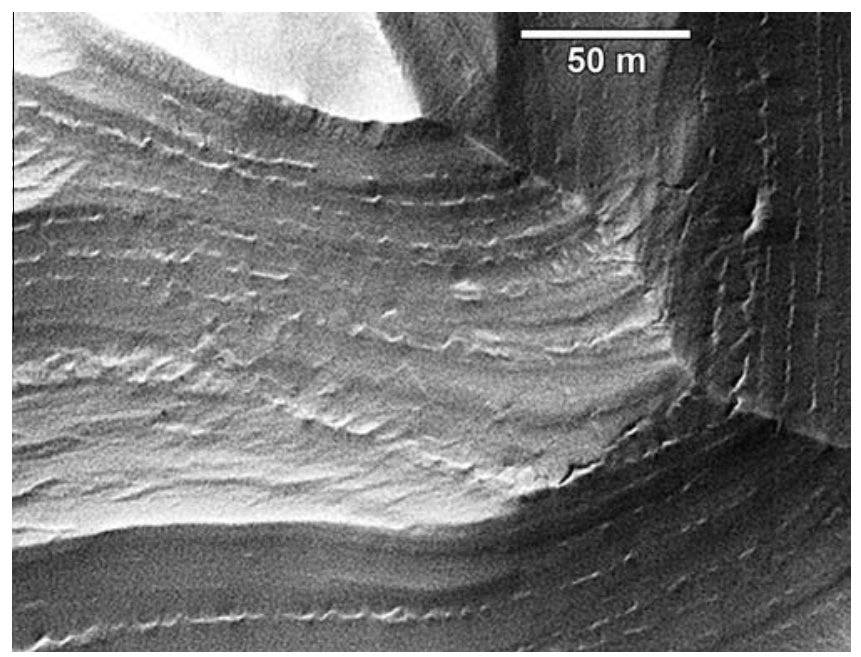

Fig. 14. Detail of thin, light-toned layers interbedded with thicker, massive layers (see Fig. 13 for context). Note the discontinuous appearance of the layers and indications of concave-upward layer cross-section. Part of HiRISE image PSP_007688_1575, centered at $22.008^{\circ} \mathrm{S}, 72.982^{\circ} \mathrm{E}$.

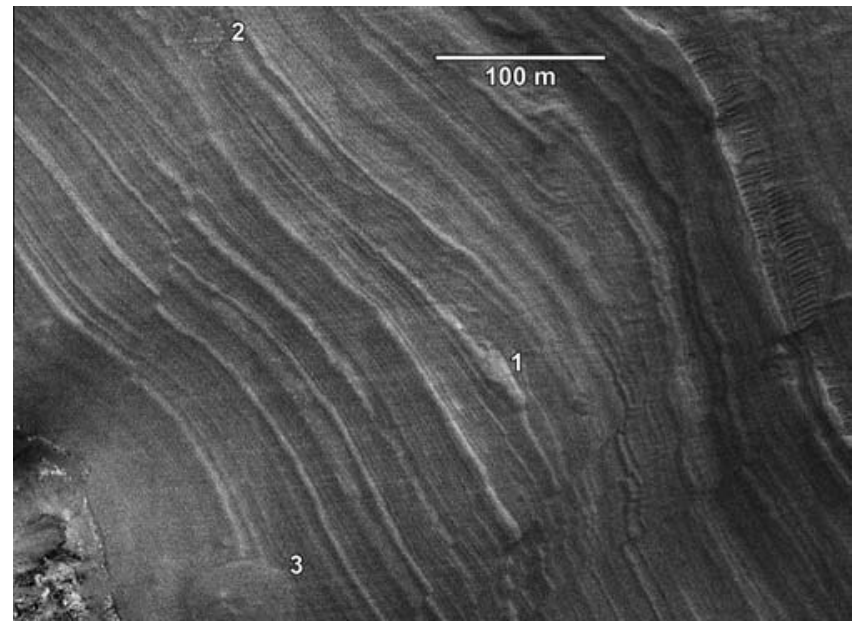

Fig. 15. Thick sequence of beds in eastern wall of a $5.3 \mathrm{~km}$ diameter crater superimposed onto fan deposits adjacent to Saheki central peak. Finest visible beds are $\sim 2$ m thick. Thicker blobs, as near "1" may be channel deposits. Circular features 2 and 3, obscuring bedding, may be scars of small impacts into interior crater wall. Note faulting in near left and right side of image, presumably due to impact deformation. Bottom of layer sequence at lower left of image where coarse crater floor or central peak materials are exposed. Image DN highly stretched to emphasize layering. Part of HiRISE image ESP_013226_1580, centered at $21.762^{\circ} \mathrm{S}, 73.046^{\circ} \mathrm{E}$

\subsubsection{Interpretation of benches}

We interpret the benches to be underlain by playa and/or possibly shallow lacustrine sediments sourced by runoff from the adjacent fans. Their level surface implies they are probably composed of fine sediment deposited from suspension. Alluvial fans in enclosed basins typically terminate in nearly level playas that receive fine suspended sediment that is carried beyond the end of the fan (Shaw and Thomas, 1989). Although the higher benches in Saheki crater are spatially limited to bordering the southern crater rim (Fig. 3), and are thus largely isolated from the fan system, the similar-appearing bench in " $L$ " crater clearly occupies a basin-central position where playa or lacustrine sedimentation would be expected (Fig. 18).

The bench surfaces appear to be thin, nearly horizontal resistant layers that have been laterally eroded, shedding boulders onto sub- jacent slopes. The numerous rounded depressions (Figs. 17 and 18) suggest that the roughness of the surface is due to impact gardening forming a blocky regolith. The resistant layers are underlain by apparently conformable layers that are more easily eroded by wind. We interpret the benches and other rough-textured level surfaces in the region to be chemically-cemented layers that have been subsequently broken up. They occur at topographic lows, or, where the benches occur at higher levels, what might have been low points prior to aeolian stripping.

Being the endpoint for both suspended and dissolved loads, playa sediments are commonly rich in salts concentrated from evaporation of ephemeral shallow lakes or delivered by groundwater (Dixon, 2009; Langer and Kerr, 1966; Shaw and Thomas, 1989; Yechieli and Wood, 2002). Solute-cemented playa deposits are common in the southwestern United States and in the salars of the Atacama Desert. In the Atacama and similar desert settings elsewhere, the segregation of mineral precipitates within the sediments often results in volumetric expansion and small-scale deformation of the surface sediments, resulting in chaotic surface topography at meter to decameter scales (e.g., the "Devil's Golf Course" in Death Valley National Park (Hunt et al., 1966; Smoot and Castens-Seidel, 1995) and similar forms in Atacama salars (Stoertz and Ericksen, 1974). The roughness of the Saheki bench surfaces may thus be a combination of chemical cementation, small-scale deformation associated with playa sedimentation, and disturbance by impact gardening.

In terrestrial enclosed basins, the fan and playa deposits interfinger during basin infilling (e.g., Shaw and Thomas, 1989). The stratigraphy of terminal deposits in enclosed basin centers often alternates between playa and lacustrine sediments, with varying degrees of interbedded and co-deposited chemical precipitates (Pueyo et al., 2001; Smith, 1957, 1974). This complex stratigraphy reflects climatic changes and the simplest explanation to account for the multiple planar benches in Saheki crater would be that the successively higher playa surfaces formed sequentially as the center of the basin became infilled. Episodes of playa cementation alternated with periods of sediment input without appreciable chemical co-deposition (creating the less-indurated layers revealed below the erosional edges of the terraces, Fig. 17). Subsequent aeolian deflation would have had to remove at least $100 \mathrm{~m}$ of basin fill sediments in the vicinity of the benches based upon their relief relative to the present basin floor (Fig. 9). By this interpretation the highest benches have experienced greater erosion and backwasting than lower benches as a result of undermining by erosion of the non-indurated finer interbeds, and the lower, younger indurated playa deposits would have extended beneath the remnant higher benches. Note that this implies an age sequence with the highest bench being youngest, inverse to the usual sequence of fluvial terraces increasing vertically in age. The " $L$ " crater basin floor (Fig. 18) would presumably resemble the basin floor at the south end of Saheki crater prior to the period of intense aeolian deflation. More complicated scenarios are also possible involving declining or varying basin floor levels in which fan and playa deposition alternate with episodes of aeolian erosion or in which the bench-forming deposits did not extend across the basin floor.

\subsection{Source basins}

The large alluvial fans in the southern highlands on Mars are generally sourced from steep dendritic valley networks incised into the interior crater walls of large, deep, relatively fresh martian craters (Mangold et al., 2012b; Moore and Howard, 2005). This is clearly the case for fans in Saheki and "L" craters (Fig. 2). Within individual craters, the largest drainage networks and largest associated fans are generally sourced from the highest portions of the hosting crater rim. The only exception to this pattern is that the 
K1 source basin occurs along a low rim section contiguous with a degraded elliptical basin beyond the NW rim of Saheki. Source basin and corresponding fan and gradients areas for the K1 and K2 fans are summarized in Table 1, with comparative average statistics for all of the fans surveyed by Moore and Howard (2005).

We find no evidence for valleys incised into the Saheki fans from runoff sourced on the fan itself. The deep aeolian erosion on the $\mathrm{K} 2$ fan could have erased evidence for such local runoff, but the relatively pristine $\mathrm{K} 1$ fan surface shows all distributaries radiating from the fan apex. Likewise, other large martian fans appear to have received little runoff directly on the fan surface because the surfaces exhibit no channelized erosion initiating from mid-fan sources - the basin headwaters (fan-hosting crater walls) were overwhelmingly the source of runoff (Grant and Wilson, 2012; Moore and Howard, 2005).

\subsection{Age relationships}

Crater density counts are a standard method of determining the relative ages of planetary surfaces. Absolute model ages can then be estimated by comparing these counts to the lunar surface, which has been radiometrically dated. The fan-bearing craters in the region lie on terrain that has been mapped as Noachian (Greeley and Guest, 1987; Irwin et al., 2013). Using a CTX basemap within ArcGIS, our crater count analysis incorporated craters with a diameter of larger than $200 \mathrm{~m}$ to avoid complications arising from the preferential erosion of smaller craters and the increasing influence of secondaries with decreasing diameter (McEwen et al., 2005; McEwen and Bierhaus, 2006). Central peaks, obvious secondary craters, and the interior rims of the host crater were excluded from the analysis. Crater statistics were compiled using CraterStats software (Michael and Neukum, 2010), using the production function of Ivanov (2001) and the chronology function of Hartmann and Neukum (2001). When using craters to derive ages, the surface area over the feature of interest must be large enough to obtain a sufficient sample of craters, and there are inherent accuracy issues with deriving ages when using craters smaller than $D<1 \mathrm{~km}$ (McEwen et al., 2005), although recent studies largely confirm the use of smaller craters (Hartmann, 2007; Hartmann et al., 2008; Hartmann and Werner, 2010; Michael and Neukum, 2010; Werner et al., 2009).

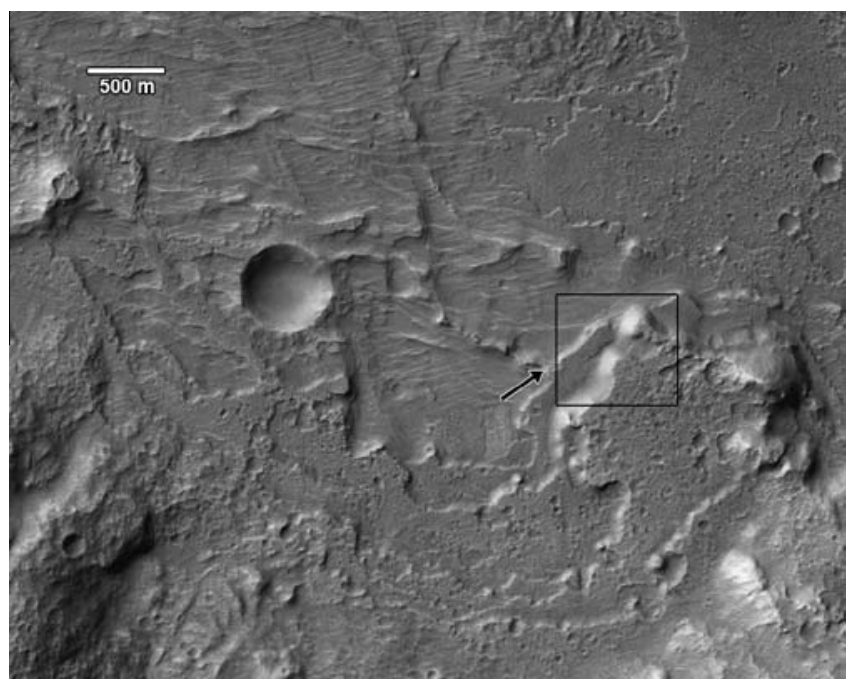

Fig. 16. Flat-topped benches at boundary between southern K2 fan deposits and Saheki crater wall. Note multiple levels and irregular terrace edges. Arrow points to location where inverted fan ridge may be at the same elevation at the adjacent terrace. Box shows location of Fig. 17. Part of CTX image P19_008545_1576_ $\mathrm{XI} \_22 \mathrm{~S} 287 \mathrm{~W}$ centered at $22.216^{\circ} \mathrm{S}$ and $72.946^{\circ} \mathrm{E}$.

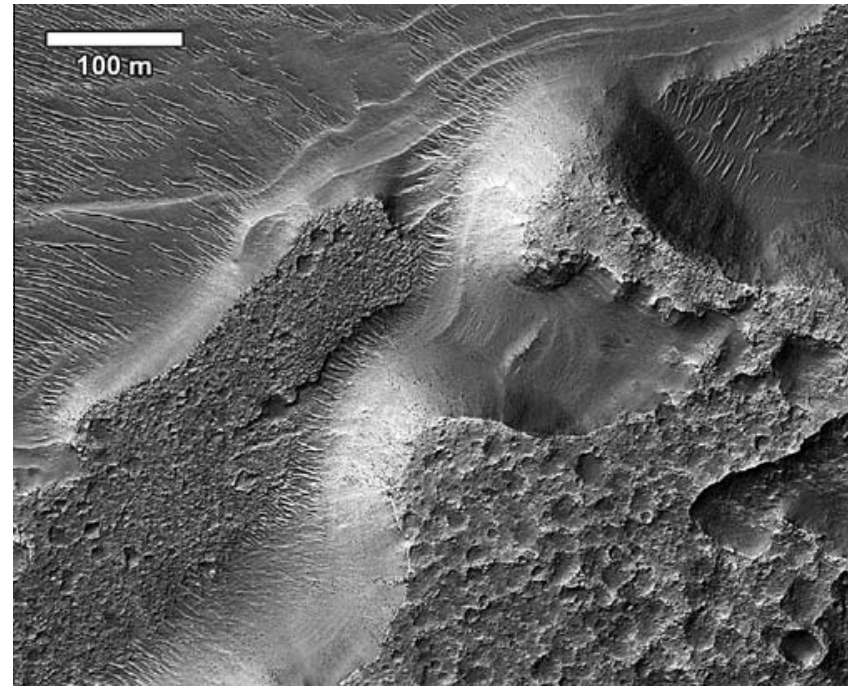

Fig. 17. Benches at two levels (see Fig. 16 for context). Note pitted surface, interpreted to be the result of impact gardening. The bench surface is mantled with coarse blocks, which are mass-wasted onto slopes at terrace edges. Fine, layered sediment that is largely conformable with overlying benches is exposed on slopes below benches. Benches are interpreted to be chemically-cemented lacustrine or playa deposits. Part of HiRISE image PSP_007688_1575.

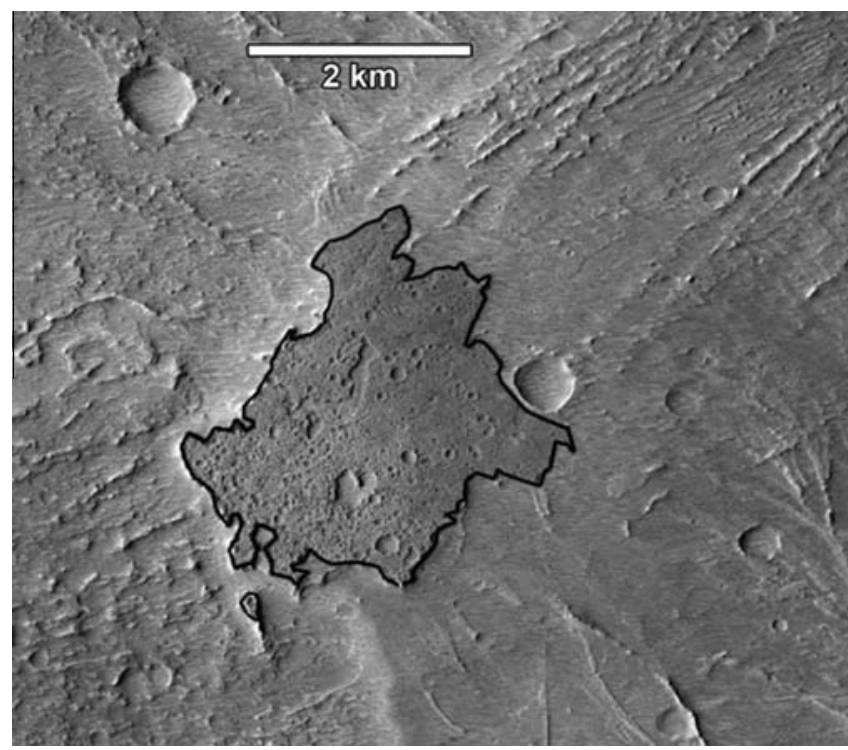

Fig. 18. Rough-textured, nearly level surface in the interior of "L" crater (red outlining), located at the point of convergence of several fans. Surface of deposit as well as ridges on surrounding fans are slightly inverted due to aeolian erosion. Deposit is interpreted as cemented playa or shallow lacustrine sediments sourced from runoff from the adjacent fans. Note the similarity in morphology to benches in Figs. 16 and 17 in Saheki crater. Part of map-projected CTX image P3_002295_1568, centered at $23.060^{\circ} \mathrm{S}, 74.030^{\circ} \mathrm{E}$. (For interpretation of the references to color in this figure legend, the reader is referred to the web version of this article.)

These limitations considered, the fan surfaces in Saheki and "L" crater date to the Mid to Late Hesperian, and in the case of fan $\mathrm{K} 2$, as late as the Early Amazonian (as defined by Tanaka (1986) and Werner and Tanaka (2011)) (Fig. 19). In fitting ages to the cumulative frequency curves in Fig. 19, we utilized craters greater than $500 \mathrm{~m}$ in diameter to minimize effects of crater degradation and we did not include the three large $(>1.4 \mathrm{~km}$ diameter) craters with large error bars. These ages are indistinguishable from those obtained for fans in Margaritifer Terra (Grant and Wilson, 2011). The K2 fan surface has a crater retention age (Early Amazonian) 
that is notably younger than that of $\mathrm{K} 1$, which is probably due to the different degrees of aeolian erosion. Ridges on the K2 fan rise as much as $70 \mathrm{~m}$ above the surrounding fan surface. If we assume a crater depth/diameter ratio of 1:5 (Garvin et al., 2003), we conservatively infer that craters smaller than $350 \mathrm{~m}$ in diameter would be completely erased from the surface record. If the estimate of $\sim 100 \mathrm{~m}$ of stripping from Fig. 9 is accurate, this erosion could eradicate craters up to diameters of $\sim 0.5 \mathrm{~km}$; deposition of dust would cause further infilling and obliteration of potentially even larger craters. In a number of places, stratigraphically higher surfaces that have not been eroded preserve significantly higher densities of craters than the underlying eroded fan surfaces (e.g., Fig. 18), confirming qualitatively that this effect is important, and that the apparent age difference is due to subsequent amount of erosion of the fan. We have detected no craters embedded in layer exposures, so that wind-exhumed craters probably contribute little to inferred ages.

\section{Discussion}

The Saheki K2 fan has a strongly bimodal character, comprising a radiating network of long distributaries and broader platforms capped by coarse (sand and cobble) fluvial bedload (possibly indurated) interspersed with finer, wind-erodible layered sediment. The strong component of fine sediment deposition in the Saheki fan complex contrasts with the types of terrestrial alluvial fans most discussed in the literature, which emphasizes steep fans in high-relief terrain. On these fans, sedimentation most frequently occurs either as coarse-grained bedload deposited by wide, often braided or sheetflood distributaries or as equally coarse debris flows (e.g., Blair and McPherson, 2009; Harvey, 1999; Stock, 2013). In such settings, the associated fine sediment is primarily deposited either in a debris flow matrix or in basin-center playas. In neither case would wind erosion be capable of creating the characteristic inverted distributary system seen in Saheki and several other craters.

The intense aeolian deflation that has affected the $\mathrm{K} 2$ fan at the southern end of Saheki crater must have resulted in removal of a vast volume of sediment. We conservatively estimate this volume to be about $10 \mathrm{~km}^{3}$, assuming $25 \mathrm{~m}$ of deflation over the distal $400 \mathrm{~km}^{2}$ of the $\mathrm{K} 2$ fans surface. A small fraction of this sediment remains trapped in the numerous TARs covering the fan surface. Because there are no major dune fields within Saheki crater, we infer that the majority of the eroded sediment must be composed of grains fine enough (sand size or smaller) to have been swept by winds out of the crater. This inference underscores our interpretation that the majority of the layered sediment in the Saheki fans is composed of fine sediment deposited from overbank sedimentation and in playa deposits. Some of this sediment appears to have been redeposited in the source basins on the crater walls, which appear to be partially infilled with fine-grained sediment.

The deflated material from the ridges and to some degree from the finer layered interbeds is interpreted to be the sediment source for the widespread TAR megaripples present between ridges (Figs. 4 and 6-8). By analogy with megaripples observed by both of the MER rovers (Jerolmack et al., 2006; Sullivan et al., 2008), we interpret them to contain a significant granule-sized component. We have also observed similar local sourcing of granules to form aeolian ripples occurring in our analog field site in the Atacama Desert (see Section 3.1.1).

\subsection{Possible terrestrial analog fans}

In only a few cases have terrestrial fans with sedimentary characteristics similar to those inferred for the Saheki K2 fan been discussed. Bull $(1962,1963)$ describes fan sedimentation in the western Central Valley of California sourced from headwaters underlain by sandstone, shale and siltstone bedrock. Both fluvial and mudflow deposits occur on these fans. Mudflow deposits are unsorted, typically containing $54 \%$ mud (clay and silt), $40 \%$ sand, and $6 \%$ gravel. Clay percentages range from $12 \%$ to $76 \%$, averaging $31 \%$. Mudflow deposits generally decrease in thickness downstream from $0.5 \mathrm{~m}$ to $0.1 \mathrm{~m}$, with abrupt terminal edges that range from $0.3 \mathrm{~cm}$ to $2.5 \mathrm{~cm}$ in thickness. Mudflows are transported through a channelized fluvial system. In upstream portions of the fan, the mudflow deposits occur as lobate overbank deposits thicker on outside channel bends, but they terminate downstream as sheet-like deposits. Mudflows develop polygonal shrinkage cracks upon drying. Some flows across the fan have a more fluvial character, creating well-sorted, thin deposits dominated by sand with typically less than $10 \%$ mud and less than $10 \%$ gravel. Fluvial flows are typically up to $0.15 \mathrm{~m}$ deep and occur as braided channels or sheetflows.

Blair (2003) discusses the sedimentology of the Cucomungo Canyon fan in California as characterized by both fluvial and mudflow deposits. The dimensions of this fan approach that of the Saheki crater fans, being $15 \mathrm{~km}$ in length, with an areal extent of $119 \mathrm{~km}^{2}$, a concave profile, and an average fan gradient of 0.03 . The fan is sourced from strongly weathered granitic bedrock. Mudflow deposits are typically 10\% mud, 70\% sand, and 20\% gravel (Table 3). Mudflow deposits on this fan are thicker than those described by Bull, ranging from 10 to $100 \mathrm{~cm}$ thick with 10 to $40 \mathrm{~cm}$ high abrupt, rounded lateral edges and terminations. Mudflows source from feeder channels and are typically 50-300 m wide but extend the length of the fan. The mudflows surfaces are smooth and develop narrow polygonal shrinkage cracks. Feeder channels are typically 5-30 m wide (width decreasing down-fan) and 2-6 $m$ deep (also decreasing depth down-fan), with smaller secondary channels. Such channels cover less than $10 \%$ of the fan surface, and deposit well-sorted deposits ranging from pebbly sand to cobbly pebble gravel. Fluvial and mudflow facies are interbedded in the fan deposits, with the proportion of fluvial gravels decreasing down-fan. A field reconnaissance conducted by the authors in 2012 on the Cucomungo Canyon fan suggests, however, that fluvial deposits are volumetrically more important than mudflow deposits on this fan, particularly on the downstream portions of the fan.

A third potential analog for the Saheki fans is a suite of fans in the Atacama Desert of Chile. These fans contain similar bimodal fluvial and mudflow deposits but also display the relief inversion due to aeolian deflation that is characteristic of the Saheki K2 fan. Because of this close morphologic analogy, the Atacama fans are described in detail below, and used to better understand the formative processes of the Saheki fans.

\subsubsection{A Chilean terrestrial analog}

The alluvial fans of the Pampa del Tamarugal region of the Chilean Atacama Desert (Fig. 20) appear to constitute a close analog in morphology and formative processes to the Saheki crater fans in the following ways:

1. The fan gradients, areas, and concavity of two representative Atacama fans fall within the range of martian fans, although the Atacama fans are somewhat smaller, steeper, and more concave that the $\mathrm{K} 1$ and $\mathrm{K} 2$ fans (Table 1 ).

2. The Atacama fans in the area of study have channels ranging from sand to boulder beds, with mud-rich overbank deposits (Figs. 21 and 22, and Table 3), mirroring what we have inferred for the Saheki fans.

3. Inactive parts of the Atacama fans are wind eroded (Fig. 23), resulting in 1-2 m of inverted channel relief (Fig. 24), consistent with the erodibility of the fine-grained overbank deposits. The Saheki fans are likewise inverted, although surface relief is greater (as much as $70 \mathrm{~m}$ ). 


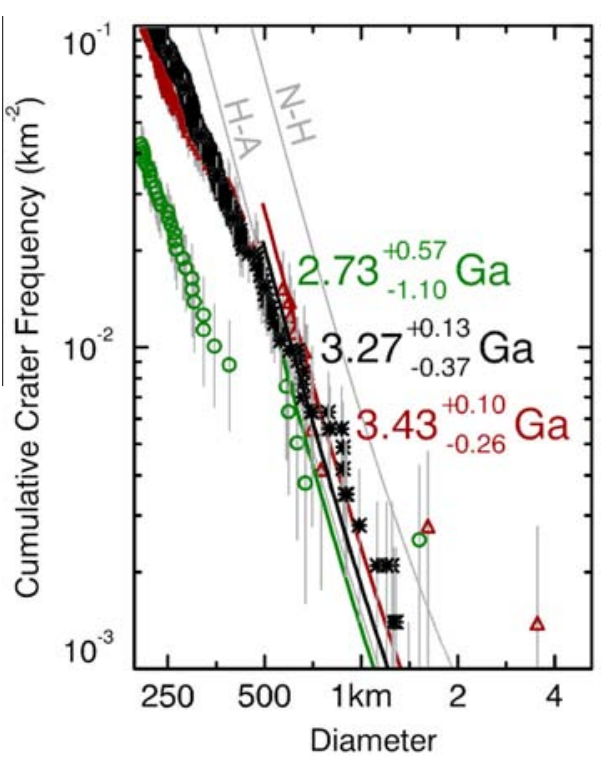

Fig. 19. Crater age determination plots. $\mathrm{N}-\mathrm{H}$ and $\mathrm{H}-\mathrm{A}$ indicate Noachian-Hesperian and Hesperian-Amazonian boundaries. Absolute age determination used craters greater than $500 \mathrm{~m}$ in diameter to avoid errors arising from aeolian erosion (see text for discussion). Red: K1 fan. Black: Aggregate of four fans in "L" Crater. Green: K2 fan. The young age and large error bars for the K2 fan can likely be attributed to high amount of aeolian modification. (For interpretation of the references to color in this figure legend, the reader is referred to the web version of this article.)

4. Overbank deposits on the Atacama fans exhibit no evidence for fluvial reworking by local runoff subsequent to deposition.

5. The Atacama fans terminate in mixed playa/lake "salars" (saltrich enclosed basins) (Amundson et al., 2012); the K2 Saheki crater distributaries terminate at possibly analogous flat-lying deposits (Sections 2.2.6 and 2.2.7).

Because of these similarities, analysis of sedimentary processes and landforms on the Atacama fans has the potential to yield insights into the mechanics and environment forming large martian fans. The fans are located along a $\sim 140 \mathrm{~km}$ transect of the western slopes of the Andes centered at about $21^{\circ} \mathrm{S}, 69^{\circ} \mathrm{W}$ (Fig. 20), radiating westward from the Andean mountains onto a hyperarid upland plateau. The fans experience only a few millimeters of direct precipitation annually and almost no locally-generated runoff (Amundson et al., 2012). Despite the hyperaridity of the immediate fan environment, flood events sourced from the superjacent Andes occur with appreciable frequency as evidenced by disruption of vehicle tracks, footprints on recent deposits, and sediment deposition on roads and railroad tracks (Houston, 2006) (see also Fig. 26).

Our study of the Atacama fans is based on a combination of reconnaissance field investigations plus remote sensing interpretation. During a field season in 2012, we surveyed fan cross-sections and longitudinal profiles using differential Global Positioning Satellite observation, excavated pits and streambank exposures, collected sediment samples, and made Ground Penetrating Radar transects across portions of the fans. Sediment grain size distributions (Table 3 ) are based on laser diffraction analysis of dispersed samples.

The fine sediment comprising these Atacama fans is originally derived from erosion of fine-grained deposits including mudstones, sandstones and volcanic ash, exposed on the flanks of the Andes to the east of the fans (Servicio Nacional de Geologia y Mineria, 2003). A representative canyon (Quebrada de Guatacondo) heading in the Andean foothills (location 25 and upstream in Fig. 20) that feeds a fan gives evidence of a spectrum of flows with markedly different properties (Fig. 25). The channel bed exposes clean sub-meter gravels and cobbles indicating that normal fluvial floods are common. The channel walls, however, are plastered with remnants of at least three recent mudflows that occurred in early 2012. The mudflows are typically nearly 50\% mud (clay and silt), $30 \%$ sand, and $20 \%$ pebbles (Table 3 ). The same event in 2012 deposited an extensive deposit on another fan (Fig. 21) that is likewise characterized by both channelized and overbank flows. As in the canyon flows shown in Fig. 25, later (waning stage?) deposits were lighter colored and more confined to distinct channels.

Where flows spread onto the aggrading fan, a distinctive and repeated pattern of deposition occurs. The differences in color resulting from variations in sediment color and darkening by aeolian erosion suggest that during an individual flow event only a few distributary channels are active, with widths typically in the range of 3-10 $\mathrm{m}$ and depths of up to a meter. The channel bed deposits consist of a mixture of grain sizes, dominated by pebble and finer sediment but containing occasional cobble and boulder bars with median grain size of about $100 \mathrm{~mm}$. Undercut banks of distributaries expose layered sediment averaging about $45 \%$ mud, $45 \%$ sand, and $10 \%$ pebbles (Table 3 ). However, beds of well-sorted sand or pebbles are interbedded with the muddier layers. Individual layers range from a few centimeters to $20 \mathrm{~cm}$ in thickness. A similar facies association of channel gravels and overbank mudflows has been described for other fans in the Pampa del Tamarugal region (Kiefer et al., 1997; Houston, 2002).

Large flow events through distributaries spread overbank, depositing sheet-like mud deposits extending a few meters to $150 \mathrm{~m}$ bilaterally around the distributary (Figs. 21, 22 and 26). Locally, however, these mudflows may extend several hundred meters to a kilometer or more across the surrounding fan surface as broad depositional lobes (Figs. 22 and 26). The overbank deposits typically contain $60 \%$ mud and $40 \%$ sand, although a few beds contain granules and fine pebbles (Fig. 27). These deposits harden to adobe-like consistency typically with well-developed mudcracks. Individual deposits are nearly homogeneous and range up to $25 \mathrm{~cm}$ in thickness. The beds generally thin away from the distributary, generally with abrupt, rounded edges a few $\mathrm{cm}$ high. Repeated flows gradually develop broad natural levees extending $>150 \mathrm{~m}$ to either side of the distributary (Fig. 28). Deposits from individual overbank events are generally easily distinguished by sharp flow margins and, often, color differences between deposits from different events (Fig. 26). We have described the formative flows as mudflows because they have abrupt, rounded lateral and downstream boundaries. Also, vertical surfaces inundated by the mudflows retain coatings several millimeters thick. Both observations indicate the flows displayed finite yield strength. However, the flows have low viscosity relative to many terrestrial mudflows as indicated by their thin terminal edges.

Locally the distributaries exhibit modest sinuosity, although vertical aggradation probably dominates over lateral shifting. As with fluvial channels in general, distributary widths are determined by the balance of erosion and deposition of the fine-grained deposits forming the channel banks. Their width is remarkably constant downstream despite the significant lateral leakage of flow that must accompany the mudflows that deposit the overbank deposits. This consistency of width suggests that formative discharges may consist of a sediment-laden early peak flow overflowing to form lateral deposits followed by slowly receding flow largely contained within the channel and responsible for determining channel width.

As channels and their natural levees aggrade though multiple flow events, the channel floor may rise $\sim 1 \mathrm{~m}$ above the fan surface within a $150-200 \mathrm{~m}$ radius (Fig. 28). This resultant relief can lead to avulsions, trenching of a new flowpath through the natural levee, a new distributary channel on the fan surface, and infilling of the abandoned distributary below the avulsion point. The 
Table 3

Grain size characteristics of Atacama fan sediment expressed as percentages with comparative values from the Cucomungo fan of California.

\begin{tabular}{|c|c|c|c|c|c|c|}
\hline Description & Property & Clay & Silt & Fine-medium sand & Coarse sand & Pebbles \\
\hline \multirow[t]{3}{*}{ Upstream mudflows } & Average $^{a}$ & 16.68 & 30.75 & 18.85 & 12.91 & 20.81 \\
\hline & Minimum & 9.99 & 21.36 & 11.27 & 0.00 & 0.00 \\
\hline & Maximum & 27.53 & 60.95 & 35.52 & 29.30 & 40.01 \\
\hline \multirow[t]{3}{*}{ Channel bank deposits } & Average $^{\mathrm{b}}$ & 15.30 & 30.92 & 33.15 & 11.35 & 9.28 \\
\hline & Minimum & 1.09 & 6.25 & 12.97 & 0.02 & 0.00 \\
\hline & Maximum & 25.95 & 55.52 & 80.61 & 37.36 & 53.73 \\
\hline \multirow[t]{3}{*}{ Overbank sediment } & Average $^{c}$ & 16.74 & 42.53 & 37.64 & 3.09 & 0.00 \\
\hline & Minimum & 12.35 & 34.12 & 12.36 & 0.00 & 0.00 \\
\hline & Maximum & 24.28 & 63.37 & 49.27 & 6.75 & 0.00 \\
\hline \multirow[t]{3}{*}{ Cucomungo fan deposits ${ }^{\mathrm{d}}$} & Average & 1.06 & 8.50 & 42.11 & 29.52 & 18.80 \\
\hline & Minimum & 0.60 & 5.40 & 24.80 & 1.30 & 0.00 \\
\hline & Maximum & 2.20 & 21.80 & 74.70 & 44.50 & 35.50 \\
\hline
\end{tabular}

ample size $=11$

b Sample size $=22$.

c Sample size $=5$.

d Summarized from Table 4 of Blair (2003).

stratigraphy resulting from multiple such events is characterized by gradually tapering layers separated by diastems (minor hiatuses).

The net result of multiple avulsions is a fan surface consisting of a complex network of active and abandoned channel segments (Fig. 26). Avulsions may lead to reoccupation of abandoned distributary channels that have gradually become topographically low relative to adjacent actively aggrading distributaries. Other inactive channel segments become buried by subsequent deposition.
Although the overbank deposits harden to such consistencies that blocks must be excavated by pickaxe, they are easily eroded on a grain-by-grain basis by wind-driven saltating grains (Fig. 23). These grains, up to a few millimeters in size, are derived from the eroding overbank deposits, and over a period of time lag layers and megaripples of granules create a thin $(0-10 \mathrm{~cm})$ pavement away from the fluvially active areas, progressively covering the overbank deposits. Burial by later overbank deposits can create diastems demarcated by granule layers.

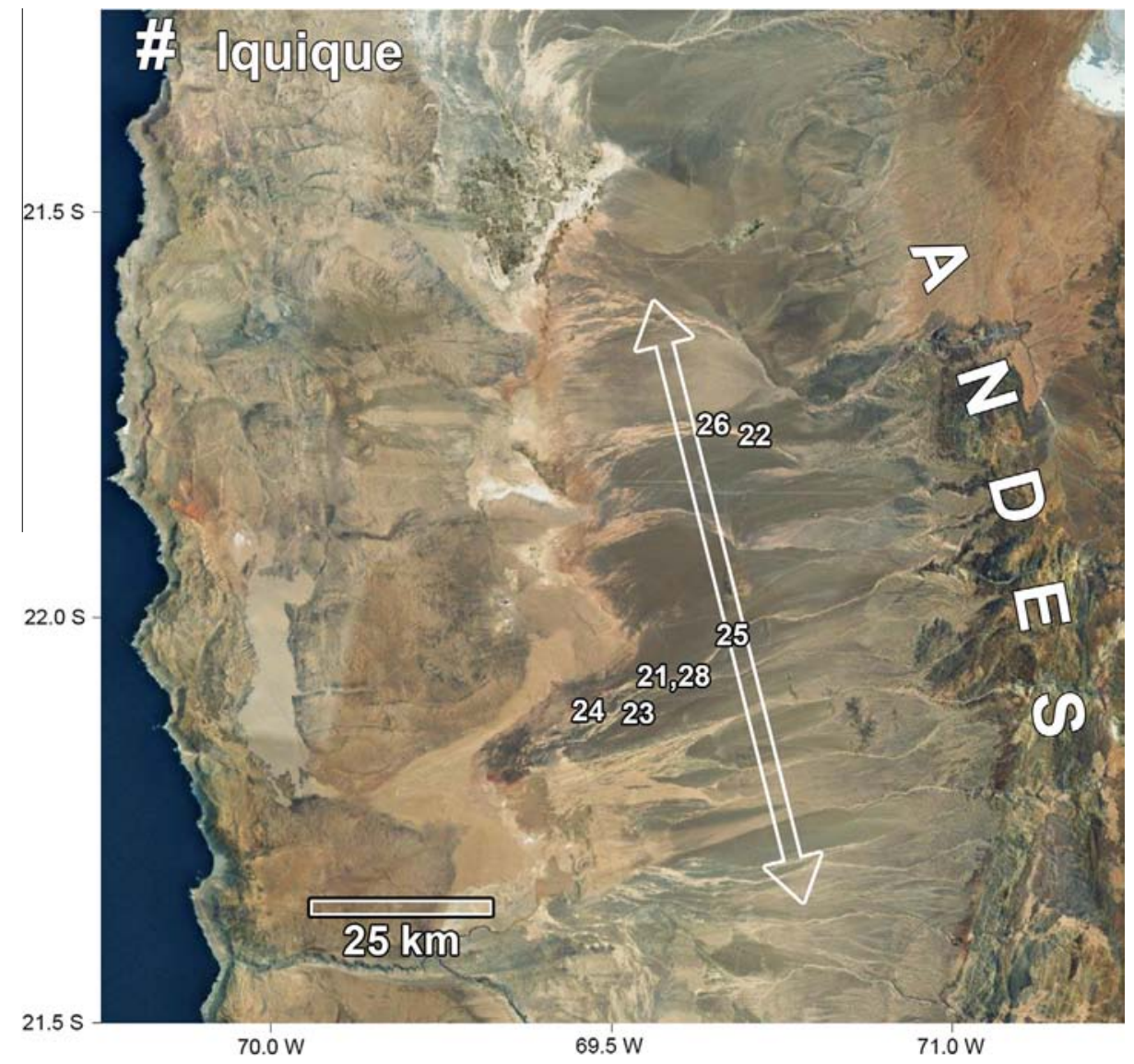

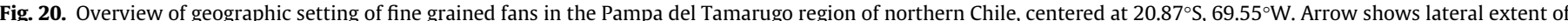

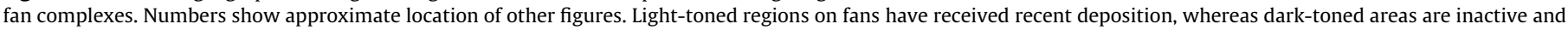
have accumulated a granule surface layer die to aeolian deflation. City of Iquique indicated. Base map from Yahoo! Maps. 


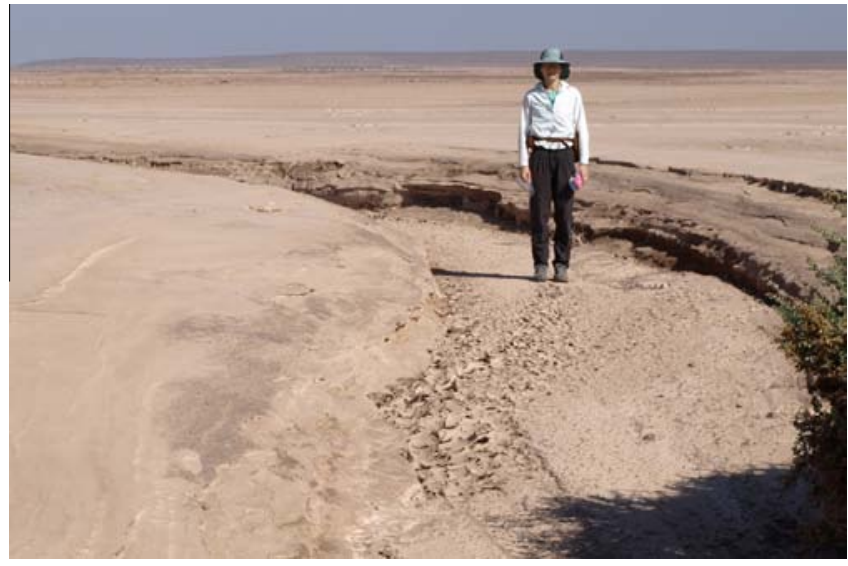

Fig. 21. Fan distributary, showing fine-grained cohesive banks and extensive overbank deposits. Bank crest to bank crest about $3 \mathrm{~m}$. Photo by A. Howard. Location at about $21.097^{\circ} \mathrm{S}, 69.486^{\circ} \mathrm{W}$.

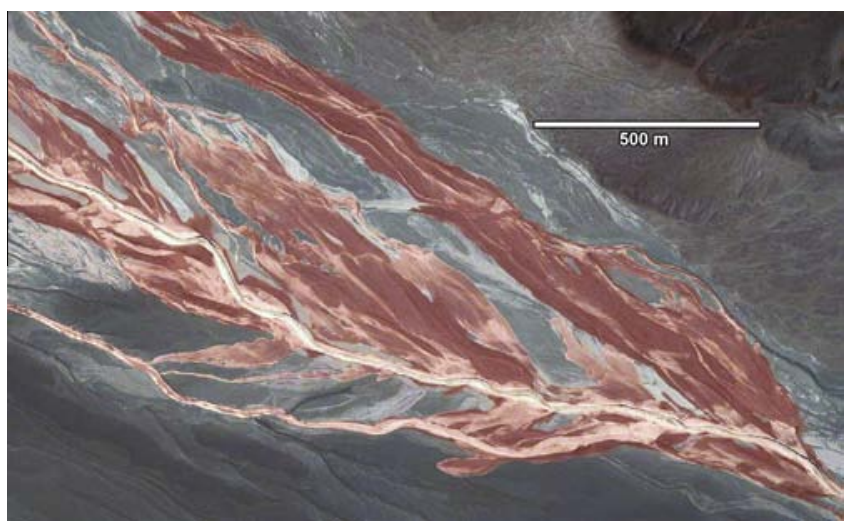

Fig. 22. Atacama fan flood deposits. Red-toned deposits deposited by an early 2012 flood sourced from the Andes foothills to the east. Deposits radiate from the end an entrenched channel section at left boundary. Broad sheet deposits source from overflow of main distributary channels. Earliest deposits are darkest red, with later overflows and channelized flow being lighter pink. Main distributary averages about $12 \mathrm{~m}$ wide. Flooding and sediment deposition continued for $25 \mathrm{~km}$ downstream, spanning the length of the alluvial fan. Center of image at $20.765^{\circ} \mathrm{S}$, $69.311^{\circ} \mathrm{W}$. North is up. Iconos $0.8 \mathrm{~m} /$ pixel image, taken $12 / 27 / 2012$. (For interpretation of the references to color in this figure legend, the reader is referred to the web version of this article.)

On the Atacama fans, the granules forming the pavement are dark colored relative to the bulk overbank deposits. Thus recently active portions of the fan systems are light-colored, but inactive portions gradually become darker as the percentage cover by granules increases (Figs. 23 and 26). This natural color-coding permits easy recognition of the relative ages of sections of fan surfaces (Fig. 26). Satellite imagery of the fans show that deposition is typically active (lacking dark sediment cover) over zones $1-5 \mathrm{~km}$ wide (measured normal to the flow direction) of the $10-20 \mathrm{~km}$ width of individual fan complexes, and within these zones of recent activity individual flood deposits occupy a cumulative width of a few hundred meters or less. The channels range from 3 to $10 \mathrm{~m}$ wide. The spatial relationship of these features indicates that fans are built though hundreds or thousands of individual flow events often separated by several years.

Inactive portions of the fan complex become modified by aeolian deflation, resulting in inverted topography as the channels containing gravel resist erosion, whereas sand saltation readily abrades the muddy overbank sediments (Figs. 23 and 24). Granules deflated from the channel and coarser overbank deposits are swept into megaripples less than $10 \mathrm{~cm}$ high that form a distributed pavement

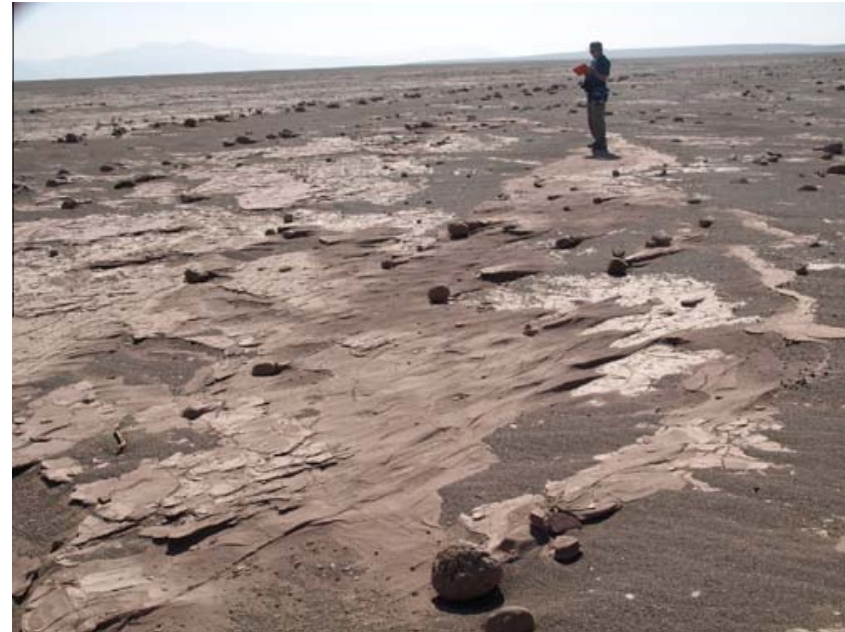

Fig. 23. Wind-scoured surface of an Atacama fan. Reddish and light-toned surfaces expose fine-grained overbank sediments, scoured by winds directed to the right Rounded balls of mud locally protect the surface from erosion, producing elongated tails. Darker granule-covered aeolian ripples mantle parts of the surface as well as infilling the channel in the middle distance. Boulders aligned along the margins of the channel were deposited by overbank flows in proximal parts of levees. Photo by A. Howard. Location $21.121^{\circ} \mathrm{S}, 69.527^{\circ} \mathrm{W}$. (For interpretation of the references to color in this figure legend, the reader is referred to the web version of this article.)

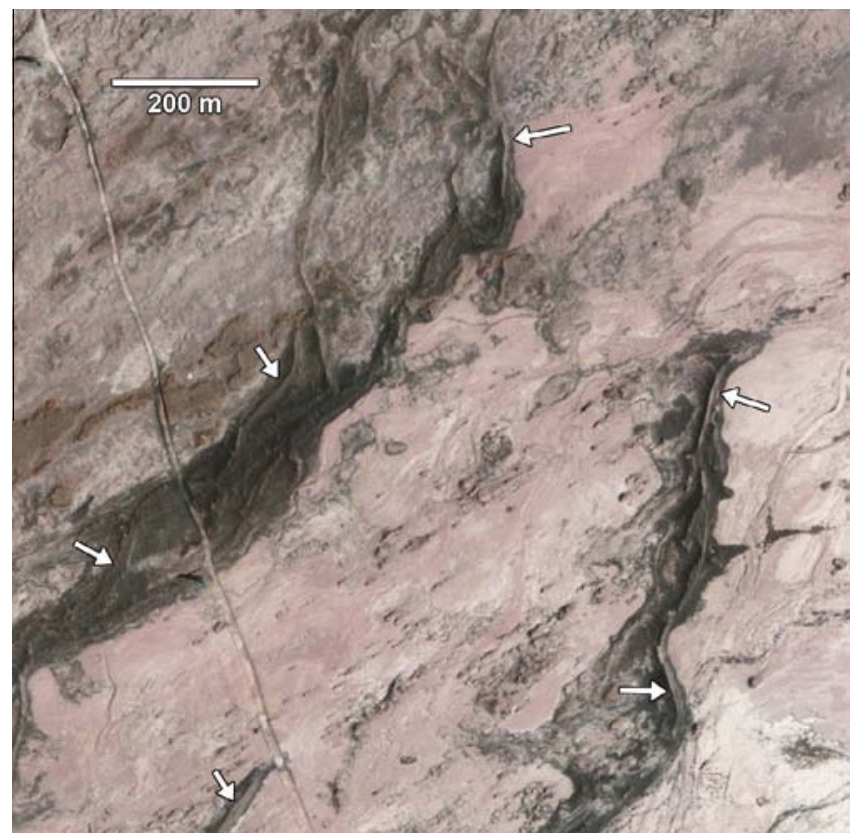

Fig. 24. Channels inverted by aeolian erosion. Arrows point to representative inverted channels. Dark coloration in vicinity of channels is granule deposits winnowed from the channel deposits. Inversion is due to coarser grain size of the channel deposits, protecting them from wind erosion and possibly chemical cementation. Note dirt track crossing image. Recent overbank deposits are pinkish. Older overbank deposits (upper left) are lightly mantled with winnowed granules as in Fig. 21. Maximum inverted channel relief 1-2 m. GeoEye imaging from Google Earth centered at $21.115^{\circ} \mathrm{S}, 69.576^{\circ} \mathrm{W}$.

limiting the rate of aeolian erosion. On the Atacama fans, the inverted channel relief is generally limited to $2 \mathrm{~m}$ or less, set by the depth of erosion of overbank deposits required to generate a coherent granule pavement and possibly by the duration of wind erosion.

The strong sedimentological and morphological similarity between the Atacama and Saheki crater fan complexes are used to formulate several working hypotheses for the Saheki fans: 
1. The Saheki fans are formed through many hundreds of flow events, often with long intervals between flow events.

2. Only a small portion of a fan complex receives flow and sedimentation during any event.

3. The bulk of the deposited sediment consists of fine-grained overbank deposits.

4. Individual overbank deposits may extend long distances downslope but likely thin and feather out laterally.

5. Avulsions are common as channels and natural levees aggrade, and individual distributary segments may be reoccupied during later flow events, resulting in a complex intertwining of channel deposits.

6. Flows vary in intensity and fine sediment content. Gravel and boulder deposits in distributaries may only be transported during the largest flow events whereas overbank mudflow deposition may occur during more frequent flows.

As with any terrestrial analog to martian landforms, there are limits to the process, material, and morphological similarities:

1. The strong tonal contrast between bright recent overbank deposits and the darker granule pavement that develops during wind erosion is much less obvious on the TARs partially mantling the wind-eroded Saheki fan than for the Atacama fans. This difference in tonal contrasts may be due to lithologic differences, smaller clay content on the martian fans, possible biofilms on the terrestrial granules, or a smaller component of granule-sized overbank sediment on Mars. A lower granule component in the Saheki deposits would limit pavement formation and promote deeper deflation of fan surfaces as observed.

2. Distributaries on the Atacama fans are narrower than estimates of the Saheki crater inverted channels (3-10 $\mathrm{m}$ for the Atacama fans (Figs. 25 and 26) versus an average of $\sim 38 \mathrm{~m}$ for Saheki; (Fig. 12)). This dissimilarity could be due to greater discharges on the martian fans, to less sediment concentration in formative flows, or to a smaller proportion of cohesive clays contributing to deposition on channel banks.

3. Individual overbank layers deposited on the Atacama fan are generally less than $25 \mathrm{~cm}$ thick and generally much thinner near flow margins, whereas observed layering in Saheki crater deposits is typically $2-3 \mathrm{~m}$ thick. The degree to which this thickness difference is due to freshness of exposures or to image resolution limitations is uncertain.

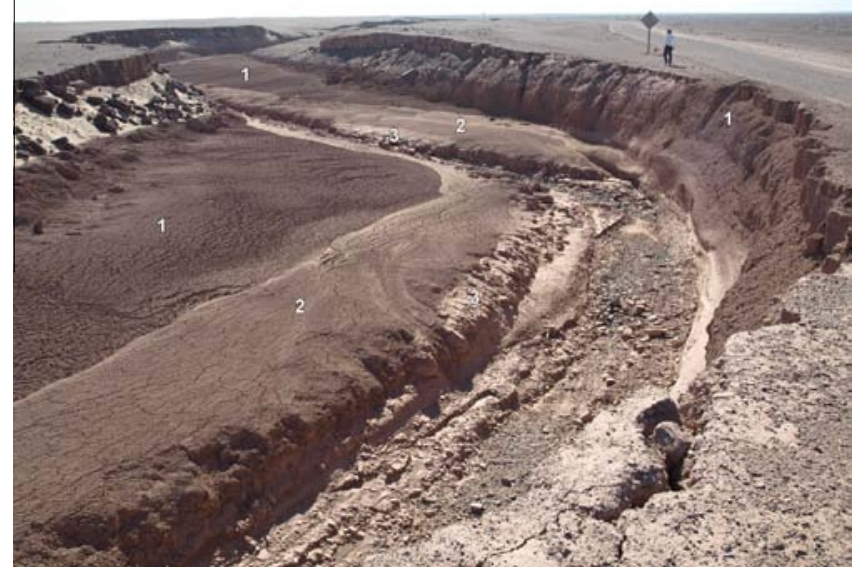

Fig. 25. View looking upstream along the Quebrada de Guatacondo channel. Three mudflows are labeled with oldest being number one. Note that mudflows coat steep banks. Channel floor is composed of clean fluvially transported coarse sediment (gravel, cobbles, and occasionally boulders). Photo by A. Howard. Location $21.024^{\circ} \mathrm{S}$, $69.367^{\circ} \mathrm{W}$.

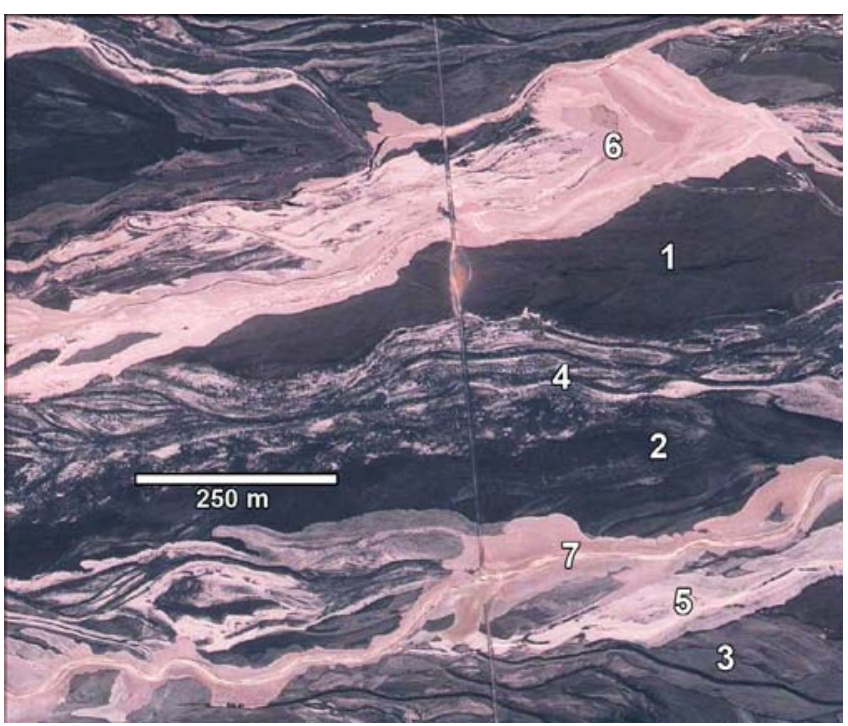

Fig. 26. Complex history of distributary history on part of a fan surface. Numbers indicate sequence of fan activity ( 1 is oldest). Note that flow 7 has covered the railroad track crossing the image. Inactive parts of fan become darker due to progressive mantling by granule ripples derived from overbank deposits. GeoEye imaging from Google Earth centered at $20.75^{\circ} \mathrm{S}, 69.40^{\circ} \mathrm{W}$, taken prior to the 2012 flood deposition.

\subsubsection{Summary of terrestrial fan analogs}

The terrestrial fans described above are relatively unusual relative to the total population of alluvial fans in having a combination of gravel-bedded distributaries with fine-grained overbank sediments deposited by mudflows. This is inferred to also characterize the Saheki crater fan sediments. Mudflows are characterized by finite yield strength, and imply an appreciable mud fraction ( silt and clay). Unlike more viscous debris flows, however, they normally do not transport sediment coarser than pebbles. The mudflow deposits of the Atacama and those described by Bull $(1962,1963)$ contain an appreciable fraction ( $>10 \%$ ) of clay, whereas the Cucomungo Canyon fan deposits (Blair, 2003) typically have about $1 \%$ clay and only $10 \%$ total mud, indicating that a high concentration of clay and silt is not necessary to support mudflow overbank transport. While the fine sediment composition of the Saheki crater overbank deposits is uncertain, it likely falls within the range of the terrestrial mudflow fans.

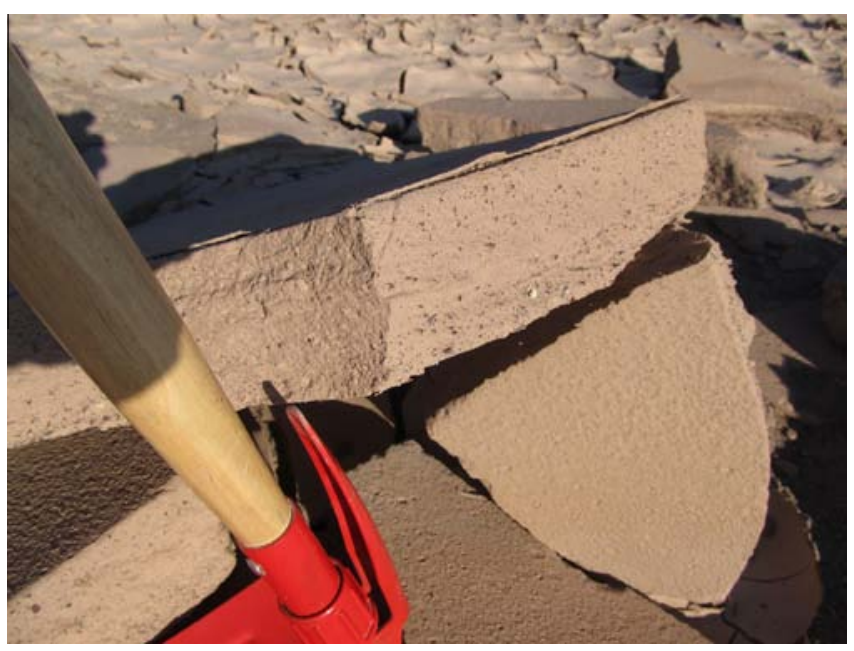

Fig. 27. Cross section of an overbank deposit containing sparse granules. Note mudcracking of overbank sediments in background. Photo by W.E. Dietrich. 

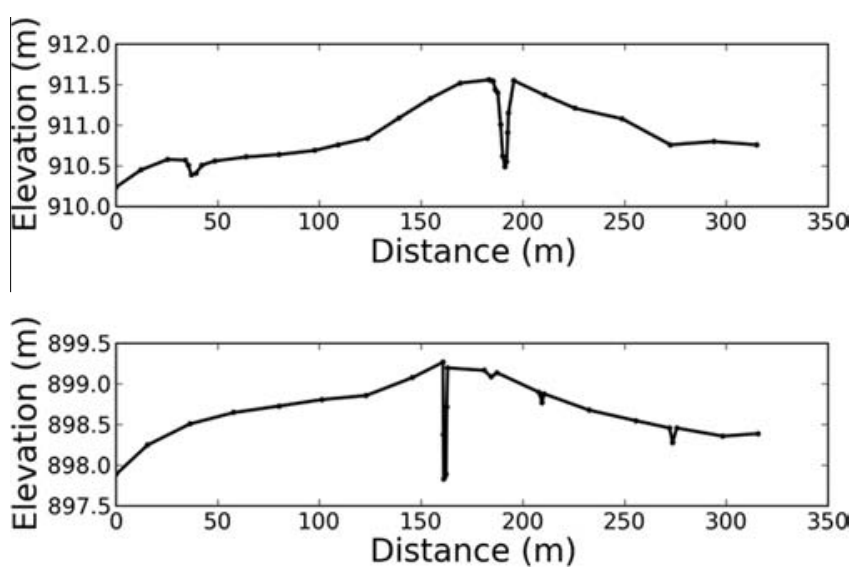

Fig. 28. Surveys across channel and overbank deposits of distributary shown in Fig. 20, showing broad natural levees. Top cross section centered on $21.093^{\circ} \mathrm{S}$, $69.478^{\circ} \mathrm{E}$, bottom cross section centered on $21.100^{\circ} \mathrm{S}, 69.490^{\circ} \mathrm{E}$. The bottom of the channel in the top survey is higher than the surrounding fan surface. Note $25 \times$ vertical exaggeration.

\subsection{Interpretation of Saheki fan stratigraphy and evolution}

The observations in Section 2 and on possible terrestrial analogs indicate that the Saheki crater fans are composed of a network of fluvial distributaries formed by channelized flows with associated fine overbank mudflow deposits, and, at the fan terminus, playa or shallow lake sediments with some chemically-cemented interbeds. The coexistence of fluvial distributaries with gravel beds and mudflow-dominated overbank deposits might seem contradictory because debris-flow dominated terrestrial alluvial fans typically are largely composed of unsorted matrix-supported deposits with lobate flow terminations (Blair and McPherson, 2009). The flows on the terrestrial analog channels discussed earlier, however, have aspects of both fluvial and mass flows. Debris flows and presumably the finer grained mudflow events commonly occur as deep, viscous noses followed by long, more watery terminal flows (Costa, 1984, 1988; Johnson, 1984) that are more channelized and winnow fine material from the bed. In addition, large discharge, deep mudflows are commonly interspersed with more frequent, lower magnitude fluvial flows. Either trailing or subsequent-event fluvial flows could be responsible for the relatively clean gravel bed of the Atacama channel shown in Fig. 25.

In the next two sections, we interpret the stratigraphy of the Saheki crater fans and their erosion by the wind in a simplified crosssectional model, followed by a discussion of the formative hydrological and climatic environment.

\subsubsection{Interpretive model of Saheki fan surface erosion}

An interpretive, semi-quantitative 2D cross-sectional model detailing the inferred fan stratigraphy undergoing aeolian deflation in Saheki (Fig. 29) is used to evaluate the viability of our interpreted fan history and material properties of the fan sediment (see Appendix A for full details of model). The model was developed to illustrate three aspects of our interpretation of the alluvial fan composition and subsequent fan erosion: (1) the fan deposits can be interpreted as the two facies of resistant channel deposits and wind-erodible overbank deposits; (2) the erosional processes include interacting processes of aeolian stripping, shallow mass wasting, and undermining of the caprock; and (3) the surface area covered by exposed channel deposits considerably exceeds their volumetric proportion within the fan deposits. The model takes as its starting condition an idealized hypothetical cross-section of the lower part of fan $\mathrm{K} 2$, comprising a randomly distributed set of rectangular "channel bodies" (blue) composed of fluvial sands and gravels scattered through a more easily eroded muddy overbank stratigraphy (uncolored). Aeolian inversion is mimicked by a set of rules for the vertical removal of the overbank material at a rate in part dependent on the local surface curvature (convexupwards surfaces erode more easily due to greater exposure to the wind), but the channel bodies containing coarser sediment cannot be directly wind-eroded. Instead, they can erode only by hillslope mass wasting, with the resulting material being transferred diffusively down sideslopes. This mass wasting exposes the overbank deposits and moves material into the adjacent topographic lows as well as becoming covered by TARs, both of which decrease the rate of wind erosion (idealized by having the rate of wind erosion diminish in concave upwards locations).

The initial surface is the horizontal black line at the top of the cross section in Fig. 29. The colored and dashed curves show the surface profile at successive times during the simulation. The model indicates that, as would be expected, erosion of channel gravels lags behind lowering of the adjacent overbanks until eroded laterally by mass wasting. Exposure of the overbank deposits occurs primarily on slopes subjacent to the gravel ridges and on low-relief surfaces in between ridges. An important effect of wind erosion is to magnify the fraction of gravel on the surface relative to its volumetric fraction. In this simulation, channel deposits occupy 25$36 \%$ of the land surface (locations where the land surface is in the blue deposits in Fig. 29) in the later stages of wind erosion compared to the $5 \%$ volumetric fraction proscribed at the start of the run. This change of proportionality over time due to the exposure of buried channels is likely true for the wind-eroded portions of the Saheki fans. We suggest that the present pattern of inverted ridges gives a false impression of what the density of channels on the active fan may have been, possibly overestimating it severalfold.

\subsubsection{Interpreted hydrological environment of Saheki fans}

In this section, we use observations and measurements of the fan slopes and channel widths with inferences about likely channel bed grain sizes and sediment loads to quantitatively interpret the discharges and flow velocities in the distributary channels at peak discharge. This information allows us to discriminate between the various possible environments of formation for the fans. We then employ these estimates to assess formation timescales for the fans, addressing in particular whether the fans could have formed by one or a few, long-duration flows, or alternatively would have required many cycles of sedimentation over perhaps thousands or tens of thousands of years.

The estimated age of the Saheki crater fans (Mid to Late Hesperian) is a time period when both the atmospheric pressure and temperature are thought to be too low to support precipitation other than as snow (Carr, 2006; Forget et al., 2013; Wordsworth et al., 2013). Groundwater discharge has been considered to be a possible water source for martian valley networks as well as modern gullies (Malin and Carr, 1999; Malin and Edgett, 2000; Harrison and Grimm, 2009; Goldspiel and Squyres, 2000, 2011). The dendritic structure of the source basins, and especially the stream heads descending from narrow ridge spurs away from the walls of the craters, argues strongly for a spatially distributed surface water source. In addition, with the exception of the $\mathrm{K} 1 \mathrm{fan}$, which has an elevated degraded crater behind the crater rim source basin, all of the source basins in the Saheki and " $\mathrm{L}$ " crater fans are eroded into the highest parts of the crater rim with negligible potential groundwater source areas beyond the head of the incised basins. Therefore in our analysis we assume that flows eroding the source basins and delivering sediment to the fans derives from melting of ice and snow by solar insolation at the surface, a conclusion also reached by Grant and Wilson (2012). 
Our method mirrors the approach of Kleinhans (2005), in that we explicitly model the effects of channel bed roughness into our discharge calculations. We assume that the flow during fluvial transport is primarily contained within the distributary channels. Because flows clearly become overbank when depositing the fine-grained inter-channel deposits, this assumption provides a minimum estimate of formative flow magnitude. In addition, we also incorporate additional constraints based on a critical Shields stress in the channels, assuming that the coarsest sediment is transported primarily by the high flows responsible for creating the observed channel geometry. This approach yields internally consistent flow velocities and discharges commensurate with what we know of terrestrial coarse bed alluvial streams.

We aim to model discharges on a single fan (K2) in Saheki crater where we have a high density of HiRISE observations from which to draw data, and where we can adequately constrain the drainage basin structure feeding the fan. Flow velocity, $u$, in streams can be modeled based on channel hydraulic radius, $h$, channel slope, $S$, and some measure of channel bed roughness. From these velocities discharges, $Q$ can be derived by conservation of mass,

$Q=u h W$

where $W$ is the channel width.

The local splaying (Figs. 7 and 8) suggests wide channels that are close to the threshold of braiding, so we assume that channels are much wider than they are deep. Under this assumption, the hydraulic radius converges with the channel depth, and we use the terms interchangeably. We also demonstrate below the channels likely have large width-to-depth (aspect) ratios (>20). Even for narrow channels, making this assumption introduces only a few percent bias. A large number of formulations exist in the literature describing calculations of flow velocity. Most follow either the form of the Manning equation,

$u=\frac{h^{0.67} S^{0.5}}{n}$

where $n$ is an empirically determined channel roughness; the Chezy equation,

$u=C \sqrt{h S}$

where $C$ is another empirically determined channel roughness term; or the Darcy-Weisbach equation,

$u=\sqrt{\frac{8 g h S}{f}}$

where $f$ is the Darcy-Weisbach friction factor, and $g$ the gravitational acceleration. Following Kleinhans (2005) and Wilson et al. (2004), we work only with the Darcy-Weisbach formulation. This equation makes explicit the dependence of the flow velocity on $g$, thus allowing more reliable extrapolation of terrestrial calibrations to martian conditions (though we note by comparison of 2, 3, and 4, that $n$ and $C$ can also be expressed as functions of $g$ ).

Determining the friction factor $f$ under various conditions has occupied many researchers over the years, as summarized by, e.g., Ferguson (2007) and Rickenmann and Recking (2011). This parameter integrates the interaction of flow turbulence with channel roughness across all length scales, and thus shows variability under differing hydrological conditions and fluvial environments. In particular, it incorporates both skin and form roughness, i.e., roughness of the bed at both grain scale and bedform scale (although the latter is neglected in many laboratory calibrations of $f$ ). The most recent forms of these equations (e.g., Ferguson, 2007; Rickenmann and Recking, 2011) seek to incorporate the effects of very high form drag throughout the flow from the largest clasts on a mixed grain size fluvial bed when flow is shallow, but recognize that flow follows logarithmic laws progressively more closely as the flow deepens and the topology of the boundary becomes less important. When compared to existing databases of terrestrial flow data, these formulations perform at least as well as the best of the older, heuristic approaches - although Ferguson (2007) notes that a factor of two error in predicted discharge should be expected in all cases.

We adopt Ferguson's favored equation for this scale-dependent roughness, which uses a power law to describe the transition zone between the "deep" and "shallow" $\left(h / D_{84}<4\right)$ flow regimes, because of both its physical basis and superior performance in terrestrial datasets. This choice is further justified by the fact that our calculated Shields stresses (see below) tell us that the relative roughness of these martian channels falls in the shallow flow regime poorly described by older approaches. The Ferguson (2007) equation is

$\sqrt{\frac{8}{f}}=17.7\left(\frac{h}{D_{84}}\right)\left[56.25+5.5696\left(\frac{h}{D_{84}}\right)^{5 / 3}\right]^{-0.5}$

The equation has been calibrated across a range of gravel to boulder bed streams, with slopes $0.0007-0.21$. These ranges bracket the measurements taken for our martian channels (see below).

To solve Eq. (4) for cross-sectional average velocity requires as inputs the channel slope, $S$, depth relative to the bed grain size, $\left(h / D_{84}\right)$, width, and absolute channel depth. We constrain channel widths by examining and measuring the inverted ridges of the fan surface, as described in Section 2.2.3. From these data, we take $W=38 \mathrm{~m}$ as the average width of these channels on the well-constrained fan K2. Channel slope can be determined directly from MOLA digital terrain models of the fan, having established that the channels and associated overbank sediments are subparallel to the exposed fan surface, and that the channel sinuosity is negligible (Fig. 3; $<5 \%$ increase in channel length compared to a straight line). Slopes were measured along the same segments used to obtain widths, and were found to be consistent with $S=0.029$ in the upper part of the $\mathrm{K} 2$ fan.

The relative depth of these channels, $\left(h / D_{84}\right)$, can be constrained by assuming a critical Shields stress, $\tau_{c}^{*}$, for the channel bed:

$\tau_{c}^{*}=\frac{S}{r}\left(\frac{h}{a D_{84}}\right), \quad r=\frac{\rho_{s}-\rho_{f}}{\rho_{f}}$

where $r$ is the relative submerged specific gravity of the sediment clasts, and $\rho_{s}$ and $\rho_{f}$ are the densities of the clasts themselves and the transporting fluid respectively. The parameter $a$ represents the sorting of the sediment (i.e., $D_{50}=a D_{84}$ ), and is very poorly constrained on Mars. We here assume $a=0.5$, a fairly typical value for coarse grained alluvial systems on Earth. Note that Eq. (6) is not sensitive to $g$, making it appropriate to apply to martian conditions. This expression was originally derived by considering the force balance on a single particle in a sediment bed, and it semiempirically describes the threshold of motion for particles in a clast bed. Terrestrial gravel channels typically transport bed sediment at discharges just slightly exceeding the threshold of motion of the $D_{50}$ grain size (Andrews, 1984; Dade and Friend, 1998; Howard, 1980; Parker, 1978; Talling, 2000), so that the dominant (channelforming, bankfull) discharge corresponds to the threshold of motion, and we assume the same is true of the martian channels. The value of $\tau_{c}^{*}$ applicable to a given channel varies somewhat, and is a complex function of bed structure, grain size magnitude and distribution, and flow characteristics. However, in almost any fluvial channel it falls in the range $0.03<\tau_{c}^{*}<0.1$, and much of the variability in the value can be folded into the variability with channel slope (e.g., Lamb et al., 2008):

$\tau_{c}=0.15 S^{0.25}$ 


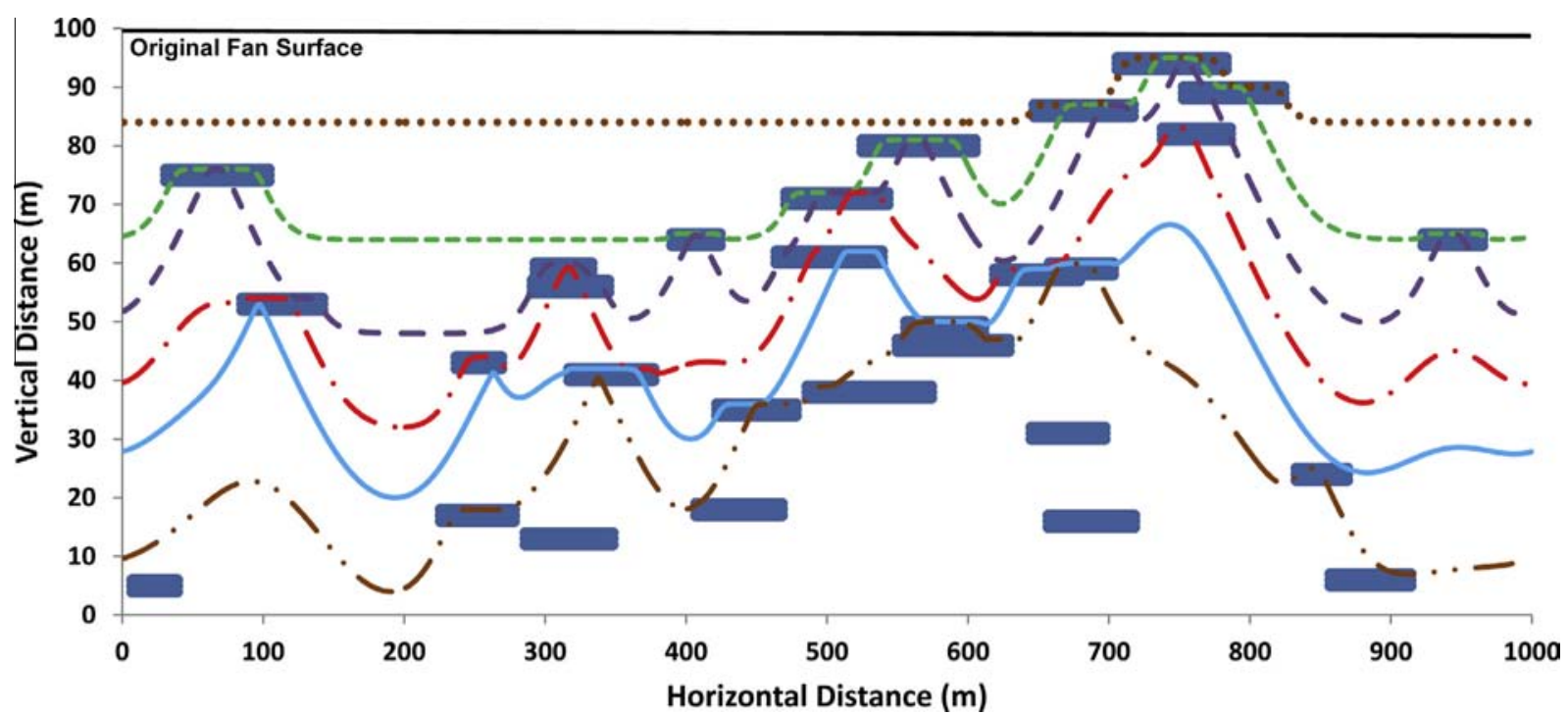

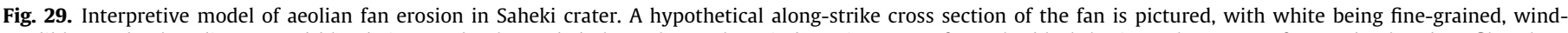

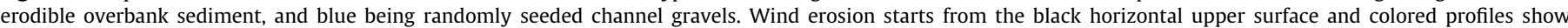

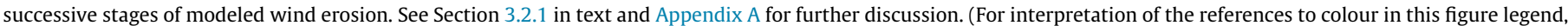
the reader is referred to the web version of this article.)

We adopt this relation, which indicates that on our fan $(S=0.029), \tau_{c}^{*}=0.062$. We take $\rho_{s}=3000 \mathrm{~kg} / \mathrm{m}^{3}$, the approximate density of basalt. We treat $\rho_{f}$ as a variable, taking $\rho_{f}=1000 \mathrm{~kg} /$ $\mathrm{m}^{3}$ for assumed clear water flow as a reference case, but allowing the value to rise to represent more realistic turbid flows. Flows can retain many of the bedload transport characteristics of fluvial flows while the sediment concentration remains $\sim<40 \%$ (e.g., Costa, 1988), and we adopt this value as a fairly arbitrary upper limit for the fluid density. Hence, using these values and following Eq. (6), $\left(h / D_{84}\right)=2.1$ for clearwater flow, decreasing as the flow becomes more turbid, reaching $\left(h / D_{84}\right)=0.7$ when $40 \%$ of the flow by volume is basalt.

The only remaining variable to constrain is the flow depth, which we can calculate by constraining the bed grain size. HiRISE imagery of the fans at $0.25 \mathrm{~m} /$ pixel scale indicates that a high proportion of the flat-topped ridges which were measured for channel width are studded with occasional boulders up to a few times the pixel width, and that the rest of the surface has a speckled appearance. This texture is qualitatively suggestive of clasts close to or slightly below the resolution limit of the camera. We place this estimate on a more quantitative footing by resampling imagery of terrestrial river bed sediment with known $D_{84}$ to varying relative resolutions (i.e., pixel resolution $/ D_{84}$ ) and comparing it to the texture seen in the HiRISE images (Fig. 30). We infer that the speckled texture seen on the ridges (Fig. 10) corresponds to a grain size in the range $12.5<D_{84}<25 \mathrm{~cm}$ (i.e., $1-2 D_{84}$ grains/pixel), and most probably towards the higher end of that range. Using our value of $\left(h / D_{84}\right)$, we obtain $0.25<h<0.5 \mathrm{~m}$ for clear water flow (and channel aspect ratios $70<W / h<150$, confirming our approximation that the channel depth equals the hydraulic radius). Such cobble-grade grain sizes are also consistent with our model for the fan inversion process, as described in Section 3.1, as the coarse sediment on the bed of the channel will not be transportable by wind.

Combining Eqs. (1), and (4), (5), (6), (7), we calculate the flow velocities and corresponding dominant discharges in each of these channels (Fig. 31). Under the range of appropriate sediment concentration and grain size values, we derive flow velocities between $\sim 0.4$ and $2.5 \mathrm{~m} / \mathrm{s}$ and dominant discharge ranged from 0.5 to $21 \mathrm{~m}^{3} / \mathrm{s}$. Note that these values are also dependent on the value chosen for the sorting parameter $a$ above; however, even if $a=1$, (i.e., $D_{50}=D_{84}$, the theoretical maximum value where there is no size variation at all amongst the coarser fraction of the sediment), the maximum values we could obtain are only $u=2.0 \mathrm{~m} / \mathrm{s}$ and $Q=95 \mathrm{~m}^{3} / \mathrm{s}$.

It is uncertain how many channels on the fan were active at any given time, and it may be necessary to multiply these channel discharges by some factor to arrive at the total discharge from the source catchment per event. However, the scarcity of bifurcations seen on the channel ridges suggests that this factor should be low, probably $\leqslant 3$ as is observed in the Atacama analog (Fig. 25). Assuming three active channels, the coarsest possible grain sizes, $a=1$, and clearwater flow, maximum total discharge across the fan could be up to $285 \mathrm{~m}^{3} / \mathrm{s}$. Much more likely total discharges are probably in the range $\sim 30-60 \mathrm{~m}^{3} / \mathrm{s}$, allowing for a small percentage of sediment in the fluid, and a grain size in the middle of our suggested range, a plausible particle size distribution, and 23 active channels (Fig. 31). We also reemphasize (following Ferguson, 2007) that a factor of two error in these figures should be assumed.

We constrain the area of the source catchment of this fan as $793 \mathrm{~km}^{2}$. In order to produce the maximum (i.e., very optimistic) discharges of $285 \mathrm{~m}^{3} / \mathrm{s}$, the source catchment would have to supply water at the rate of $1.3 \mathrm{~mm} / \mathrm{h}$. Our preferred, lower discharges $\sim 30-60 \mathrm{~m}^{3} / \mathrm{s}$ would result in proportionally lower supply rates of $\sim 0.1-0.2 \mathrm{~mm} / \mathrm{h}$. These estimates are probably somewhat conservative, as we cannot account quantitatively for refreezing, evaporation, or infiltration in the system. However, if discharge is sourced from an overlying wet snowpack over permafrost, the contributions of all three loss mechanisms are likely to be relatively minor. Such discharges would have to be sustained for at least a timescale comparable with the time taken for water to move through the catchment system, to allow the discharge to integrate across the whole drainage area. For the $\sim 20 \mathrm{~km}$ length $\mathrm{K} 2$ basin, and assuming flow velocities as seen on the fan are typical of flow velocities higher in the catchment (a conservative assumption, $u \sim 1 \mathrm{~m} / \mathrm{s}$ ), then discharge across the catchment would have to be sustained for at least several hours. 
We can however test snow or ice ablation as a mechanism for sourcing the discharges based on our data, a hypothesis for the water source for fans and deltas in the Margaritifer Terra region (Grant and Wilson, 2012), and also suggested for contemporaneous shallow channels in Newton and Gorgonum basins (Howard and Moore, 2011). Ablation of ice is fundamentally limited by the energy balance of the icepack itself, including incoming solar flux, reflection at the surface and in the atmosphere, re-radiation from the ice itself, downwelling longwave heat flux from the atmosphere (e.g., from clouds), and potentially complex effects from convection (e.g., winds), advection (e.g., water drainage, dust movements), and secular changes in the driving parameters (e.g., day/night, seasons, obliquity changes). Were all the incoming solar flux to be converted into latent heat to melt ice, we acquire a hard (and physically implausible) upper limit for water supply rates of $5.4-7.5 \mathrm{~mm} / \mathrm{h}$, assuming solar insolation of $500-700 \mathrm{~W}$ under the modern orbital eccentricity of Mars (c.f., Laskar et al., 2004). Other authors have used more sophisticated energy balances to investigate the melt rates and total discharges expected from melting snow on Mars. Williams et al. (2008, 2009a) concluded runoff $>1 \mathrm{~mm} / \mathrm{h}$ at spatially averaged rates exceeding $0.25 \mathrm{~mm} / \mathrm{h}$ would be readily possible in the martian mid-latitudes over the past $5 \mathrm{Ma}$, and their data suggests occasionally somewhat higher rates and discharges may also be possible. Kite et al. (2013) suggest that in general across Mars' history, maximum snow melt rates should be $2-3 \mathrm{~mm} / \mathrm{h}$, with melt occurring in widely spaced discrete temporal windows, promoted by either orbital parameter variation or by transient darkening of snow surfaces by ash or ejecta.

Our estimates of runoff production rates in the catchment for the K2 fan are comparable to Williams et al.'s (2009a) estimates for "typical" snow melt events for recent Mars, and comfortably below Kite et al. (2013) long term maxima for melt production rates. We thus conclude that melt by ablation of snow deposits on the crater walls is a viable mechanism for the production of the flows that built the $\mathrm{K} 2$ fan, and by inference, the other fans in Saheki and crater L that have relief characteristics to the $\mathrm{K} 2$ fan (Moore and Howard, 2005). This analysis cannot address the physics of melt production beneath a snowpack, which is likely complex and nonlinearly dependent on the timing of warming of the pack in the solar year (e.g., Williams et al., 2008), but indicates that the flux magnitude is not sufficient to reject the snow melt hypothesis.

Large terrestrial alluvial fans form over thousands of years of seasonal or rarer flows (such as for the Atacama Desert fans discussed above). Scenarios have been proposed that martian fandeltas (Jerolmack et al., 2004; Mangold et al., 2012b) and some small channel systems (Morgan and Head, 2009; Mangold, 2012) have been created over a short time period by relatively continuous flows resulting from thermal anomalies created, for example, by energy resulting from by bolide impacts. Here we evaluate whether the Saheki fans could have formed from one or a few relatively continuous flow events. Our analysis suggests maximum flow rate to the $\mathrm{K} 1$ and $\mathrm{K} 2$ fans was unlikely to be more than $\sim 100 \mathrm{~m}^{3} / \mathrm{s}$. The $\mathrm{K} 1$ and $\mathrm{K} 2$ fan volume is about $586 \mathrm{~km}^{3}$. Assuming a generous sediment concentration of $20 \%$ of water flow volume, a continuous flow could create the fans in a minimum of $\sim 500$ Mars ( $\sim 1000$ Earth) years. The primary issue, however, is in generating the flows. As discussed previously, groundwater flow is an unlikely source, so precipitation on the crater walls (almost certainly as snow) would have been required. For the $20 \%$ sediment concentration across the known headwater area a total runoff depth of $3.57 \mathrm{~km}$ of water would be required. Given sublimation losses and the high porosity of snow, a total snow accumulation several times that figure would have been required. If, say, $10 \mathrm{~km}$ of snowfall were required of the headwater areas to form the fan in
500 martian years, this would require an annual snow accumulation of $\sim 20 \mathrm{~m}$. A more reasonable scenario would be seasonal snowmelt occurring for $6 \mathrm{~h}$ per day, 100 days per Mars year, requiring $\sim 3600$ martian years to form the fan and an annual snow accumulation rate of $\sim 3 \mathrm{~m} / \mathrm{yr}$. This is still a very optimistic scenario given the high average sediment loads assumed.

Another check on a minimum timescale comes from the observed layer stratigraphy. If the $\sim 2$ m-thick beds observed in HiRISE images (Figs. 13 and 15) represent annual accumulations and we take an average fan thickness of $\sim 400 \mathrm{~m}$, then approximately 200 deposition events are recorded at any given location. If as much as $10 \%$ of the fan surface were active during any given year, then 2000 martian years would have been required. It is likely, however, that higher resolution imaging of clean layer exposures would reveal finer-scale layering than observed. Thus we conclude that at least a few thousand martian years was required to form the alluvial fans. More likely, given the probability of lower sediment load percentages, less frequent flow events, and thinner annual bed thickness, the fans may have required a few tens of thousands of martian years to form at a minimum. These years need not have been sequential. A fan lifetime with a small number of annual events during favorable obliquity may have been separated by long inactive periods through multiple obliquity cycles. We do note, however, that we have seen no evidence for impact cratering having disturbed visible bedding during deposition, although appreciable cratering has occurred subsequent to fan deposition.

\subsection{Comparison with other martian fans}

Large alluvial fans on Mars have morphological characteristics that vary through a narrow range of fan gradients, ratios of gradient to contributing area, and ratios of fan area to contributing basin area (Moore and Howard, 2005) (Table 1). These characteristics suggest very similar hydrological and sedimentary processes and materials characterized most martian fans. The "L" crater $25 \mathrm{~km}$ southeast of Saheki crater hosts fans that are of similar size and morphology as those of Saheki crater. The major differences appear to be the multiple fans in "L" sourcing from all quarters of the rim, and lesser aeolian stripping of the fan surface (although, as in Saheki crater, the greatest wind erosion has occurred on the southern fans). Recent high-resolution imaging, however, reveals differences in fan morphology and geologic context among other fan-bearing craters. In Harris crater (Fig. 1), the fans show pronounced distributary patterns like Saheki, but the fan in the northeast quadrant exhibits an isolated, rough-surfaced, bouldery deposit crossing the fan with a wide, lobate planform morphology that has been interpreted as a debris flow deposit (Williams et al., 2011). The fans on the west side of this same crater overlie a light-toned, layered deposit not found in Saheki crater. The fan surfaces in Runanga crater (Fig. 1) exhibit inverted distributaries, but the interbedded layered deposits are light-toned and are broken by meter to decameter polygonal fracturing, which might be explained by either more coherent sediment or a different weathering environment. Most of the fans in Margaritifer Terra studied by Grant and Wilson (2012) exhibit radiating distributary patterns similar to those in Saheki and "L" craters, but one set of fans terminates in steep-fronted lobes that could be explained by their deposition into a concomitant lake (with the fan-delta in Eberswalde crater being a prominent case of interaction with a lake (Malin and Edgett, 2003; Moore et al., 2003)). Finally, Holden crater features a more complicated history of successive fan development than has been proposed for Saheki crater (Grant and Wilson, 2012).

These observations illustrate a range of fan stratigraphic patterns across martian fans, perhaps reflecting local climate or differences in source materials. Nonetheless, the general pattern 

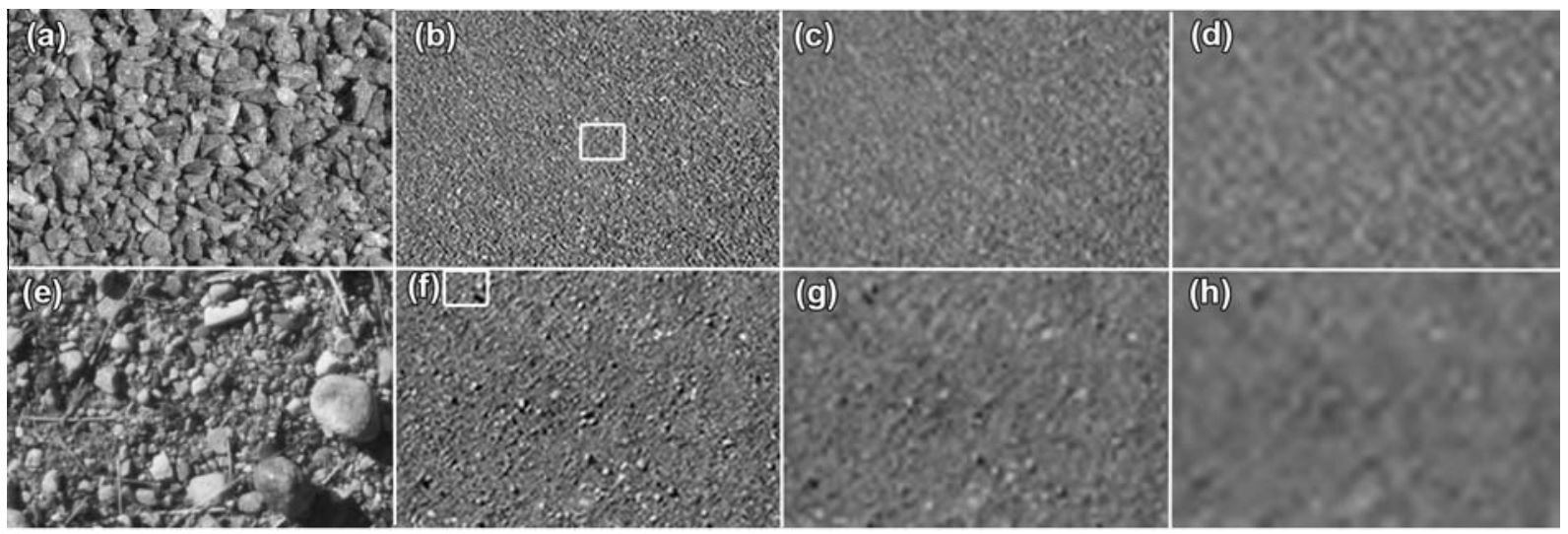

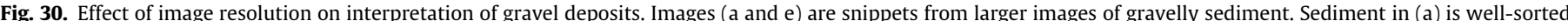

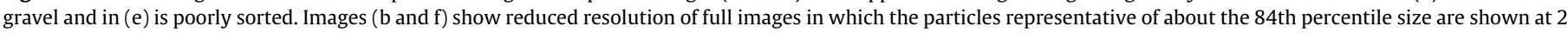

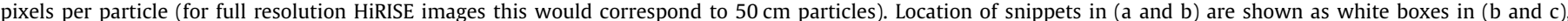

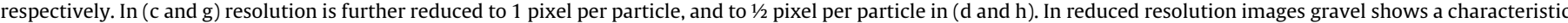

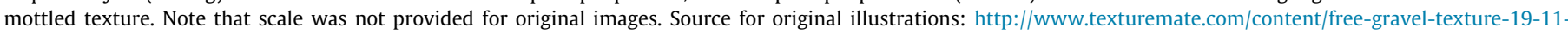
2011-001 (a-d) http://aquaponics.wiki.com/wiki/gravel?file=Gravel_small_stones.jpg (e-h).

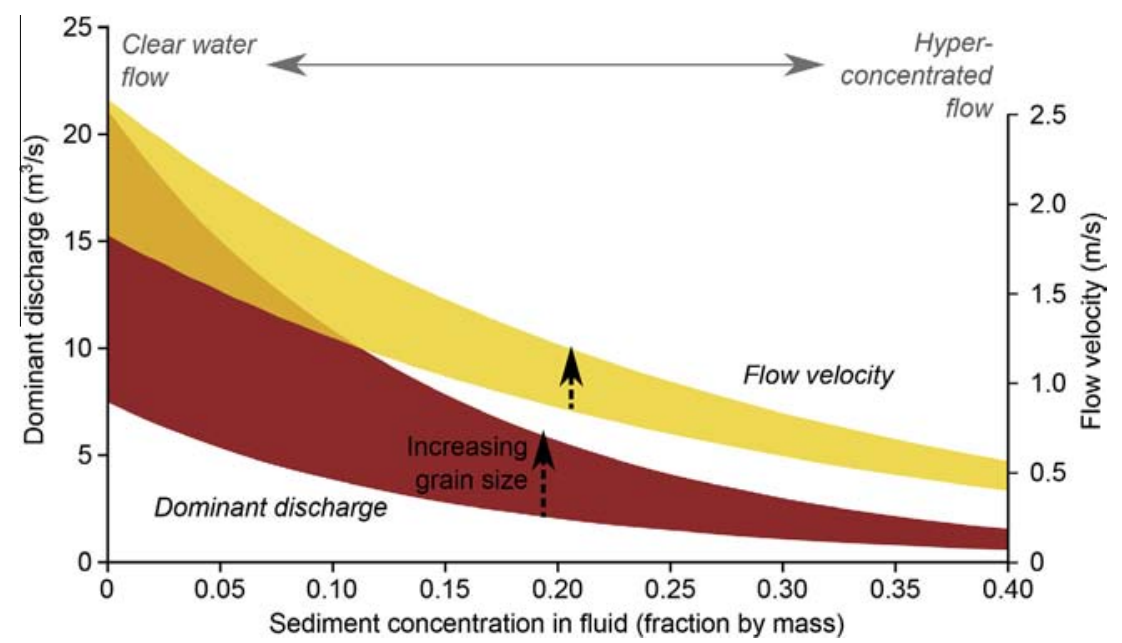

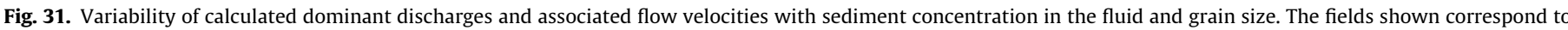

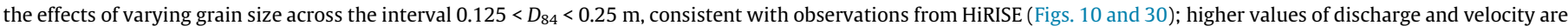
derived from the coarser grain sizes.

seen in Saheki and "L" craters - of radiating distributaries composed of wind-resistant sediment interbedded with finer, layered sediments - characterizes most martian fans which have been sufficiently exposed by aeolian erosion to reveal their stratigraphy.

\section{Conclusions}

The Hesperian Period is generally thought of as a cold and dry period dominated by extensive volcanism, canyon formation, and large outflow channels. Recent studies have suggested that fluvial activity was widespread though probably sporadic on Mars well into Hesperian and perhaps occurring as late as the Hesperian/Amazonian transition (Fassett et al., 2010; Grant and Wilson, 2011, 2012; Howard and Moore, 2011; Mangold et al., 2012a). Widespread post-Noachian fluvial features which require precipitation (probably as snow) as their water source are indicative of a global climate favorable to surface water transport as suggested by Grant and Wilson $(2011,2012)$ and Howard and Moore (2011).
The precipitation and discharge of water is the premier question in understanding the climatic implications to fan formation. Our calculated discharges and the origin of runoff being the highest portions of hosting crater rims effectively rule out the possibility of groundwater as a source of water feeding the fans, leaving atmospheric precipitation as the likely candidate. Given the constraints imposed by the martian climate during the Hesperian as well as the lack of fluvial channel heads on the fan surface, torrential rain is very unlikely. Our hydrological analysis (Section 3.2.2) shows that snowmelt appears to be adequate to drive the required discharges.

One of the most enigmatic observations of the alluvial fan systems on Mars is their highly localized distribution. On a global scale, large fans are limited to within mid-latitude band craters (Kraal et al., 2008; Moore and Howard, 2005; Wilson et al., 2012), and even within craters fans are limited in their spatial distribution. Despite being just several tens of kilometers apart, "L" crater contains seven fans sourcing from all sides of the crater rim while Saheki contains only three, one of which is too small to be of much significance. The high crater rims of the relatively 
young craters hosting fans may have helped to create a microclimate that could trigger appreciable snow accumulation. Restriction of fans to certain portions of crater rims may also be attributed to crater rims containing deposits susceptible to erosion by modest runoff rates, that is, predominantly fine-grained and unconsolidated materials. Both of the main Saheki fans source from a region that intersects both the western rim of a larger adjacent crater as well as the elongated basin to the northwest (Fig. 2), both of which could be potential sites of antecedent sediment accumulation.

Fans on Mars exhibit vastly different levels of subsequent aeolian erosion. The two fans within Saheki crater have slightly different crater-derived surface ages, yet interfingering of distributaries along their border is suggestive that the fans formed at the same time and that the apparent age difference is due to the subsequent amount of erosion of the fan surface. The amount of aeolian erosion is thus not solely a function of surface age, but rather a product of other factors including sediment composition and wind direction and intensity. However, while different fans have undergone varying levels of erosion, they mostly share the same morphological characteristics. We propose many of the large fans in this latitude belt formed from similar hydrologic processes and conditions as the Saheki fans. Therefore, even though Saheki crater was chosen for detailed study due to the high amount of information revealed from surface aeolian erosion, other fans have formed through similar processes, albeit with some variations in processes, materials, and setting as indicated in Section 3.3.

Evidence from the fans in Saheki crater and elsewhere represent significant fluvial activity relatively late in martian history and contribute to our ever-changing understanding of the fate of Mars' climate. These fans could not have formed in a single event; their formation requires many years and multiple periods of snow accumulation and subsequent runoff. Moreover, for snow to preferentially accumulate on local topographic highs, the atmospheric pressure had to be higher during this time than at present (Wordsworth et al., 2013). The sedimentological characteristics of the Saheki and "L" crater fans indicate that flows during at least the final stages of fan activity were fluvial flows with occasional overbank mudflows, so that volumes of sediment that could be transported during individual flow events would be limited to a fraction of the discharge volumes. The modest discharges that would be available from the source basins suggests that only a few distributaries were active in any given flow event. The lack of evidence for deep lakes occupying Saheki crater during the time of fan formation indicates formative flows were of limited volume and duration, requiring many flow events to construct the fans. The thin, light-toned beds in the fine-grain deposits may relate to modifications occurring during depositional hiatuses (Figs. 13 and 14). Flow events did not necessarily follow a yearly cycle; rather, there may have been epochal periods of snow accumulation followed by periods of release during favorable orbital configurations or transient aperiodic but repeated global warming events such as volcanic eruptions. In addition, occurrence of snowfall may have been tied to availability of source water, possibly related to phreatomagmatic eruptions or flood events in outflow channels.

\section{Acknowledgments}

This study was partially supported by the NASA Graduate Student Researchers Program (NASA grant NNX12AM73H), Cooperative Grant from NASA Ames (NNX08AE47A), NASA Planetary Geology and Geophysics (NNX08AM91G), NASA Mars Data
Analysis Program (NNX09AM02G), and by an award to Y. Matsubara by the Department of Environmental Sciences, University of Virginia.

\section{Appendix A. Idealized model for aeolian inversion of Saheki fans}

The starting conditions are a hypothetical cross-section of the lower part of fan $\mathrm{K} 2$, with the cross-section being taken normal to the dominant flow direction with a $1000 \mathrm{~m}$ section taken across the fan perpendicular to the downslope direction and a $100 \mathrm{~m}$ vertical extent (Fig. 29). In this model the uncolored area is envisioned to consist of fine-grained overbank deposits. Interbedded with the overbank deposits are gravel channel deposits scattered randomly within the cross section. The width of each channel is randomly sampled from a uniform distribution from 30 to $80 \mathrm{~m}$, and each channel deposit is $2 \mathrm{~m}$ thick. Coordinates for channel deposits are selected randomly within the cross-section, and deposits are added (blue boxes in Fig. 29) until 5\% of the total cross-sectional area (an arbitrary number) is channel gravel. The stack of channel and overbank deposits is then wind-eroded, with the initial surface being a flat surface at the top of the stack (black line). The channel deposits are assumed to be inerodible by wind, but the overbank deposits on a flat surface are eroded at a rate $\dot{z}_{w f}$ of $5.0 \mathrm{~m} / \mathrm{t}$ (time, $\mathrm{t}$, and the erosion rate $\dot{z}_{w f}$ are in arbitrary but consistent units relative to other simulation parameters). Wind erosion is also assumed to be more rapid on convex slopes due to greater exposure. The wind erosion rate, $\dot{z}_{w}(\mathrm{~m} / \mathrm{t})$ relative to a flat surface rate $\dot{z}_{w f}$ is given by:

$\dot{z}_{w}=\dot{z}_{w f} \exp \left(-K_{w} \nabla^{2} z\right)$

where $K_{w}$ is a scale constant and has the value $40 \mathrm{~m}$ and $z$ is the surface elevation. The value of $K_{w}$ was selected to rapidly scour ridges no longer capped by gravels, because uncapped hills of layered sediment are rare on the $\mathrm{K} 2$ fan.

As time progresses and wind vertically erodes sediment (which is assumed to be entirely removed from the cross-section), diffusive mass wasting occurs using a non-linear relationship (Hanks and Andrews, 1989; Roering et al., 1999, 2001):

$\vec{q}_{m}=-\frac{K_{m} \vec{S}}{\left[1-\left(S / S_{c}\right)^{2}\right]}$

where $\vec{q}_{m}$ is the vector mass wasting flux (volume per unit width of slope in $\mathrm{m}^{2} / \mathrm{t}$ ) $S$ is slope gradient (as a vector in the numerator), $S_{c}$ is a critical slope gradient (the angle of repose for loose sediment, set to 0.6 here), and $K_{m}$ is diffusivity. For these simulations $K_{m}$ was set at $10.0 \mathrm{~m}^{2} / \mathrm{t}$. Net erosion or deposition rate is given as:

$\dot{z}_{m}=-\nabla \cdot \vec{q}_{m}$

Erosion of the channel gravels is assumed to occur only through mass wasting. The majority of the eroding slope surface is underlain by the overbank deposits. We assume that the gravels make up a minor component of the slope mantle and have no effect upon mass wasting rates or aeolian deflation of the portions of the slope on overbank deposits. Note that we consider the aeolian erosion and the mass wasting to be independent, additive processes. Additive processes are commonly assumed in landform evolution models, such as in modeling drainage basin evolution by mass wasting and fluvial erosion (e.g., Howard, 1994). The net rate of surface change, $\dot{z}$, is the sum of $\dot{z}_{w}$ plus $\dot{z}_{m}$.

The absolute values of the rate constants in the model are arbitrary. Their relative values were chosen to reproduce the topographic patterns observed on the wind-eroded surface of the southern Saheki K2 fan (e.g., Figs. 3 and 6-9). We view the model 
to be an illustrative portrayal of the pattern of wind erosion and layer exposure pattern, rather than being quantitatively accurate.

\section{References}

Amundson, R. et al., 2012. Geomorphologic evidence for the late Pliocene onset of hyperaridity in the Atacama Desert. Geol. Soc. Am. Bull. 124, 1048-1070.

Anderson, R., Bell, J.F.I., 2010. Geologic mapping and characterization of Gale crater and implications for its potential as a Mars Science Laboratory landing site. Mars J. 5, 76-128.

Andrews, E.D., 1984. Bed-material entrainment and hydraulic geometry of gravelbed rivers in Colorado. Geol. Soc. Am. Bull. 95, 371-378.

Ansan, V. et al., 2011. Stratigraphy, mineralogy, and origin of layered deposits inside Terby crater, Mars. Icarus 211, 273-304.

Armitage, J.J., Warner, N.H., Goddard, K., Gupta, S., 2011. Timescales of alluvial fan development by precipitation on Mars. Geophys. Res. Lett. 38, L17203. http:// dx.doi.org/10.1029/2011GL048907.

Balme, M., Berman, D.C., Bourke, M.C., Zimbelman, J.R., 2008. Transverse aeolian ridges (TARs) on Mars. Geomorphology 101, 703-720.

Berman, D.C., Balme, M.R., Rafkin, S.C.R., Zimbelman, J.R., 2011. Transverse aeolian ridges (TARs) on Mars II: Distributions, orientations, and ages. Icarus 213, 116130.

Blair, T.C., 2003. Features and origin of the giant Cucomungo Canyon alluvial fan, Eureka Valley, California. In: Chan, M.A., Archer, A.W. (Eds.), Extreme Depositional Environments: Mega End Members in Geologic Time. Geological Society of America, Denver, CO, pp. 105-126, Special Paper 370.

Blair, T.C., McPherson, J.G., 2009. Processes and forms of alluvial fans. In: Parsons, A.J., Abrahams, A.D. (Eds.), Geomorphology of Desert Environments. Springer Science+Business Media B.V., pp. 413-466.

Bull, W.B., 1962. Relation of textural (CM) patterns to deposition environment of alluvial-fan deposits. J. Sediment. Petrol. 32, 211-216.

Bull, W.B., 1963. Alluvial-fan deposits in western Fresno County, California. J. Geol. 71, 243-251.

Burr, D.M., Enga, M.-T., Williams, R.M.E., Zimbelman, J.R., Howard, A.D., Brennand, T.A., 2009. Pervasive aqueous paleoflow features in the Aeolis/Zephyria Plana region, Mars. Icarus 200, 52-76.

Burr, D.M., Williams, R.M.E., Wendell, K.D., Chojnacki, M., Emery, J.P., 2010. Inverted fluvial features in the Aeolis/Zephyria Plana region, Mars: Formation mechanism and initial paleodischarge estimates. J. Geophys. Res. 115, E07011. http://dx.doi.org/10.1029/2009JE003496.

Carr, M.H., 2006. The Surface of Mars, second ed. Cambridge University Press, Cambridge.

Carr, M.H., Head, J.W., 2010. Geologic history of Mars. Earth Planet. Sci. Lett. 294, 185-203.

Chan, M.A., Yonkee, W.A., Netoff, D.I., Seiler, W.M., Ford, R.L., 2008. Polygonal cracks in bedrock on Earth and Mars: Implications for weathering. Icarus 194, $65-71$.

Costa, J.E., 1984. Physical geomorphology of debris flows. In: Costa, J.E., Fleisher, P.J. (Eds.), Developments and Applications of Geomorphology. Springer-Verlag, pp. 268-317.

Costa, J.E., 1988. Rheologic, geomorphic, and sedimentologic differentiation of water floods, hyperconcentrated flows, and debris flows. In: Baker, V.R. et al. (Eds.), Flood Geomorphology. Wiley-Interscience, pp. 113-122.

Dade, W.B., Friend, P.F., 1998. Grain-size, sediment-transport regime, and channel slope in alluvial rivers. J. Geol. 106, 661-675.

Dixon, J.C., 2009. Aridic soils, patterned ground, and desert pavements. In: Parsons, A.J., Abrahams, A.D. (Eds.), Geomorphology of Desert Environments. Springer Science+Business Media B.V., pp. 101-122.

El Maarry, M.R., Markiewicz, W.J., Mellon, M.T., Goetz, W., Dohm, J.M., Pack, A., 2010. Crater floor polygons: Desiccation patterns of ancient lakes on Mars? J. Geophys. Res. 115, E10006. http://dx.doi.org/10.1029/2010JE003609.

El Maarry, M.R., Kodikara, J., Wijessoriya, S., Markiewicz, W.J., Thomas, N., 2012. Desiccation mechanism for formation of giant polygons on Earth and intermediate-sized polygons on Mars: Results from a pre-fracture model. Earth Planet. Sci. Lett. 323-324, 19-26.

Fassett, C.I., Head, J.W., 2011. Sequence and timing of conditions on early Mars. Icarus 211, 1204-1214.

Fassett, C.I., Dickson, J.L., Head, J.W., Levy, J.S., Marchant, D.R., 2010. Supraglacial and proglacial valleys on Amazonian Mars. Icarus 208, 86-100.

Ferguson, R., 2007. Flow resistance equations for gravel- and boulder-bed streams. Water Resour. Res. 43, W05427. http://dx.doi.org/10.1029/2006WR005422.

Field, J., 2001. Channel avulsion on alluvial fans in southern Arizona. Geomorphology 37, 93-104.

Forget, F., Wordsworth, R., Millour, E., Madeleine, J.-B., Kerber, L., Leconte, J., Marcq, E., Haberle, R.M., 2013. 3D modelling of the early martian climate under a denser $\mathrm{CO}_{2}$ atmosphere: Temperatures and $\mathrm{CO}_{2}$ ice clouds. Icarus 222, 8199.

Garvin, J.B., Sakimoto, S., Frawley, J.J., 2003. Craters on Mars: Global geometric properties from gridded MOLA topography. In: Sixth Intern. Conf. Mars, Pasadena, CA. Abstract 3277.

Gillies, J.A., Nickling, W.G., Tilson, M., Furtak-Cole, E., 2012. Wind-formed gravel bed forms, Wright Valley, Antarctica. J. Geophys. Res. 117, F04017. http://dx.doi.org/ 10.1029/2012JF002378.
Goldspiel, J.M., Squyres, S.W., 2000. Groundwater sapping and valley formation on Mars. Icarus 148, 176-192.

Goldspiel, J.M., Squyres, S.W., 2011. Groundwater discharge and gully formation on martian slopes. Icarus 2011, 238-258.

Grant, J.A., Wilson, S.A., 2011. Late alluvial fan formation in southern Margaritifer Terra, Mars. Geophys. Res. Lett. 38, L08201. http://dx.doi.org/10.1029/ 2011 GL046844.

Grant, J.A., Wilson, S.A., 2012. A possible synoptic source of water for alluvial fan formation in southern Margaritifer Terra, Mars. Planet. Space Sci. 72, 4452.

Greeley, R., Guest, J.E., 1987. Geologic Map of the Eastern Equatorial Region of Mars. U.S. Geological Survey Miscellaneous Investigations Series Map. I-1802-B.

Greeley, R., White, B., Leach, R., Iversen, J., Pollack, J., 1976. Mars: Wind friction speeds for particle movement. Geophys. Res. Lett. 3, 417-420.

Hanks, T.C., Andrews, D.J., 1989. Effect of far-field slope on morphologic dating of scarp-like landforms. J. Geophys. Res. 94, 565-573.

Harris, R.C., 2004. Giant Dessication Cracks in Arizona. Arizona Geological Survey. Open-File Report 04-01, pp. 1-93.

Harrison, K.P., Grimm, R.E., 2009. Regionally compartmented groundwater flow on Mars. J. Geophys. Res. 114, E04004. http://dx.doi.org/10.1029/2008JE003000.

Hartmann, W.K., 2007. Martian cratering 9: Toward resolution of the controversy about small craters. Icarus 189, 274-278.

Hartmann, W.K., Neukum, G., 2001. Cratering chronology and the evolution of Mars Space Sci. Rev. 96, 165-194.

Hartmann, W.K., Werner, S.C., 2010. Martian cratering 10. Progress in use of crater counts to interpret geological processes: Examples from two debris aprons. Earth Planet. Sci. Lett. 294, 230-237.

Hartmann, W.K., Neukum, G., Werner, S., 2008. Confirmation and utilization of the "production function" size-frequency distributions of martian impact craters. Geophys. Res. Lett. 35, L02205. http://dx.doi.org/10.1029/2007GL031557.

Harvey, A.M., 1999. The occurrence and role of arid zone alluvial fans. In: Thomas, D.S.G. (Ed.), Arid Zone Geomorphology. Halstead Press, New York, pp. 136158.

Houston, J., 2002. Groundwater recharge through an alluvial fan in the Atacama Desert, northern Chile: Mechanisms, magnitudes and causes. Hydrol. Process. 16, 3019-3035.

Houston, J., 2006. The great Atacama flood of 2001 and its implications for Andean hydrology. Hydrol. Process. 20, 591-610.

Howard, A.D., 1980. Thresholds in river regimes. In: Coates, D.R., Vitek, J.D. (Eds.), Thresholds in Geomorphology. George Allen \& Unwin, London, pp. 227258.

Howard, A.D., 1994. A detachment-limited model of drainage-basin evolution. Water Resour. Res. 30, 2261-2285.

Howard, A.D., 2009. Badlands and gullying. In: Parsons, A.J., Abrahams, A.D. (Eds.) Geomorphology of Desert Environments. Springer Verlag, pp. 233-263.

Howard, A.D., Moore, J.M., 2011. Late Hesperian to early Amazonian midlatitude martian valleys: Evidence from Newton and Gorgonum basins. J. Geophys. Res. 116, E05003. http://dx.doi.org/10.1029/2010JE003782.

Howard, A.D., Moore, J.M., Irwin III, R.P., 2005. An intense terminal epoch of widespread fluvial activity on early Mars: 1 . Valley network incision and associated deposits. J. Geophys. Res. 110. http://dx.doi.org/10.1029/ 2005JE002459.

Hunt, C.B., Robinson, T.W., Bowles, W.A., Washburn, A.L., 1966. General Geology of Death Valley, California; Hydrologic Basin. U.S. Geological Survey Professional Paper. Report: P 0494-B.

Hynek, B.M., Beach, M., Hoke, M.R.T., 2010. Updated global map of martian valley networks and implications for climate and hydrologic processes. J. Geophys. Res. 115, E09008. http://dx.doi.org/10.1029/2009JE003548.

Irwin, R.P.I., Tanaka, K.L., Robbins, S.J., 2013. Distribution of Early, Middle, and Late Noachian cratered surface in the martian highlands: Implications for resurfacing events and processes. J. Geophys. Res. 118, 278-291. http:// dx.doi.org/10.1002/jgre.20053.

Ivanov, B.A., 2001. Mars/Moon cratering rate ratio estimates. Space Sci. Rev. 96, $87-$ 104.

Jerolmack, D.J., Mohrig, D., Zuber, M.T., Byrne, S., 2004. A minimum time scale for formation of Holden Northeast fan, Mars. Geophys. Res. Lett. 31, L21701. http:// dx.doi.org/10.1029/2004GL021326.

Jerolmack, D.J., Mohrig, D., Grotzinger, J.P., Fike, D.A., Watters, W.A., 2006. Spatial grain size sorting in eolian ripples and estimation of wind conditions on planetary surfaces: Application to Meridiani Planum, Mars. J. Geophys. Res. 111, E12S02. http://dx.doi.org/10.1029/2005je002544.

Johnson, A.M., 1984. Debris flow. In: Brunsden, D., Prior, D.B. (Eds.), Slope Instability. John Wiley \& Sons, Chichester, pp. 257-361.

Kiefer, E., Dörr, M.J., Ibbeken, H., Götze, H.J., 1997. Gravity-based mass balance of an alluvial fan giant: The Arcas Fan, Pampa del Tamarugal, northern Chile. Rev. Geol. Chile 24, 165-185.

Kite, E.S., Halevy, I., Kahre, M.A., Wolff, M.J., Manga, M., 2013. Seasonal melting and the formation of sedimentary rocks on Mars, with predictions for the Gale crater mound. Icarus 223, 181-210.

Kleinhans, M.G., 2005. Flow discharge and sediment transport models for estimating a minimum timescale of hydrological activity and channel and delta formation on Mars. J. Geophys. Res. 110, E12003. http://dx.doi.org/ 10.1029/2005JE002521.

Knighton, A.D., 1998. Fluvial Forms and Processes: A New Perspective. Arnold, London. 
Korteniemi, J., Kreslavsky, M.A., 2012. Patterned ground in martian high northern latitudes: Morphology and age constraints. Icarus 225, 960-970. http:/ dx.doi.org/10.1016/j.icarus.2013.09.032.

Kraal, E.R., Asphaug, E., Moore, J.M., Howard, A., Bredt, A., 2008. Catalogue of large alluvial fans in martian impact craters. Icarus 194, 101-110.

Lamb, M.P., Dietrich, W.E., Sklar, L.S., 2008. A model for fluvial bedrock incision by impacting suspended and bed load sediment. J. Geophys. Res. 113, F03025. http://dx.doi.org/10.1029/2007JF000915.

Langer, A.M., Kerr, P.F., 1966. Mojave Playa crusts; physical properties and mineral content. J. Sediment. Petrol. 36, 377-396.

Laskar, J., Correia, A.C.M., Gastineau, M., Joutel, F., Levrard, B., Robutel, P., 2004. Long term evolution and chaotic diffusion of the insolation quantities of Mars. Icarus $170,343-364$.

Lasue, J. et al., 2013. Quantitative assessments of the martian hydrosphere. Space Sci. Rev. 174, 155-212.

Levy, J., Head, J., Marchant, D., 2009. Thermal contraction crack polygons on Mars: Classification, distribution, and climate implications from HiRISE observations. J. Geophys. Res. 114, E01007. http://dx.doi.org/10.1029/2008JE003273.

Lewis, K.W.. Aharonson, O., 2006. Stratigraphic analysis of the distributary fan in Eberswalde crater using stereo imagery. J. Geophys. Res. 111, E06001, http:/ dx.doi.org/10.1029JE002558.

Malin, M.C., Carr, M.H., 1999. Groundwater formation of martian valleys. Nature 397, 589-591.

Malin, M.C., Edgett, K.S., 2000. Evidence of recent groundwater seepage and surface runoff on Mars. Science 288, 2330-2335.

Malin, M.C., Edgett, K.S., 2003. Evidence for persistent flow and aqueous sedimentation on early Mars. Science 302, 1931-1934.

Malin, M.C. et al., 2007. Context Camera Investigation on board the Mars Reconnaissance Orbiter. J. Geophys. Res. E: Planets 112, http://dx.doi.org/ 10.1029JE002808. Article Number E05S04.

Mangold, N., 2012. Fluvial valleys on fresh impact ejecta on Mars. Planet. Space Sci. 62, 69-85.

Mangold, N., Forget, F., Maurice, S., Feldman, W.C., Costard, F., 2004. Spatial relationships between patterned ground and ground ice detected by the Neutron Spectrometer on Mars. J. Geophys. Res. E: Planets 109, E08001. http:/ dx.doi.org/10.1029/2004JE002235.

Mangold, N., Adeli, S., Conway, S., Ansan, V., Langlais, B., 2012a. A chronology of early Mars climatic evolution from impact crater degradation. J. Geophys. Res. 117, E04003. http://dx.doi.org/10.1029/2011JE004005.

Mangold, N. et al., 2012b. The origin and timing of fluvial activity at Eberswalde crater, Mars. Icarus 220, 530-551.

Matsubara, Y., Howard, A.D., Burr, D.M., Williams, R.M., Moore, J.M., 2012 Meandering channels in a non-vegetated area: Quinn River, NV as a martian analog. Lunar Planet. Sci. 43. Abstract 2534.

McEwen, A.S., Bierhaus, E.B., 2006. The importance of secondary cratering to age constraints on planetary surfaces. Annu. Rev. Earth Planet. Sci. 34, 535567.

McEwen, A. et al., 2005. The rayed crater Zunil and interpretations of small impact craters on Mars. Icarus 176, 351-381.

McEwen, A.S. et al., 2007. Mars Reconnaissance Orbiter's High Resolution Imaging Science Experiment (HiRISE). J. Geophys. Res. E: Planets 112. http://dx.doi.org 10.1029/2005JE002605. Article Number E05S02.

Mellon, M.T., 1997. Small-scale polygonal features on Mars: Seasonal thermal contraction cracks in permafrost. J. Geophys. Res. 102, 2561725628.

Michael, G.G., Neukum, G., 2010. Planetary surface dating from crater sizefrequency distribution measurements: Partial resurfacing events and statistical age uncertainty. Earth Planet. Sci. Lett. 294, 223-229.

Moore, J.M., Howard, A.D., 2005. Large alluvial fans on Mars. J. Geophys. Res. 110 E04005. http://dx.doi.org/10.1029/2004JE002352.

Moore, J.M., Howard, A.D., Dietrich, W.E., Schenk, P.M., 2003. Martian layered fluvial deposits: Implications for Noachian climate scenarios. Geophys. Res. Lett. 30 2292. http://dx.doi.org/10.1029/2003GL019002.

Morato, Z.M., Broxton, M.J., Beyer, R.A., Lundy, M., Husmann, K., 2010. Ames Stereo Pipeline, NASA's open source automated stereogrammetry software. Lunar Planet. Sci. 41. Abstract 2364

Morgan, G.A., Head III, J.W., 2009. Sinton crater, Mars: Evidence for impact into a plateau icefield and melting to produce valley networks at the HesperianAmazonian boundary. Icarus 202, 39-59.

Morgan, A.M., Beyer, R.A., Howard, A.D., Moore, J.M., 2012a. The alluvial fans of Saheki crater. Lunar Planet. Sci. 43. Abstract \#2815.

Morgan, A.M., Howard, A.D., Moore, J.M., Hobley, D.E.J., Beyer, R.A., 2012b. Episode(s) of intense alluvial deposition during an era of drought on Mars: Evidence from fans at Saheki (and Gale?). American Geophysical Union (Fall) Abstract P11B-1830.

Murchie, S. et al., 2007. Compact Reconnaissance Imaging Spectrometer for Mars (CRISM) on Mars Reconnaissance Orbiter (MRO). J. Geophys. Res. 112, E05S03. http://dx.doi.org/10.1029/2006JE002682.

Neal, J.T., Langer, A.M., Kerr, P.F., 1968. Giant dessication polygons of Great Basin playas. Geol. Soc. Am. Bull. 79, 69-90.

Parker, G., 1978. Self-formed straight rivers with equilibrium banks and mobile bed Part 2. The gravel river. J. Fluid Mech. 89, 127-146.

Pondrelli, M., Rossi, A.P., Marinagleli, L., Hauber, E., Gwinner, K., Baliva, A., Di Lorenzo, S., 2008. Evolution and depositional environments of the Eberswalde fan delta, Mars. Icarus 197, 429-451.
Pondrelli, M., Rossi, A.P., Platz, T., Ivanov, A., Marinangeli, L., Baliva, A., 2011. Geological, geomorphological, facies and allostratigraphic maps of the Eberswalde fan delta. Planet. Space Sci. 59, 1166-1178.

Pueyo, J.J., Chong, G., Jensen, A., 2001. Neogene evaporites in desert volcanic environments: Atacama Desert, northern Chile. Sedimenology 48, 14111431.

Rickenmann, D., Recking, A., 2011. Evaluation of flow resistance in gravel-bed rivers through a large field data set. Water Resour. Res. 47, W07538. http://dx.doi.org/ 10.1029/2010WR009703.

Roering, J.J., Kirchner, J.W., Dietrich, W.E., 1999. Evidence for nonlinear, diffusive sediment transport on hillslopes and implications for landscape morphology. Water Resour. Res. 35, 853-870.

Roering, J.J., Kirchner, J.W., Dietrich, W.E., 2001. Hillslope evolution by nonlinear, slope-dependent transport; steady state morphology and equilibrium adjustment timescales. J. Geophys. Res. B: Solid Earth Planets 106, 1649916513.

Servicio Nacional de Geologia y Mineria, G.d.C., 2003. Mapa Geologico de Chile: Version Digital. Publication Geologica Digital, No. 4.

Shaw, P.A., Thomas, D.S.G., 1989. Playas, pans and salt lakes. In: Thomas, D.S.G. (Ed.), Arid Zone Geomorphology. John Wiley \& Sons, New York, pp. 184-205.

Smith, G.I., 1957. Core Logs from Owens, China, Searles and Panamint Basins, California. U.S. Geological Survey Bulletin 1045-A.

Smith, G.I., 1974. Subsurface Stratigraphy and Geochemistry of Late Quaternary Evaporites, Searles Lake, California. U.S. Geological Survey Professional Paper 1043, pp. 1-130.

Smoot, J.P., Castens-Seidel, B., 1995. Sedimentary Features Produced by Efflorescent Salt Crusts, Saline Valley and Death Valley, California. Sedimentology and Geochemistry of Modern and Ancient Saline Lakes. Society for Sedimentary Geology, pp. 73-90.

Spötl, Wright, 1992. Groundwater dolocretes from the Upper Triassic of the Paris Basin, France: A case study of an arid, continental diagenetic facies. Sedimentology 36, 1119-1136.

Stock, J.D., 2013. Waters Divided: A History of Alluvial Fan Research and a View of Its Future. In: Shroder, J.F. (Ed.), Treatise on Geomorphology. Academic Press, San Diego, pp. 413-458.

Stock, J.D., Schmidt, K.M., Miller, D.M., 2008. Controls on alluvial fan long-profiles. Geol. Soc. Am. Bull. 120, 619-640.

Stoertz, G.E., Ericksen, G.E., 1974. Geology of Salars in Northern Chile. U.S. Geological Survey. Professional Paper 811, 65p.

Sullivan, R. et al., 2008. Wind-driven particle mobility on Mars: Insights from Mars Exploration Rover observations at "El Dorado" and surroundings at Gusev Crater. J. Geophys. Res. 113, E06S07. http://dx.doi.org/10.1029/ 2008JE003101.

Talling, P.J., 2000. Self-organization of river networks to threshold states. Water Resour. Res. 36, 1119-1128.

Tanaka, K.L., 1986. The stratigraphy of Mars. J. Geophys. Res. 91 (B13), E139-E158.

Ward, W.R., 1979. Present obliquity oscillations of Mars - Fourth-order accuracy in orbital E and I. J. Geophys. Res. 84, 237-241.

Weinberger, R., 1999. Initiation and growth of cracks during dessication of stratified muddy sediments. J. Struct. Geol. 21, 379-386.

Wentworth, C.K., 1922. A scale of grade and class terms for clastic sediments. J. Geol. 30, 377-392.

Werner, S.C., Tanaka, K.L., 2011. Redefinition of the crater-density and absolute-age boundaries for the chronostratigraphic system of Mars. Icarus 215, 603-607. http://dx.doi.org/10.1016/j.icarus.2011.07.024.

Werner, S.C., Ivanov, B.A., Neukum, G., 2009. Theoretical analysis of secondary cratering on Mars and an image-based study on the Cerberus Plains. Icarus 200, 406-417.

Williams, R.M.E., Malin, M.C., 2008. Sub-kilometer fans in Mojave Crater, Mars. Icarus 198, 365-383.

Williams, K., Toon, O., Heldmann, J., McKay, C., Mellon, M., 2008. Stability of midlatitude snowpacks on Mars. Icarus 196, 565-577.

Williams, K., Toon, O., Heldmann, J., Mellon, M., 2009a. Ancient melting of mid-latitude snowpack on Mars as a water source for gullies. Icarus 200, 418425.

Williams, R.M.E., Irwin, R.P., Zimbelman, J.R., 2009b. Evaluation of paleohydrologic models for terrestrial inverted channels: Implications for application to martian sinuous ridges. Geomorphology 107, 300-315.

Williams, R.M.E. et al., 2011. Evidence for episodic alluvial fan formation in far western Terra Tyrrhena, Mars. Icarus 211, 222-237.

Williams, R.M.E. et al., 2013. Martian fluvial conglomerates at Gale crater. Science 340, 1068-1072.

Wilson, S.A., Zimbelman, J.R., 2004. Latitude-dependent nature and physical characteristics of transverse aeolian ridges on Mars. J. Geophys. Res. E: Planets 109, E10003. http://dx.doi.org/10.1029/2004JE002247.

Wilson, L., Ghatan, G.J., Head, I.J.W., Mitchell, K.L., 2004. Mars outflow channels: A reappraisal of the estimation of water flow velocities from water depths, regional slopes, and channel floor properties. J. Geophys. Res. E: Planets 109, E09003, 1-10.

Wilson, S.A., Howard, A.D., Moore, J.M., Grant, J.A., 2007. Geomorphic and stratigraphic analysis of Crater Terby and layered deposits north of Hellas basin, Mars. J. Geophys. Res. E: Planets 112, E08009. http://dx.doi.org/10.1029/ 2006JE002870.

Wilson, S.A., Grant, J.A., Howard, A.D., 2012. Distribution of intracrater alluvial fans and deltaic deposits in the southern highlands of Mars. Lunar Planet. Sci. 43. Abstract 2462 
Wordsworth, R., Forget, F., Millour, E., Head, J.W., Madeleine, J.-B., Charnay, B., 2013. Global modeling of the early martian climate under a censer $\mathrm{CO}_{2}$ atmosphere: Water cycle and ice evolution. Icarus 222, 1-19.

Yechieli, Y., Wood, W.W., 2002. Hydrogeologic processes in saline systems: Playas, sabkhas, and saline lakes. Earth-Sci. Rev. 58, 343-365.
Zimbelman, J.R., Irwin, R.P.I., Williams, S.H., Bunch, F., Valdez, A., Stevens, S., 2009

The rate of granule ripple movement on Earth and Mars. Icarus 203, 7176.

Zuber, M.T. et al., 1992. The Mars Observer laser altimeter investigation. J. Geophys. Res. 97, 7781-7797. 